\title{
ITS-based diversity of Colletotrichum from India
}

\section{Sharma G ${ }^{1}$, Pinnaka $\mathrm{AK}^{1}$, and Shenoy $\mathrm{BD}^{1,2, *}$}

\author{
${ }^{1}$ Microbial Type Culture Collection and Gene Bank, CSIR-Institute of Microbial Technology, Sector 39-A, Chandigarh \\ - 160036, India \\ ${ }^{2}$ Present Address: CSIR-National Institute of Oceanography, Dona Paula, Goa - 403004, India
}

Sharma G, Pinnaka AK, Shenoy BD 2013 - ITS-based diversity of Colletotrichum from India. Current Research in Environmental \& Applied Mycology 3(2), 194-220, doi 10.5943/cream/3/2/3

Rapid and precise species identification of plant pathogens such as Colletotrichum is essential for their effective control. Colletotrichum species have been traditionally identified based on conidial morphology and host-specificity. Recently, extra emphasis has been placed on DNA sequence comparison for rapid and accurate identification. In this study, we have analyzed the suitability of using internal transcribed spacer (ITS)/ 5.8S rRNA gene, which is the universal fungal barcode marker towards accurate identification of Colletotrichum species. We have sequenced 207 isolates of Colletotrichum and compared their ITS/ 5.8S rRNA gene-sequence data with that of the 183 reference sequences available for the 143 accepted Colletotrichum type strains. The results of phylogenetic analysis based on ITS/ 5.8S rRNA gene-sequence dataset along with sequencecomparison hints at the nomenclatural ambiguity of many isolates, which were initially diagnosed based on morphological characters. A local-BLAST analysis of the 588 GenBank sequences from India shows that $79 \%$ of the sequences were erroneously named and $97 \%$ of the 159 isolates procured from Indian culture collection centres were found to be misidentified. Mycologists need to work on identification of a potential secondary barcode for this genus as ITS/ 5.8S rRNA is found to be ineffective in accurate identification of Colletotrichum. Researchers should also follow a polyphasic approach for species identification, which would definitely not be rapid; nevertheless would be more reliable and accurate.

Key words - Barcoding - NCBI-BLAST - GenBank - species identification

\section{Article Information}

Received 22 August 2013

Accepted 26 September 2013

Published online 23 October 2013

*Corresponding author: Belle Damodara Shenoy - e-mail - shenoynio@ gmail.com

\section{Introduction}

Identification is an important aspect of taxonomy. Accurate identification of an isolate facilitates the recognition of species, its morphological and biochemical features, with positive implications in ecological and biodiversity research (Hajibabaei et al. 2007, Seifert et al. 2007, Begerow et al. 2010). Identification is followed by taxonomic processes such as determination and classification (Shenoy et al. 2007a). Firstly, the essential attributes of a fungus such as: morphology, host specificity, DNA sequencedata and physiological features are characterized (identification), followed by determination of its relationships with the closely related extant fungi, leading to a hierarchy of biological classification system. 
Developments in DNA barcoding have transformed the field of fungal taxonomy (Summerbell et al. 2005, Shenoy et al. 2007a, Seifert 2009). DNA barcoding (Hebert et al. 2003a) is a method to diagnose a species based on standard short DNA sequences such as mitochondrial cytochrome c oxidase 1 ( coxl) in animals (Folmer et al. 1994, Hebert et al. 2003a, b), large subunit of the ribulosebiphosphate carboxylase gene $(r b c L)$ and maturase $\mathrm{K}$ gene of chloroplast (matK) in plants (Consortium for the Barcode of Life (CBOL) Plant Working Group 2009). The ITS/ 5.8S rRNA gene region has been widely used for species identification and phylogenetic analyses of many fungal genera (Soltis et al. 1999, Summerbell et al. 2005, Nilsson et al. 2009, Seifert 2009) and it has been projected as the best candidate for barcoding of fungi in the All Fungi Barcoding Meeting held in 2007 (Rossman 2007, Bellemain et al. 2010). This is attributed to the fact that this region is easy to sequence with the help of specific primers (White et al. 1990), provides good specieslevel resolution in many fungal groups of endophytes as well as phyto-pathogens and also has a high capability to evolve rapidly (Nilsson et al. 2008). Recently, Schoch et al. (2012) have declared nuclear ribosomal internal transcribed spacer (ITS) region as a universal DNA barcode marker for Fungi.

Colletotrichum is an important fungal genus whose members are known to cause various diseases in a variety of commercial, ornamental plants and perennial crops (Hyde et al. 2009a, b, Cannon et al. 2012). It is reported mainly from tropical regions (Freeman et al. 1998). This genus has been implicated in symptoms like fruit-lesions, fruit-rot, leaf-spot and leaf wilts from different parts of the world. Colletotrichum species can infect a growing crop directly (pre-harvest) as well as cause latent infections (fruit decay) as a post-harvest pathogen (Bailey et al. 1992, Waller 1992, Freeman et al. 1998, Farr and Rossman 2013). Colletotrichum has emerged as an important post-harvest pathogen owing to its ability to cause latent infection (Muirhead et al. 1981, Everett 1997, Fokulnang et al. 2000). Colletotrichum species have been implicated in serious damages to agricultural crops in India (Sharma et al. 2005, Shenoy et al. 2007b,
Agarwal et al. 2012, Gautam et al. 2012, Hubballi et al. 2012, Kumar et al. 2012, Sawant et al. 2012, Sharma et al. 2012, Wilson and Naseema 2012, Sharma et al. 2013a, b).

Taxonomically, Colletotrichum is a complex genus. As reports on anamorphteleomorph connection were limited (Hyde et al. 2009b, Cannon et al. 2012), Colletotrichum species have been traditionally identified based on conidial characters and host-specificity (Cai et al. 2009). Identification based on morphology, however, has been shown to be ineffective and unreliable in many cases such as C. gloeosporioides species-complex (Cannon et al. 2008, Weir et al. 2012) and $C$. graminicola species complex (Crouch et al. 2009).

Recently, taxonomic revisions have been made in the Colletotrichum genus by revisiting the phylogenies of members of $C$. gloeosporioides, $C$. acutatum and $C$. boninense species complexes based on multigene phylogeny and genealogical concordance phylogenetic species recognition (GCPSR) criterion (Damm et al. 2012 a, b, Weir et al. 2012). Cannon et al. (2012) have reviewed and enlisted 119 species under Colletotrichum genus and around 30 species are expected to possess a Glomerella sexual stage. At present there are 143 accepted species names under the genus Colletotrichum (Cannon et al. 2012, Noireung et al. 2012, Rakotoniriana et al. 2012, Barimani et al. 2013, Doyle et al. 2013, Huang et al. 2013, Liu et al. 2013b, Manamgoda et al. 2013, Peng et al. 2013, Tao et al. 2013, Udayanga et al. 2013).

DNA based species-identification, is expected to provide a potentially reliable framework for identification as DNA characters are not known to be directly affected by environmental factors (Cannon et al. 2000). Though ITS/ 5.8S rRNA gene region is a widely used gene marker in Colletotrichum taxonomy (Summerbell et al. 2005, Seifert 2007, Shenoy et al. 2007a), recent studies have shown that this gene region offers moderate species resolution in Colletotrichum. However, until other or better gene markers are described, it remains to be the best available sequence dataset till date (Cai et al. 2009, Hyde et al. 2009b). There is a need to revisit the taxonomy of this economically important 
phytopathogenic fungal genus from India, as majority of cultures deposited in various culture collections have been identified based on morphological features. In addition, the NCBI-GenBank sequences deposited from India also needs amendments based on the latest ITS/ 5.8S rRNA sequence dataset (Cannon et al. 2012). This study reveals the nomenclatural ambiguity in many morphologically identified Colletotrichum species from India, based on the phylogenetic analysis and sequence comparison results.

\section{Materials and Methods}

\section{Fungal isolates}

Plant substrates from different hosts were collected from IMTECH campus and neighboring areas in Punjab. A total of 49 endophytic Colletotrichum were isolated from the collected tissues following the method described in Cai et al. (2009). The plant tissues were surface-sterilized in $70 \%$ ethanol for 1 minute, followed by $1 \%$ sodium hypochlorite for 1 minute, rinsed thrice with sterilized water and finally dried on sterilized tissue paper. The plant tissue were then placed on potato dextrose agar (PDA) medium (Difco, catalogue number 213400, Maryland, USA) containing $50 \mu \mathrm{g} / \mathrm{ml}$ chloromphenicol (BioBasic, catalogue number CB0118, Ontario, Canada). The fresh mycelia from tissues were subcultured on PDA medium and grown at $20^{\circ} \mathrm{C}$ for 7 days to isolate DNA for molecular study. A total of 158 Colletotrichum isolates were procured from different culture collection facilities across India and subcultured in a similar manner. All the 207 fungal isolates were preserved at $-70{ }^{\circ} \mathrm{C}$ and $\mathrm{LN}_{2}$ in $10 \%$ glycerol for future use. Colletotrichum strains from this study are represented in Table 1 (list of endophytes) and Table 2 (list of isolates from different culture collection centre of India). List of Colletotrichum type species whose reference ITS/5.8S rRNA gene sequence has been used, are tabulated in Table 3 .

DNA extraction, PCR amplification and sequencing of ITS / 5.8S rRNA gene region

Genomic DNA from fresh mycelia was isolated using DNA isolation kit (Zymo Research, catalogue number D6005, USA) following the manufacturer's protocol and stored at $-20{ }^{\circ} \mathrm{C}$. Polymerase chain reaction (PCR) was done in a $50 \mu \mathrm{l}$ reaction volume. Each reaction tube contained $3 \mu \mathrm{l}$ of total genomic DNA, $10 \mu \mathrm{l}$ of $5 \mathrm{x}$ GoTaq Green Buffer (Promega, USA), $1.5 \mu \mathrm{l}$ each of $10 \mu \mathrm{M}$ forward primer (ITS 5) and reverse (ITS 4) primer (White et al. 1990), $3 \mu \mathrm{l}$ of $25 \mathrm{mM}$ $\mathrm{MgCl}_{2}, 1 \mu \mathrm{l}$ of $10 \mathrm{mM}$ dNTPs, $0.25 \mu \mathrm{l}$ of $5 \mathrm{U}$ Go Taq Polymerase enzyme (Promega) and $29.75 \mu \mathrm{l}$ of sterile water. The PCR reactions were carried out in Eppendorf Mastercycler (Eppendorf, Germany) with cycling parameters as described in White et al. (1990). The PCR products were run on a $1 \%$ Tris-Acetate-EDTA agarose gel stained with ethidium bromide $(0.5$ $\mu \mathrm{g} / \mathrm{ml}$ ) at $100 \mathrm{~V}, 400 \mathrm{~mA}$ for 45 minutes to check the presence of desired band of 500-600 bp. The PCR products were further cleaned with QIAquick PCR purification kit (QIAGEN, catalogue number 28106) according to the manufacturer's protocol. The purified PCR products were quantified using Nanodrop Spectrophotometer ND-1000 (Thermo). The PCR products were sequenced using ITS 5 and ITS 4 primers (White et al. 1990) with ABI Big Dye v3.1 Terminator Ready Reaction cycle sequencing kit (Applied Biosystems) using manufacturer's protocol. The samples were purified to remove excess salt, denatured with HiDi-Formamide at $95{ }^{\circ} \mathrm{C}$ for 3 minutes and analysed using 3730 DNA Analyzer (Applied Biosystems) at the Central DNA sequencing facility available at the CSIR-Institute of Microbial Technology, Chandigarh, India.

\section{Sequence alignment and phylogenetic analysis}

The forward and reverse sequences obtained for each strain were aligned using Sequencher version 4.10.1 (Gene Codes Corp., Ann Arbor, Michigan, USA) to generate a consensus sequence. The ends of the sequences were trimmed with the help of ITS 5 and ITS 4 primer sequences and aligned using MUSCLE algorithm (Edgar 2004) in MEGA version 5.2 (Tamura et al. 2011). Analysis of sequence divergence was done using Kimura-2 Parameter (K2P) distance (Kimura 1980) and the rate variation among sites was modeled with a gamma distribution (shape parameter = 5). The phylogram for ITS/ 5.8S rRNA gene 
region was generated with Neighbor-Joining (NJ) method (Saitou and Nei 1987) with bootstrap analysis (Felsenstein 1985) of 100 replicates using MEGA. All positions containing alignment gaps and missing data were removed in pairwise sequence comparisons. The resulting NJ tree with branch support and bootstrap value is shown in Fig. 1. The sequences generated in this study have been deposited in NCBI-GenBank (Table 1 and 2) (Benson et al. 1997, 2006).

\section{Retrieval of sequences from NCBI-GenBank and local BLAST analysis}

A total of 588 sequences were retrieved from NCBI-GenBank on 29.03.2013 using the keywords "Colletotrichum ITS India" for local BLAST analysis. List of the Colletotrichum isolates from India whose sequences have been retrieved from NCBI-GenBank for local BLAST analysis, are tabulated in Supplementary Table 1. A local database including the type sequences of Colletotrichum species (Table 3) was created using BioEdit (Hall 1999). BLAST similarity search analysis (Altschul et al. 1990) of ITS/5.8S rRNA gene sequences retrieved from NCBI-GenBank were performed against this local database and the result is presented in Fig. 2 and the local BLAST score and \% identity for each GenBank sequence from India is tabulated in detail in Supplementary Table 1. Similarly, local BLAST analysis was also done for the 207 Colletotrichum isolates sequenced in this study and the local BLAST score and \% identity is tabulated in detail in Table 1 and 2.

\section{Result}

\section{Phylogeny}

The phylogenetic analysis included 391 sequences including the outgroup Monilochaetes infuscans (CBS 869.96) and a total of 719 characters. All ambiguous regions were excluded from the analysis. The phylogenetic tree generated based on Neighbor-Joining method with branch support in a bootstrap analysis of 100 replicates is shown in Fig. 1.

The NJ tree thus generated is very poorly resolved which shows that ITS/ 5.8S rRNA signal is poor in case of Colletotrichum genus. ITS/ 5.8S rRNA gene marker is able to cluster the Colletotrichum isolates only to their respective species complex level. A total of 163 Colletotrichum isolates from his study clustered within the $C$. gloeosporioides species complex clade comprising 31 type strain sequences (Clade gloeosporioides) (Weir et al. 2012). MTCC 2175 did not align with any of the existing Colletotrichum type strain, however; it remained basal to the type strains of recently described two new species: $C$. thailandicum (Noireung et al. 2012) and $C$. gigasporum (Rakotoniriana et al. 2012).

Six isolates clustered within the $C$. boninense species complex clade comprising 18 type strain sequences (Clade boninense) (Damm et al. 2012a). A total of 23 isolates clustered within the $C$. truncatum species complex clade comprising three type strain sequences (Clade truncatum). Four isolates clustered within the $C$. graminicola species complex clade comprising 18 type strain sequences (Clade graminicola). Three isolates (GS30, ITCC 6271, ITCC 6272) clustered with a recently described new species $C$. brevisporum (Noireung et al. 2012), while four isolates (ITCC 4765, ITCC 5213, ITCC 6032, GUFCC 15503) clustered with type strain of $C$. cliviae. ITCC 6079 clustered with type strain of C. nigrum (Liu et al. 2013a). There were no representative isolates for 14 Colletotrichum type strains in our study including: $C$. agaves, C. chlorophyti, C. coccodes, C. dracaenophilum, $C$. lindemuthianum, $C$. orbiculare, C. orchidophilum, C. phaseolorum, C. pseudoacutatum, C. rusci, C. sansevieriae, C. trichellum, $C$. tropicicola and $C$. yunnanense.

Recently, Cannon et al. (2012) reviewed the current status of Colletotrichum systematics and have described nine major clades within this genus. In our study, the ITS/ 5.8S rRNA gene marker was able to identify species belonging to different species complexes into their respective clades: for eg. Clade gloeosporioides, Clade boninense, Clade dematium, Clade spaethianum, Clade destructivum and Clade acutatum. However, species belonging to the Clade graminicola were not fully resolved based on ITS/ $5.8 \mathrm{~S}$ rRNA gene marker. Similar finding has been reported earlier by Crouch et al. (2009). 


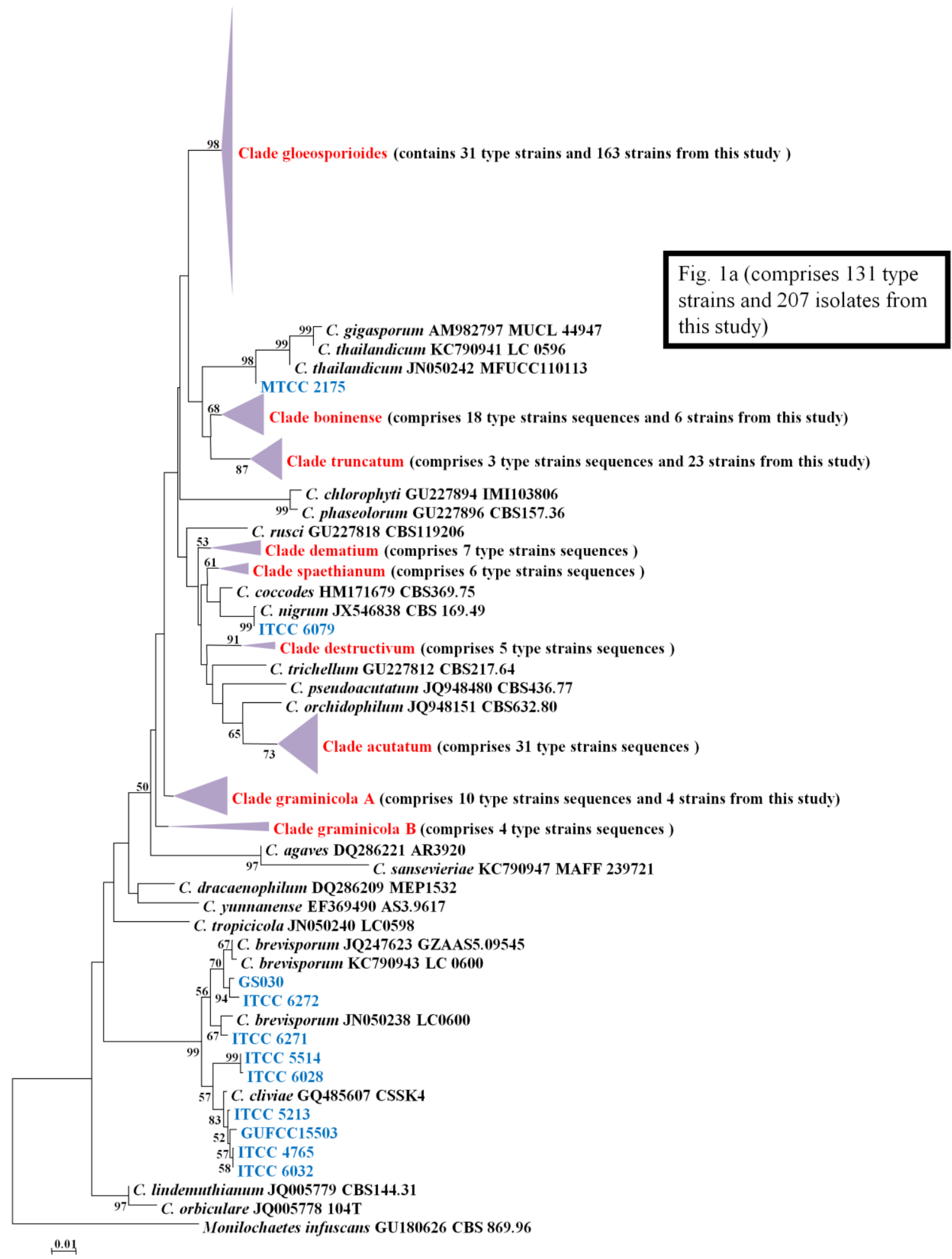

Fig. 1 - a NJ tree based on ITS/ 5.8S rRNA gene sequences of 207 Colletotrichum isolates from India and 131 type strain sequences (Sequences highlighted in blue are from this study; clade names highlighted in red contains isolates from India, details about each clade has been mentioned in the clade title) 


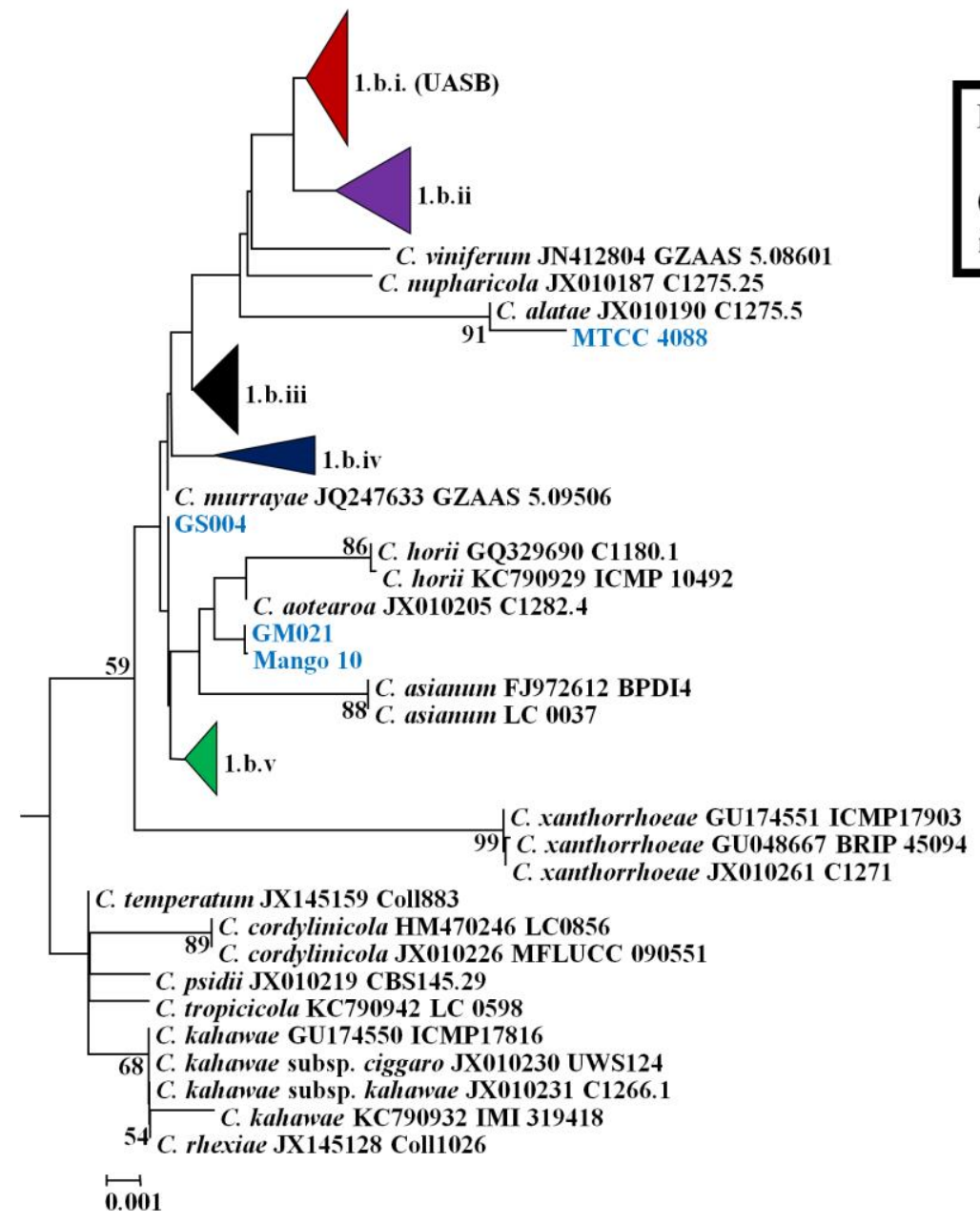

Fig. 1b Clade gloeosporioides

(comprises 31 type strains and 163

isolates from this study)

Fig. 1 - (contd.) b. Isolates in clade gloeosporioides (further split in parts i-v)

\section{Local BLAST analysis}

A total of 588 sequences were retrieved from NCBI-GenBank for the local BLAST analysis and to validate the authenticity of the sequences deposited from India. Identification was based on the sequence comparison with the DNA sequence data of ITS/ 5.8S rRNA gene region of 183 Colletotrichum type strain sequences using Local-BLAST application in BioEdit. The results of local BLAST have been summarized in Supplementary Table 1.

Approximately $79 \%(463 / 588)$ of the DNA sequence entries of Indian origin retrieved from NCBI-GenBank were found to be erroneously named (Fig. 2a). However, all the sequences named "G. tucumanensis" were correctly named and were found to show 9899\% identity with the type strain sequence of $C$. falcatum. One sequence each of $C$. curcumae, $C$. chlorophyti and $C$. siamense were correctly named and showed 100\% identity with their respective type strain sequence (Fig. 3). Out of the 277 sequences deposited as $C$. gloeosporioides only two sequences showed identity with the type strain sequence of $C$. gloeosporioides sensu stricto. Colletotrichum musae (5/7) remained the most correctly named strain within the members of C. gloeosporioides species complex. Besides, approximately $97 \%(155 / 159)$ of the isolates procured from various culture collections of India (Fig. 2b) were found to be misidentified. 
Current Research in Environmental \& Applied Mycology Doi 10.5943/cream/3/2/3

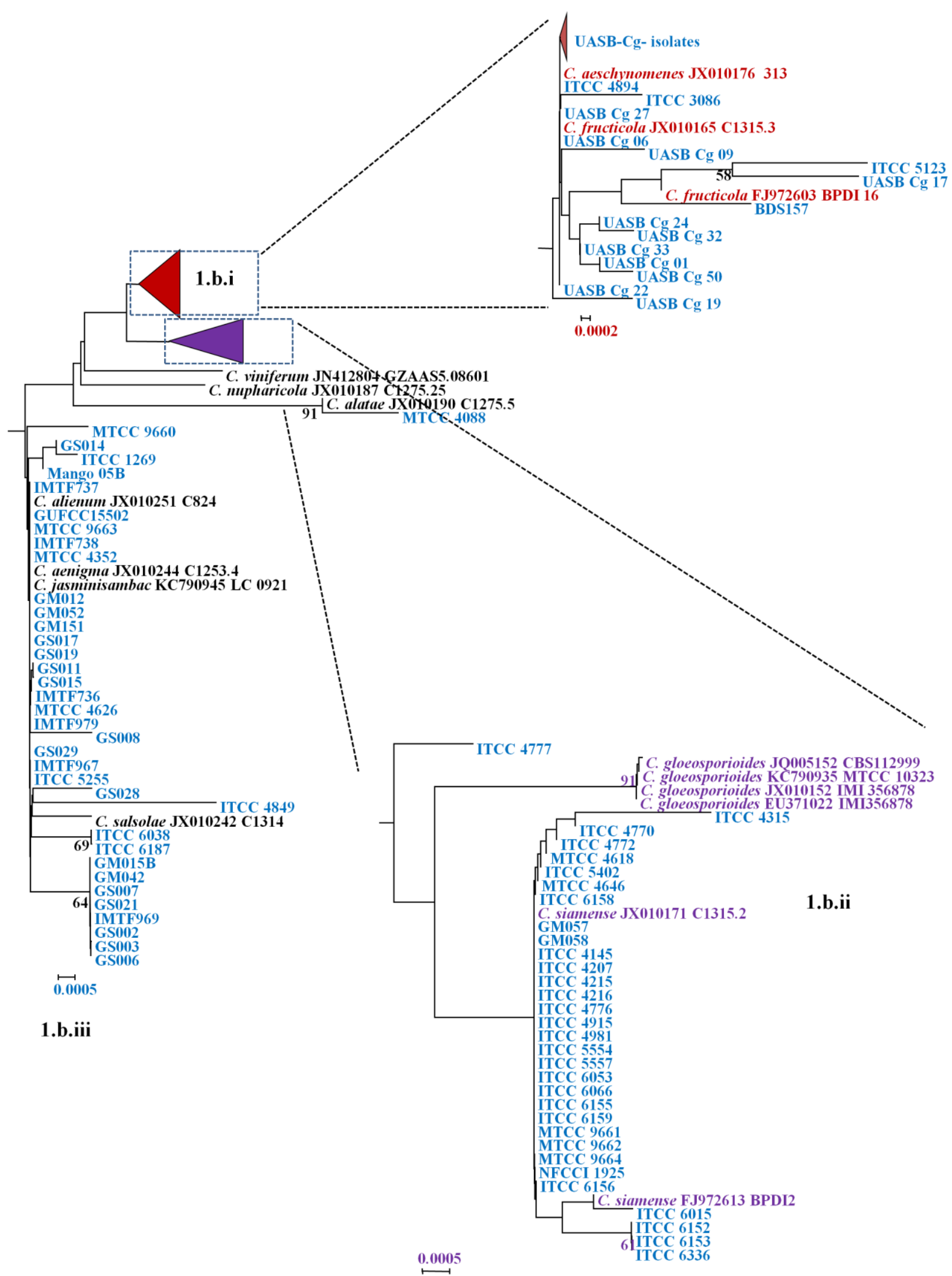

Fig. 1 - (contd.) b. Isolates in clade gloeosporioides (parts i-iii) 
Current Research in Environmental \& Applied Mycology Doi 10.5943/cream/3/2/3

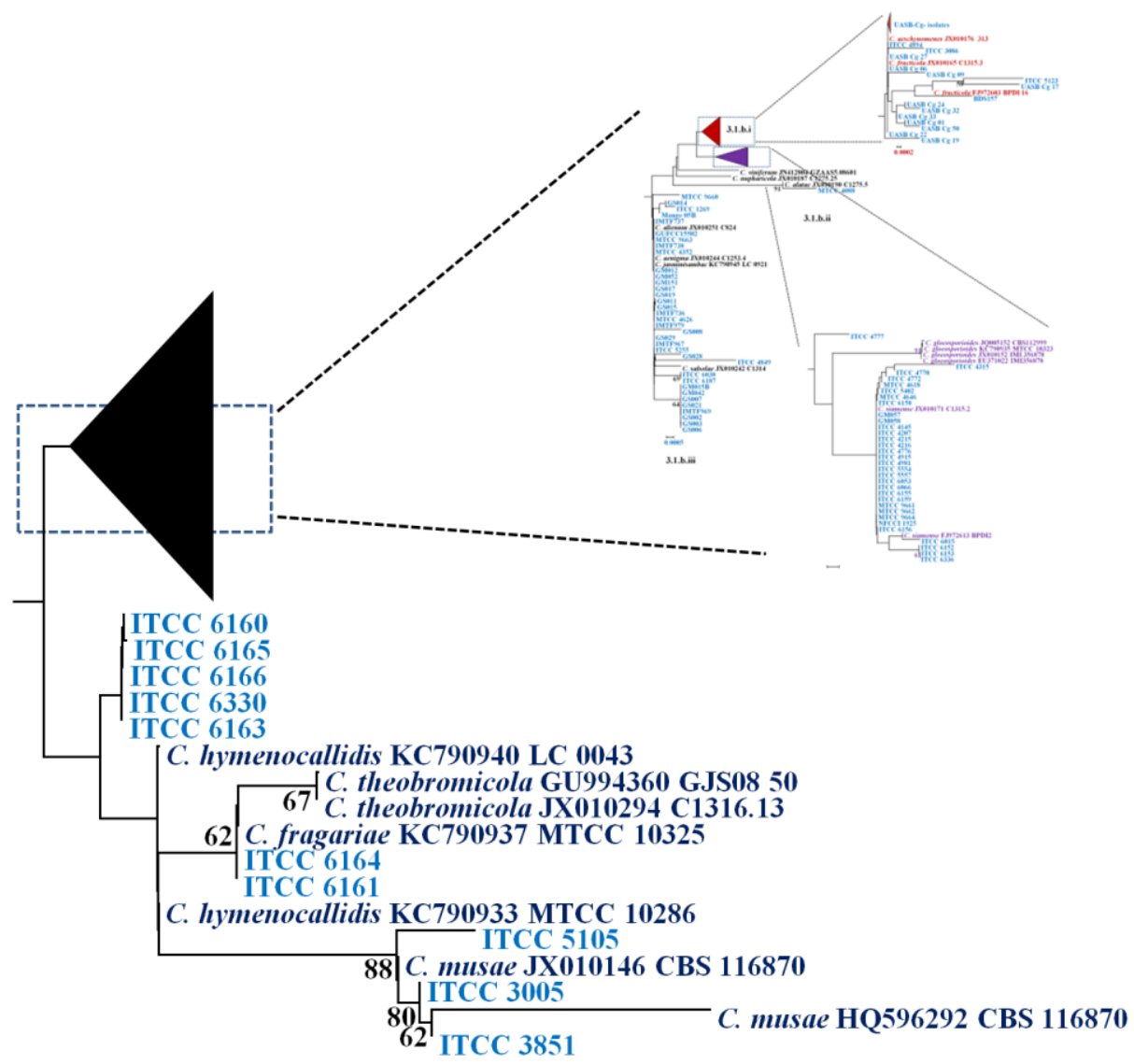

$\stackrel{\longmapsto}{0.001}$

1.b.iv

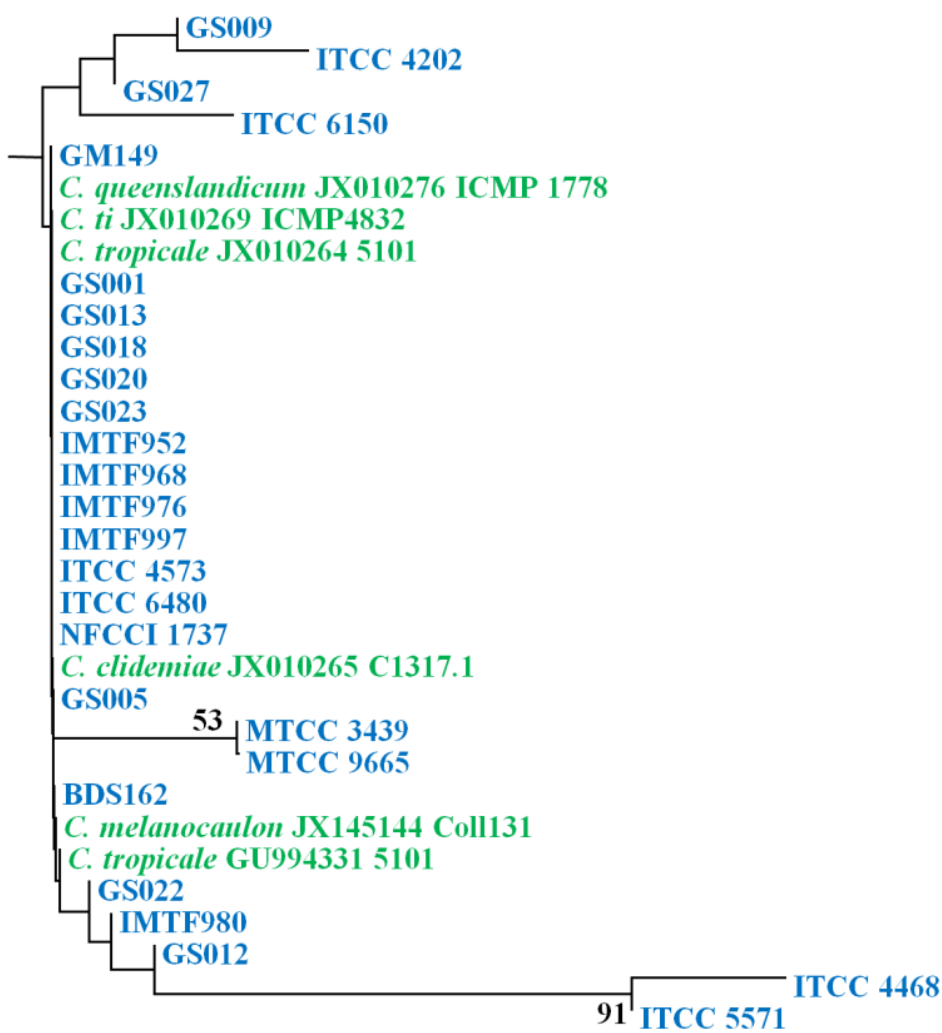

0.0002

1.b.v

Fig. 1 - (contd.) b. Isolates in clade gloeosporioides (parts iv-v) 


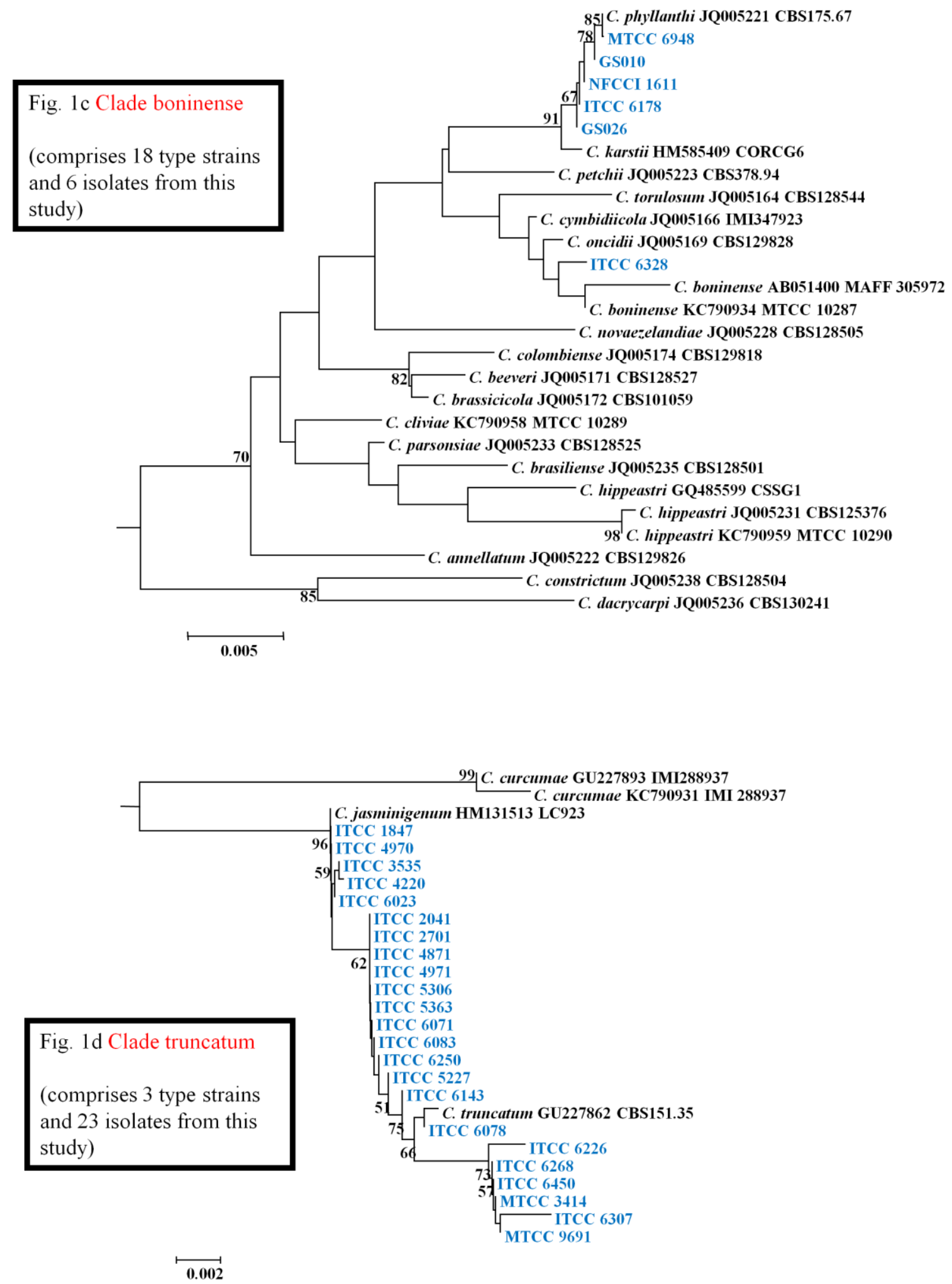

Fig. 1 - (contd.) c. Isolates in clade boninense d. Isolates in clade truncatum 


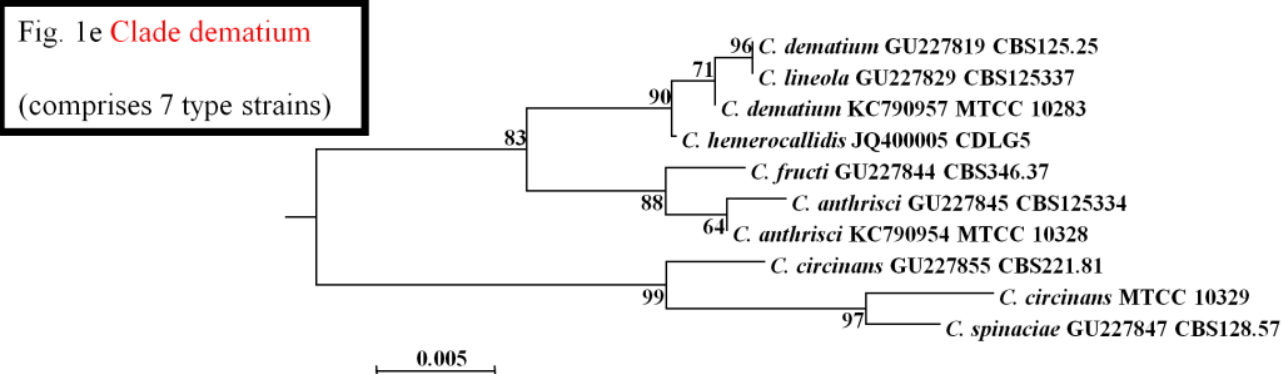

Fig. If Clade spaethianum
(comprises 6 type strains)

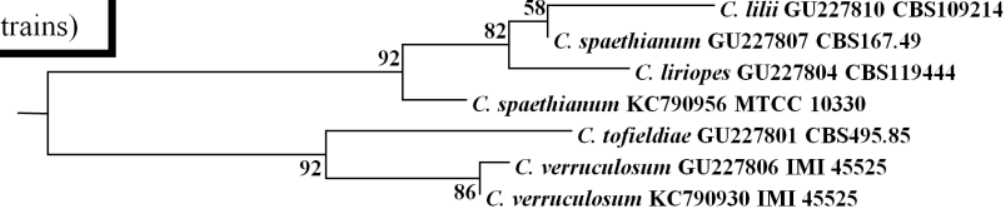

0.002

Fig. 1g Clade destructivum

(comprises 5 type strains)

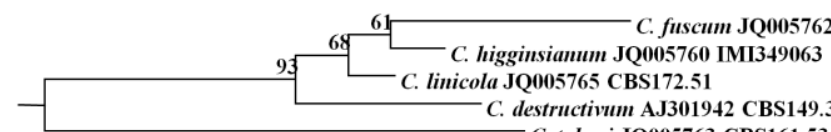
destructivum AJ301942 CBS149.3

0.002

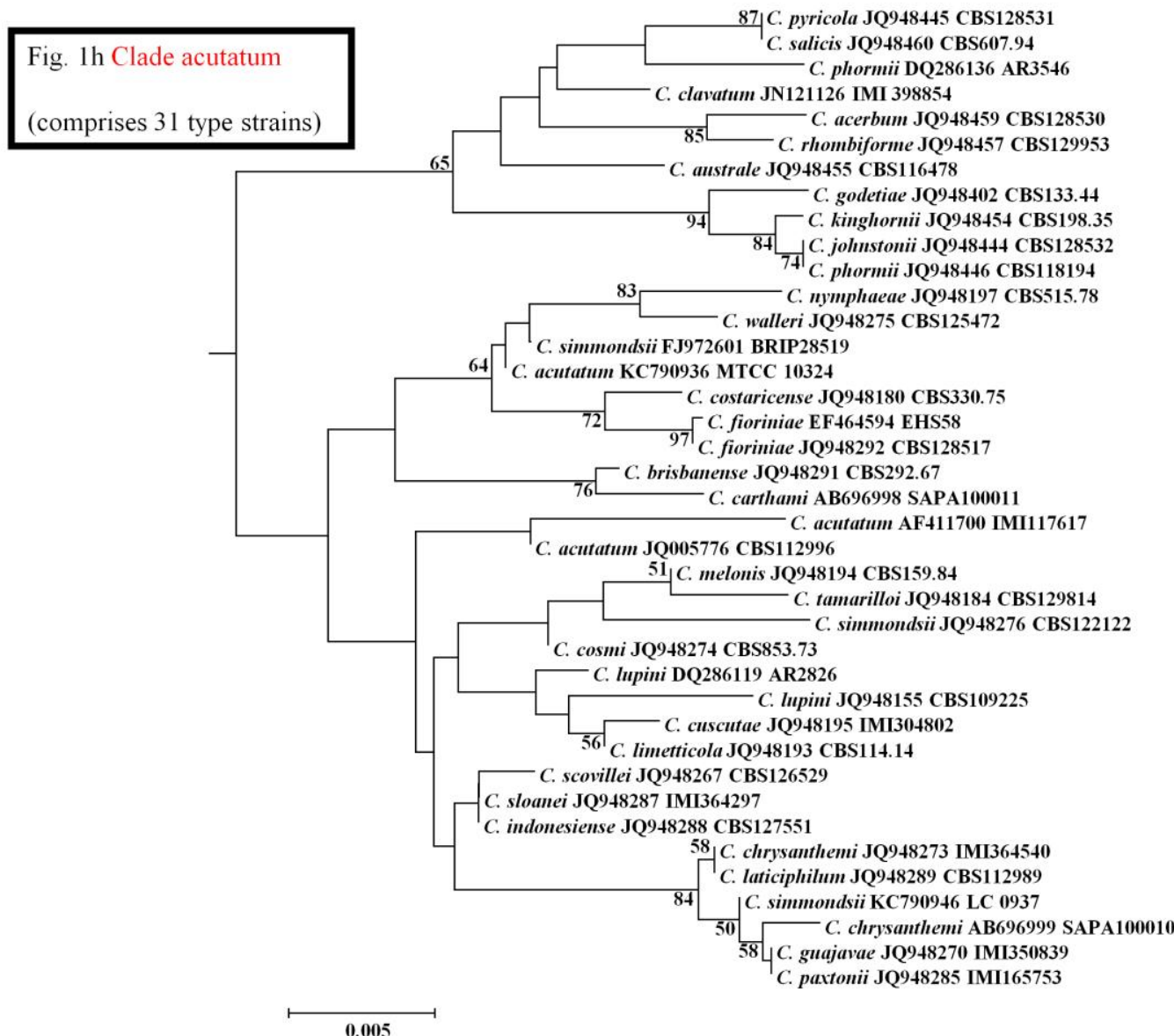

Fig. 1 - (contd.) e. Isolates in clade dematium f. Isolates in clade spaethianum $\mathbf{g}$. Isolates in clade destructivum $\mathbf{h}$. Isolates in clade acutatum 


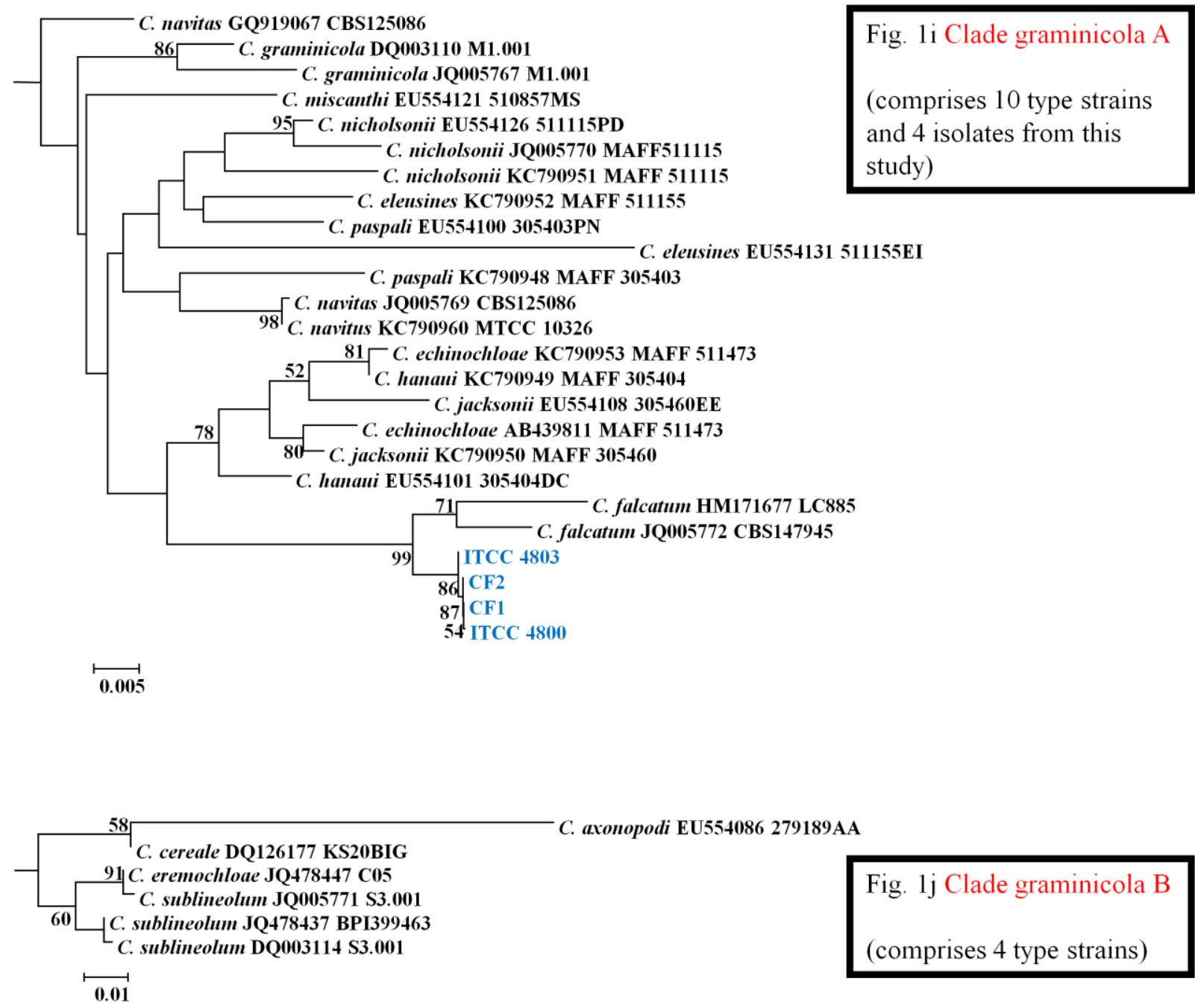

Fig. 1 - (contd.) i. Isolates in clade graminicola A j. Isolates in clade graminicola B

a

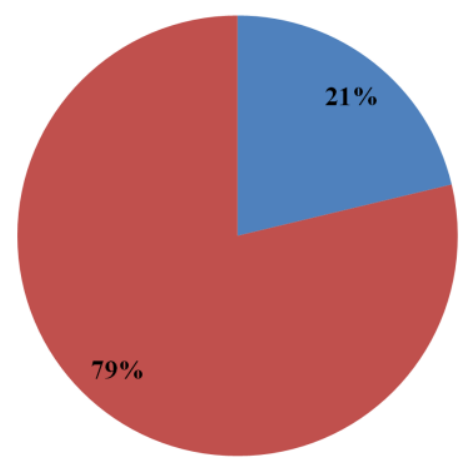

b

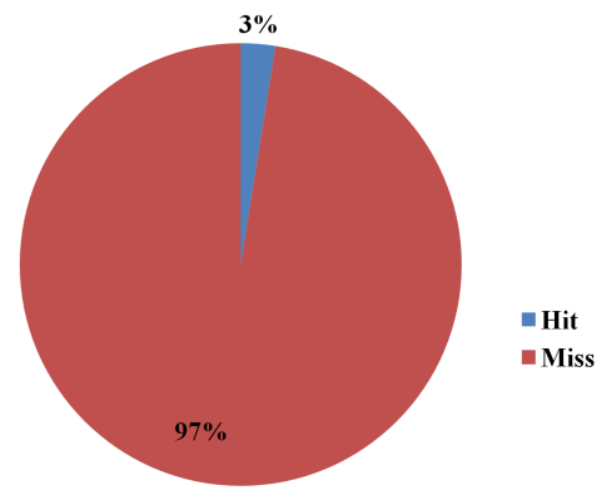

Fig. 2 - Pie chart showing the percentage of correct hits and mismatches in the local BLAST sequence comparison for a. the 558 GenBank sequences submitted from India b. the 159 isolates procured from Indian culture collection centres 


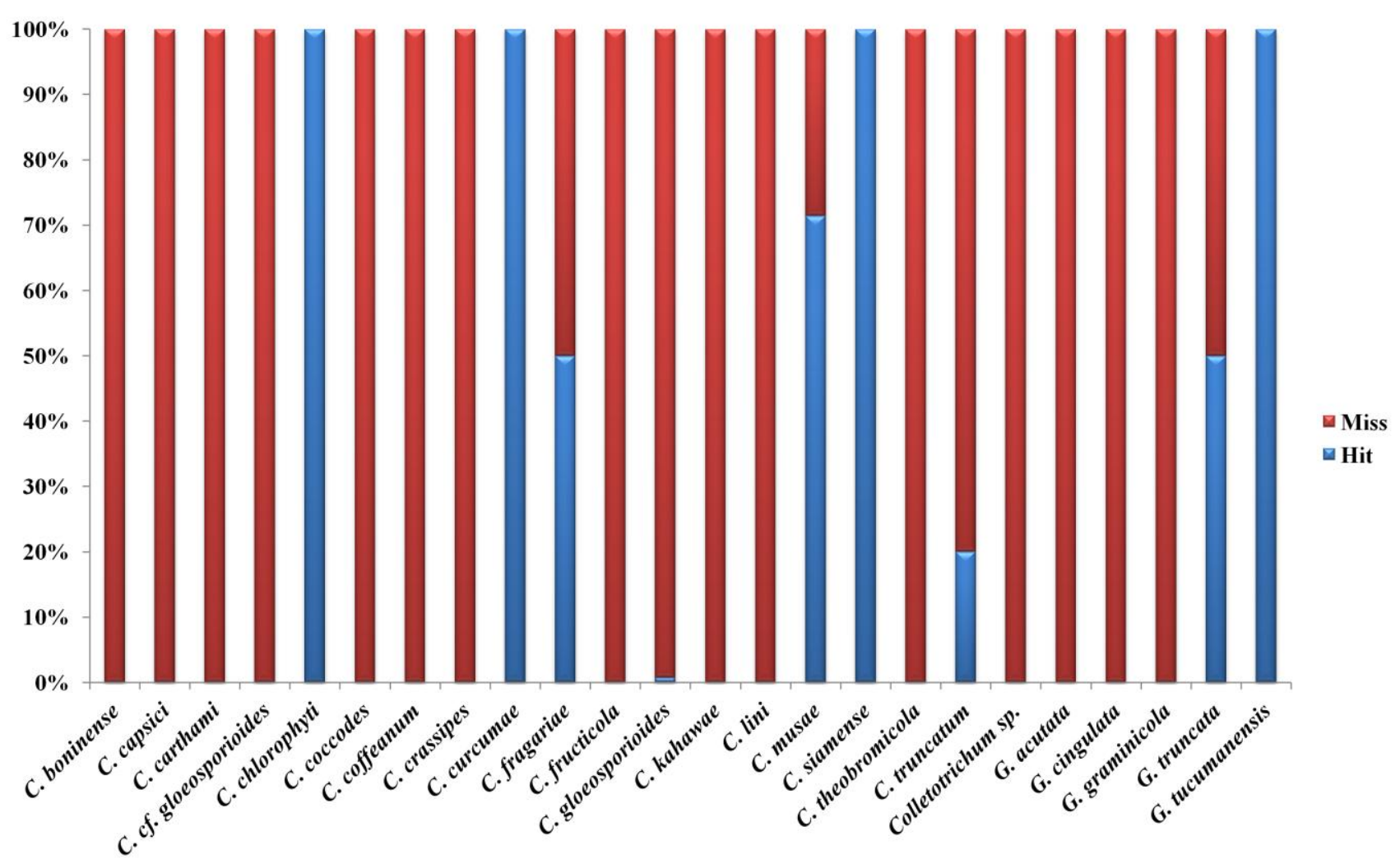

Fig. 3 - Bar diagram showing the percentage of correctly (Hit) or erroneously named (Miss) GenBank sequences submitted from India

\section{Discussion}

Accurate identification of economically important plant pathogenic fungi is a major concern at present, as it aids in early and accurate disease diagnosis. Anthracnose diseases caused by Colletotrichum species have had a considerable impact on world agricultural production through their capacity to cause economic losses on a number of important cereal, legume, fruit, vegetables and cash crops (Bailey et al. 1992, Waller 1992, Pakdeevaraporn et al. 2005). The fruits and vegetables, infected by anthracnose are not acceptable for export market (Waller 1992). The major bio-security concern regarding plant quarantine also involves accurate species identification. Thus, it becomes necessary to move ahead of traditional approach based on morphology and incorporate modern ways for species recognition.

In the present study we have tried to analyze the suitability of using ITS/ 5.8S rRNA gene region as a marker for precise identification of Colletotrichum species from India. Although the ITS/ 5.8S rRNA based identification is a rapid way of preliminary identification of fungal species, but the reliability and accuracy of this method still remains a concern. ITS/ 5.8S rRNA region is rich in indels but its difficulty to align makes its usage in phylogenetic reconstruction difficult (Seifert 2009). In addition to it, ITS as a marker has its own limitation since it is not able to fully resolve many species of $C$. gloeosporioides species complex completely as is reflected in Fig. 1.

There are more than 6300 NCBIGenBank (Benson et al. 1997, 2006) entries (6396 as on $7^{\text {th }}$ June 2013) for ITS/ 5.8S rRNA gene, which is maximum $(\sim 29 \%)$ among all the gene sequences (21528 total nucleotide entries for the genus) available in NCBI (Ryberg et al. 2009), but majority of them are erroneous and not authentic (Bridge et al. 2003, Nilsson et al. 2006, Cai et al. 2009, Crouch et al. 2009). In a recent study, a high rate of misidentification $(86 \%)$ was observed while using BLAST similarity search of ITS/ 5.8S rRNA sequences for $C$. graminicola species (Crouch et al. 2009). The reference type sequences have not been considered while analyzing in BLAST, which further leads to accumulation of wrong information in public databases in the longer run. 
Table 1 List of the Colletotrichum endophytes included in this study with information on taxon, strain designation, host, geographic location, GenBank accession number for the ITS/ 5.8S rRNA sequences and results for the local BLAST sequence similarity search

\begin{tabular}{|c|c|c|c|c|c|c|c|c|}
\hline 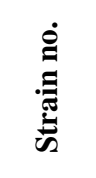 & $\overrightarrow{\stackrel{\vec{n}}{0}}$ & 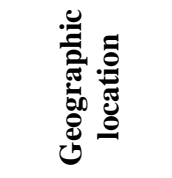 & 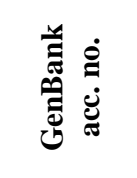 & 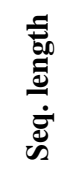 & 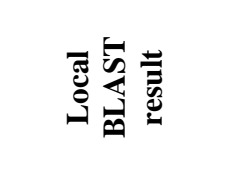 & Dूँ & 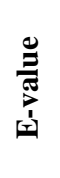 & 氖 \\
\hline GS01 & $\begin{array}{l}\text { Bauhinia } \\
\text { variegata }\end{array}$ & $\begin{array}{c}\text { IMTECH, } \\
\text { Chandigarh }\end{array}$ & $\begin{array}{c}\mathrm{JN} 24866 \\
8\end{array}$ & 556 & $\begin{array}{c}\mathrm{JX} 010264(C . \\
\text { tropicale })\end{array}$ & 1102 & 0 & $\begin{array}{l}556 / 556 \\
(100 \%)\end{array}$ \\
\hline GS02 & B. variegata & $\begin{array}{l}\text { IMTECH, } \\
\text { Chandigarh }\end{array}$ & $\begin{array}{c}\mathrm{JN} 24866 \\
9\end{array}$ & 541 & $\begin{array}{c}\text { KC790945 }(C . \\
\text { jasminisambac) }\end{array}$ & 1065 & 0 & $\begin{array}{c}540 / 541 \\
(99 \%)\end{array}$ \\
\hline GS03 & B. variegata & $\begin{array}{l}\text { IMTECH, } \\
\text { Chandigarh }\end{array}$ & $\begin{array}{c}\mathrm{JN} 24867 \\
0\end{array}$ & 538 & $\begin{array}{l}\text { KC790945 (C. } \\
\text { jasminisambac) }\end{array}$ & 1045 & 0 & $\begin{array}{c}537 / 539 \\
(99 \%)\end{array}$ \\
\hline GS04 & B. variegata & $\begin{array}{l}\text { IMTECH, } \\
\text { Chandigarh }\end{array}$ & $\begin{array}{c}\mathrm{JN} 24867 \\
1\end{array}$ & 556 & $\begin{array}{c}\mathrm{JX} 010264(C . \\
\text { tropicale })\end{array}$ & 1096 & 0 & $\begin{array}{c}555 / 556 \\
(99 \%)\end{array}$ \\
\hline GS05 & B. variegata & $\begin{array}{l}\text { IMTECH, } \\
\text { Chandigarh }\end{array}$ & $\begin{array}{c}\mathrm{JN} 24867 \\
2\end{array}$ & 555 & $\begin{array}{c}\mathrm{JX} 010264(C . \\
\text { tropicale })\end{array}$ & 1086 & 0 & $\begin{array}{c}555 / 556 \\
(99 \%)\end{array}$ \\
\hline GS06 & Saraca indica & $\begin{array}{l}\text { IMTECH, } \\
\text { Chandigarh }\end{array}$ & $\begin{array}{c}\mathrm{JN} 24867 \\
3\end{array}$ & 541 & $\begin{array}{c}\text { KC790945 }(C . \\
\text { jasminisambac) }\end{array}$ & 1065 & 0 & $\begin{array}{c}540 / 541 \\
(99 \%)\end{array}$ \\
\hline GS07 & $\begin{array}{l}\text { Bauhinia } \\
\text { variegata }\end{array}$ & $\begin{array}{l}\text { IMTECH, } \\
\text { Chandigarh }\end{array}$ & $\begin{array}{c}\mathrm{JN} 24867 \\
4\end{array}$ & 556 & $\begin{array}{l}\text { KC790945 (C. } \\
\text { jasminisambac) }\end{array}$ & 1094 & 0 & $\begin{array}{c}555 / 556 \\
(99 \%)\end{array}$ \\
\hline GS08 & B. variegata & $\begin{array}{l}\text { IMTECH, } \\
\text { Chandigarh }\end{array}$ & $\begin{array}{c}\mathrm{JN} 24867 \\
5\end{array}$ & 540 & $\begin{array}{l}\mathrm{KC} 790945(C . \\
\text { jasminisambac) }\end{array}$ & 1063 & 0 & $\begin{array}{c}539 / 540 \\
(99 \%)\end{array}$ \\
\hline GS09 & B. variegata & $\begin{array}{l}\text { IMTECH, } \\
\text { Chandigarh }\end{array}$ & $\begin{array}{c}\mathrm{JN} 24867 \\
6\end{array}$ & 536 & $\begin{array}{c}\mathrm{JX} 010264(C . \\
\text { tropicale })\end{array}$ & 1063 & 0 & $\begin{array}{l}536 / 536 \\
(100 \%)\end{array}$ \\
\hline GS10 & B. variegata & $\begin{array}{l}\text { IMTECH, } \\
\text { Chandigarh }\end{array}$ & $\begin{array}{c}\mathrm{JN} 24867 \\
7\end{array}$ & 564 & $\begin{array}{l}\text { JQ005221 (C. } \\
\text { phyllanthi) }\end{array}$ & 1100 & 0 & $\begin{array}{l}555 / 555 \\
(100 \%)\end{array}$ \\
\hline GS11 & B. variegata & $\begin{array}{l}\text { IMTECH, } \\
\text { Chandigarh }\end{array}$ & $\begin{array}{c}\mathrm{JN} 24867 \\
8\end{array}$ & 533 & $\begin{array}{c}\text { KC790945 }(C . \\
\text { jasminisambac) }\end{array}$ & 1057 & 0 & $\begin{array}{l}533 / 533 \\
(100 \%)\end{array}$ \\
\hline GS12 & B. variegata & $\begin{array}{l}\text { IMTECH, } \\
\text { Chandigarh }\end{array}$ & $\begin{array}{c}\mathrm{JN} 24867 \\
9\end{array}$ & 527 & $\begin{array}{l}\text { KC790940 }(C . \\
\text { hymenocallidis })\end{array}$ & 1037 & 0 & $\begin{array}{c}526 / 527 \\
(99 \%)\end{array}$ \\
\hline GS13 & $\begin{array}{c}\text { Azadirachta } \\
\text { indica }\end{array}$ & $\begin{array}{l}\text { IMTECH, } \\
\text { Chandigarh }\end{array}$ & $\begin{array}{c}\mathrm{JN} 24868 \\
0\end{array}$ & 556 & $\begin{array}{c}\mathrm{JX} 010264(C . \\
\text { tropicale })\end{array}$ & 1102 & 0 & $\begin{array}{l}556 / 556 \\
(100 \%)\end{array}$ \\
\hline GS14 & Ficus elastica & $\begin{array}{l}\text { IMTECH, } \\
\text { Chandigarh }\end{array}$ & $\begin{array}{c}\mathrm{JN} 24868 \\
1\end{array}$ & 497 & $\begin{array}{l}\text { KC790945 (C. } \\
\text { jasminisambac) }\end{array}$ & 985 & 0 & $\begin{array}{r}497 / 497 \\
(100 \%)\end{array}$ \\
\hline GS15 & $\begin{array}{l}\text { Bauhinia } \\
\text { variegata }\end{array}$ & $\begin{array}{l}\text { IMTECH, } \\
\text { Chandigarh }\end{array}$ & $\begin{array}{c}\mathrm{JN} 24868 \\
2\end{array}$ & 530 & $\begin{array}{l}\text { KC790945 (C. } \\
\text { jasminisambac) }\end{array}$ & 1051 & 0 & $\begin{array}{c}530 / 530 \\
(100 \%)\end{array}$ \\
\hline GS17 & Psidium guajava & $\begin{array}{l}\text { IMTECH, } \\
\text { Chandigarh }\end{array}$ & $\begin{array}{c}\mathrm{JN} 24868 \\
3\end{array}$ & 556 & $\begin{array}{l}\text { KC790945 }(C . \\
\text { jasminisambac })\end{array}$ & 1102 & 0 & $\begin{array}{l}556 / 556 \\
(100 \%)\end{array}$ \\
\hline GS18 & P. guajava & $\begin{array}{l}\text { IMTECH, } \\
\text { Chandigarh }\end{array}$ & $\begin{array}{c}\mathrm{JN} 24868 \\
4\end{array}$ & 556 & $\begin{array}{c}\mathrm{JX} 010264(C . \\
\text { tropicale })\end{array}$ & 1102 & 0 & $\begin{array}{l}556 / 556 \\
(100 \%)\end{array}$ \\
\hline GS19 & $\begin{array}{l}\text { Unidentified } \\
\text { plant }\end{array}$ & $\begin{array}{l}\text { IMTECH, } \\
\text { Chandigarh }\end{array}$ & $\begin{array}{c}\mathrm{JN} 24868 \\
5\end{array}$ & 556 & $\begin{array}{l}\text { KC790945 }(C . \\
\text { jasminisambac })\end{array}$ & 1102 & 0 & $\begin{array}{l}556 / 556 \\
(100 \%)\end{array}$ \\
\hline GS20 & $\begin{array}{l}\text { Unidentified } \\
\text { plant }\end{array}$ & $\begin{array}{l}\text { IMTECH, } \\
\text { Chandigarh }\end{array}$ & $\begin{array}{c}\mathrm{JN} 24868 \\
6\end{array}$ & 556 & $\begin{array}{c}\mathrm{JX} 010264(C . \\
\text { tropicale })\end{array}$ & 1102 & 0 & $\begin{array}{l}556 / 556 \\
(100 \%)\end{array}$ \\
\hline GS21 & $\begin{array}{l}\text { Unidentified } \\
\text { plant }\end{array}$ & $\begin{array}{l}\text { IMTECH, } \\
\text { Chandigarh }\end{array}$ & $\begin{array}{c}\mathrm{JN} 24868 \\
7\end{array}$ & 556 & $\begin{array}{l}\text { KC790945 }(C . \\
\text { jasminisambac })\end{array}$ & 1094 & 0 & $\begin{array}{c}555 / 556 \\
(99 \%)\end{array}$ \\
\hline GS22 & $\begin{array}{l}\text { Unidentified } \\
\text { plant }\end{array}$ & $\begin{array}{l}\text { IMTECH, } \\
\text { Chandigarh }\end{array}$ & $\begin{array}{c}\mathrm{JN} 24868 \\
8\end{array}$ & 531 & $\begin{array}{c}\mathrm{JX} 010264(C . \\
\text { tropicale })\end{array}$ & 1053 & 0 & $\begin{array}{l}531 / 531 \\
(100 \%)\end{array}$ \\
\hline GS23 & Curcuma longa & $\begin{array}{l}\text { IMTECH, } \\
\text { Chandigarh }\end{array}$ & $\begin{array}{c}\mathrm{JN} 24868 \\
9\end{array}$ & 556 & $\begin{array}{c}\mathrm{JX} 010264(C . \\
\text { tropicale })\end{array}$ & 1102 & 0 & $\begin{array}{c}556 / 556 \\
(100 \%)\end{array}$ \\
\hline GS26 & $\begin{array}{l}\text { Bougainvillea } \\
\text { sp. }\end{array}$ & $\begin{array}{l}\text { IMTECH, } \\
\text { Chandigarh }\end{array}$ & $\begin{array}{c}\mathrm{JN} 24869 \\
0\end{array}$ & 576 & $\begin{array}{l}\text { JQ005221 }(C . \\
\text { phyllanthi) }\end{array}$ & 1100 & 0 & $\begin{array}{l}555 / 555 \\
(100 \%)\end{array}$ \\
\hline GS27 & $\begin{array}{l}\text { Bougainvillea } \\
\text { sp. }\end{array}$ & $\begin{array}{l}\text { IMTECH, } \\
\text { Chandigarh }\end{array}$ & $\begin{array}{c}\mathrm{JN} 24869 \\
1\end{array}$ & 537 & $\begin{array}{c}\mathrm{JX} 010264(C . \\
\text { tropicale })\end{array}$ & 1065 & 0 & $\begin{array}{l}537 / 537 \\
(100 \%)\end{array}$ \\
\hline GS28 & $\begin{array}{l}\text { Unidentified } \\
\text { plant }\end{array}$ & $\begin{array}{l}\text { IMTECH, } \\
\text { Chandigarh }\end{array}$ & $\begin{array}{c}\mathrm{JN} 24869 \\
2\end{array}$ & 557 & $\begin{array}{c}\text { KC790945 }(C . \\
\text { jasminisambac) }\end{array}$ & 1080 & 0 & $\begin{array}{c}555 / 557 \\
(99 \%)\end{array}$ \\
\hline GS29 & $\begin{array}{l}\text { Unidentified } \\
\text { plant }\end{array}$ & $\begin{array}{l}\text { IMTECH, } \\
\text { Chandigarh }\end{array}$ & $\begin{array}{c}\mathrm{JN} 24869 \\
3\end{array}$ & 556 & $\begin{array}{l}\text { KC790945 (C. } \\
\text { jasminisambac) }\end{array}$ & 1102 & 0 & $\begin{array}{c}556 / 556 \\
(100 \%)\end{array}$ \\
\hline GS30 & $\begin{array}{l}\text { Unidentified } \\
\text { plant }\end{array}$ & $\begin{array}{l}\text { IMTECH, } \\
\text { Chandigarh }\end{array}$ & $\begin{array}{c}\mathrm{JN} 24869 \\
4\end{array}$ & 544 & $\begin{array}{l}\text { KC790943 }(C . \\
\text { brevisporum })\end{array}$ & 1047 & 0 & $\begin{array}{c}537 / 540 \\
(99 \%)\end{array}$ \\
\hline $\begin{array}{l}\text { IMTF } \\
736\end{array}$ & Cassia sp. & $\begin{array}{l}\text { IMTECH, } \\
\text { Chandigarh }\end{array}$ & $\begin{array}{c}\mathrm{JN} 24869 \\
5\end{array}$ & 539 & $\begin{array}{c}\mathrm{KC} 790945(C . \\
\text { jasminisambac })\end{array}$ & 1068 & 0 & $\begin{array}{l}539 / 539 \\
(100 \%)\end{array}$ \\
\hline $\begin{array}{l}\text { IMTF } \\
737\end{array}$ & Cassia sp. & $\begin{array}{l}\text { IMTECH, } \\
\text { Chandigarh }\end{array}$ & $\begin{array}{c}\mathrm{JN} 24869 \\
6\end{array}$ & 541 & $\begin{array}{l}\text { KC790945 (C. } \\
\text { jasminisambac) }\end{array}$ & 1072 & 0 & $\begin{array}{l}541 / 541 \\
(100 \%)\end{array}$ \\
\hline
\end{tabular}




\begin{tabular}{|c|c|c|c|c|c|c|c|c|}
\hline 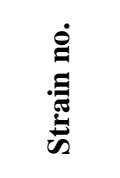 & $\stackrel{\overrightarrow{0}}{\stackrel{\theta}{*}}$ & 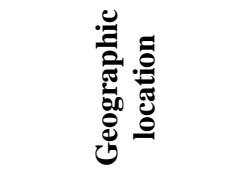 & 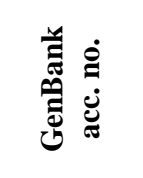 & 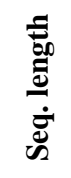 & 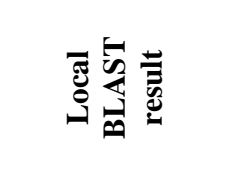 & D্ّ & 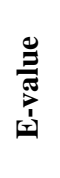 & 氖 \\
\hline $\begin{array}{c}\text { IMTF } \\
738\end{array}$ & Cassia sp. & $\begin{array}{l}\text { IMTECH, } \\
\text { Chandigarh }\end{array}$ & $\begin{array}{c}\text { JN24869 } \\
7\end{array}$ & 548 & $\begin{array}{c}\text { KC790945 }(C . \\
\text { jasminisambac })\end{array}$ & 1086 & 0 & $\begin{array}{l}548 / 548 \\
(100 \%)\end{array}$ \\
\hline IMTF & & IMTECH, & JN24869 & & JX010264 (C. & & & $556 / 556$ \\
\hline 952 & Curcuma longa & Chandigarh & 8 & 556 & tropicale) & 1102 & 0 & $(100 \%)$ \\
\hline IMTF & Unidentified & IMTECH, & JN24869 & & KC790945 (C. & & & $556 / 556$ \\
\hline 967 & plant & Chandigarh & 9 & 556 & jasminisambac) & 1102 & 0 & $(100 \%)$ \\
\hline IMTF & Unidentified & IMTECH, & JN24870 & & JX010264 (C. & & & $556 / 556$ \\
\hline 968 & plant & Chandigarh & 0 & 556 & tropicale) & 1102 & 0 & $(100 \%)$ \\
\hline IMTF & Unidentified & IMTECH, & JN24870 & & KC790945 (C. & & & $555 / 556$ \\
\hline 969 & plant & Chandigarh & 1 & 556 & jasminisambac) & 1094 & 0 & (99\%) \\
\hline IMTF & Unidentified & IMTECH, & JN24870 & & $\mathrm{JX} 010264(C$ & & & $556 / 556$ \\
\hline 976 & plant & Chandigarh & 2 & 556 & tropicale) & 1102 & 0 & $(100 \%)$ \\
\hline IMTF & & IMTECH, & JN24870 & & KC790945 (C. & & & $556 / 556$ \\
\hline 979 & Psidium guajava & Chandigarh & 3 & 556 & jasminisambac) & 1102 & 0 & $(100 \%)$ \\
\hline IMTF & $P$ ougiava & IMTECH, & JN24870 & & $\mathrm{JX010264}(C$ & & & $531 / 531$ \\
\hline 980 & P. $g$ & Chandigarh & 4 & 531 & tropicale) & 1053 & 0 & $(100 \%)$ \\
\hline IMTF & Unidentified & IMTECH, & JN24870 & & $\mathrm{JX} 010264(C$. & & & $556 / 556$ \\
\hline 997 & plant & Chandigarh & 5 & 556 & tropicale) & 1102 & 0 & $(100 \%)$ \\
\hline $\begin{array}{l}\text { Mango } \\
5 \mathrm{~B}\end{array}$ & $\begin{array}{l}\text { Mangifera } \\
\text { indica }\end{array}$ & $\begin{array}{c}\text { CSIO, } \\
\text { Chandigarh }\end{array}$ & $\begin{array}{c}\mathrm{JN} 24870 \\
6\end{array}$ & 534 & $\begin{array}{l}\text { KC790945 (C. } \\
\text { jasminisambac) }\end{array}$ & 1043 & 0 & $\begin{array}{l}33 / 534 \\
(99 \%)\end{array}$ \\
\hline $\begin{array}{c}\text { Mango } \\
10\end{array}$ & M. indica & $\begin{array}{l}\text { Sector } 40 \text { Market, } \\
\text { Chandigarh }\end{array}$ & $\begin{array}{c}\mathrm{JN} 24870 \\
7\end{array}$ & 531 & $\begin{array}{l}\mathrm{JX} 010264(C . \\
\text { tropicale })\end{array}$ & 1017 & 0 & $\begin{array}{c}530 / 533 \\
(99 \%)\end{array}$ \\
\hline GM 12 & M. indica & $\begin{array}{c}\text { CSIO, } \\
\text { Chandigarh }\end{array}$ & $\begin{array}{c}\mathrm{JN} 24870 \\
8\end{array}$ & 556 & $\begin{array}{l}\text { KC790945 }(C . \\
\text { jasminisambac })\end{array}$ & 1102 & 0 & $\begin{array}{l}556 / 556 \\
(100 \%)\end{array}$ \\
\hline $\begin{array}{l}\mathrm{GM} \\
15 \mathrm{~B}\end{array}$ & M. indica & $\begin{array}{c}\text { CSIO, } \\
\text { Chandigarh }\end{array}$ & $\begin{array}{c}\mathrm{JN} 24870 \\
9\end{array}$ & 556 & $\begin{array}{l}\text { KC790945 (C. } \\
\text { jasminisambac) }\end{array}$ & 1094 & 0 & $\begin{array}{c}555 / 556 \\
(99 \%)\end{array}$ \\
\hline GM 21 & M. indica & $\begin{array}{c}\text { Sector } 40 \text { Market, } \\
\text { Chandigarh }\end{array}$ & $\begin{array}{c}\mathrm{JN} 24871 \\
0\end{array}$ & 549 & $\begin{array}{c}\mathrm{JX} 010264(C . \\
\text { tropicale })\end{array}$ & 1080 & 0 & $\begin{array}{c}548 / 549 \\
(99 \%)\end{array}$ \\
\hline GM 42 & M. indica & $\begin{array}{l}\text { Malihabad, } \\
\text { Lucknow }\end{array}$ & $\begin{array}{c}\mathrm{JN} 24871 \\
1\end{array}$ & 556 & $\begin{array}{c}\text { KC790945 }(C . \\
\text { jasminisambac) }\end{array}$ & 1094 & 0 & $\begin{array}{c}555 / 556 \\
(99 \%)\end{array}$ \\
\hline GM 52 & M. indica & CISH, Lucknow & $\begin{array}{c}\mathrm{JN} 24871 \\
2\end{array}$ & 556 & $\begin{array}{l}\text { KC790945 }(C . \\
\text { jasminisambac) }\end{array}$ & 1102 & 0 & $\begin{array}{l}556 / 556 \\
(100 \%)\end{array}$ \\
\hline GM 57 & M. indica & $\begin{array}{l}\text { Valsad, Nand } \\
\text { Sagar, Gujrat }\end{array}$ & $\begin{array}{c}\text { JN24871 } \\
3\end{array}$ & 556 & $\begin{array}{l}\mathrm{KC} 790945(C . \\
\text { jasminisambac) }\end{array}$ & 1102 & 0 & $\begin{array}{l}556 / 556 \\
(100 \%)\end{array}$ \\
\hline GM 58 & M. indica & $\begin{array}{l}\text { Valsad, Nand } \\
\text { Sagar, Gujrat }\end{array}$ & $\begin{array}{c}\mathrm{JN} 24871 \\
4\end{array}$ & 556 & $\begin{array}{l}\text { JX010171 (C. } \\
\text { siamense })\end{array}$ & 1102 & 0 & $\begin{array}{l}556 / 556 \\
(100 \%)\end{array}$ \\
\hline GM 149 & M. indica & Navsari, Gujrat & $\begin{array}{c}\mathrm{KF} 21463 \\
3\end{array}$ & 557 & $\begin{array}{l}\text { KC790940 }(C . \\
\text { hymenocallidis })\end{array}$ & 1096 & 0 & $\begin{array}{c}556 / 557 \\
(99 \%)\end{array}$ \\
\hline GM 151 & M. indica & Navsari, Gujrat & $\begin{array}{c}\text { KF21463 } \\
4\end{array}$ & 556 & $\begin{array}{l}\text { KC790945 (C. } \\
\text { jasminisambac) }\end{array}$ & 1102 & 0 & $\begin{array}{c}556 / 556 \\
(100 \%)\end{array}$ \\
\hline
\end{tabular}

In this study, ITS/ 5.8S rRNA region was sequenced for a few type strain sequences including $C$. sansevieriae, whose original sequence (AB212991) was too short and hence not included in the analysis. The newly generated type sequences have been highlighted in bold in Table 3. An updated file comprising the ITS/ 5.8S rRNA gene sequence for the 135 type strains of Colletotrichum (Post Cannon et al. 2012) was made and used to validate the identities of the Colletotrichum isolates deposited in various culture collection centres across India and the GenBank sequences deposited from India. Based on the NJ tree (Fig. 1) and the local-BLAST analysis done in BioEdit; almost 97 \% (155/159) of the isolates procured from various culture collection centres of India were found to be misidentified. Also, about $79 \%$ of the GenBank sequences deposited from India were found to be erroneously named. The reason for this could be the fact that, in many Institutes and Universities of India, traditional morphology based approach for species-identification is still more popular. The sequence based identification is yet not popular owing to its high cost.

DNA sequence based species identification could be a recent trend, but based on our study, we are forced to think whether it is judicious to spend so much money on a process which ultimately leads us nowhere but towards a clutter of confusion. Thus, in current scenario ITS/ 5.8S rRNA based species 
Table 2 List of the Colletotrichum isolates included in this study, procured from different culture collection centres of India; with information on taxon, strain designation, host, geographic location, GenBank accession number for the ITS/ 5.8S rRNA sequences and results for the local BLAST sequence similarity search $\left({ }^{*}=\right.$ Taxon name as mentioned in GenBank)

\begin{tabular}{|c|c|c|c|c|c|c|c|c|c|}
\hline 㺼 & 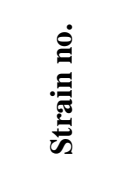 & $\stackrel{\overrightarrow{0}}{\stackrel{0}{0}}$ & 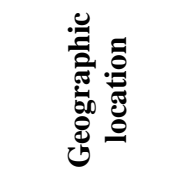 & 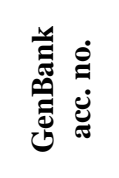 & 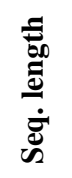 & 式芯 & : & 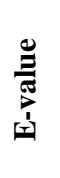 & : \\
\hline C. falcatum & CF1 & Saccharum sp. & $\begin{array}{l}\text { Coimbatore, } \\
\text { Tamil Nadu }\end{array}$ & $\begin{array}{c}\text { JN3909 } \\
36\end{array}$ & 535 & $\begin{array}{l}\text { JQ005772 }(C . \\
\text { falcatum })\end{array}$ & 1029 & 0 & $\begin{array}{l}531 / 535 \\
(100 \%)\end{array}$ \\
\hline C. falcatum & $\mathrm{CF} 2$ & Saccharum sp. & $\begin{array}{l}\text { Coimbatore, } \\
\text { Tamil Nadu }\end{array}$ & $\begin{array}{c}\text { JN3909 } \\
37\end{array}$ & 535 & $\begin{array}{l}\text { JQ005772 ( } C . \\
\text { falcatum })\end{array}$ & 1029 & 0 & $\begin{array}{l}531 / 535 \\
(100 \%)\end{array}$ \\
\hline $\begin{array}{l}\text { Colletotrichum } \\
\text { sp. }\end{array}$ & $\begin{array}{c}\text { GUFCC } \\
15502\end{array}$ & Diffenbakia sp. & unknown & $\begin{array}{c}\text { JN3909 } \\
34\end{array}$ & 557 & $\begin{array}{c}\text { JX010251 (C. } \\
\text { alienum) }\end{array}$ & 1104 & 0 & $\begin{array}{l}557 / 557 \\
(100 \%)\end{array}$ \\
\hline $\begin{array}{l}\text { Colletotrichum } \\
\text { sp. }\end{array}$ & $\begin{array}{c}\text { GUFCC } \\
15503\end{array}$ & $\begin{array}{l}\text { Calamus } \\
\text { thwaitesii }\end{array}$ & $\begin{array}{l}\text { Netravali, } \\
\quad \text { Goa }\end{array}$ & $\begin{array}{c}\mathrm{JN} 3909 \\
35\end{array}$ & 528 & $\begin{array}{c}\text { KC790943 (C. } \\
\text { brevisporum) }\end{array}$ & 975 & 0 & $\begin{array}{c}520 / 528 \\
(98 \%)\end{array}$ \\
\hline C.papayae & $\begin{array}{c}\text { ITCC } \\
1269\end{array}$ & unknown & Delhi & $\begin{array}{c}\mathrm{JN} 3908 \\
35\end{array}$ & 543 & $\begin{array}{c}\mathrm{JX} 010251(C . \\
\text { alienum })\end{array}$ & 1066 & 0 & $\begin{array}{l}538 / 538 \\
(100 \%)\end{array}$ \\
\hline C. truncatum & $\begin{array}{l}\text { ITCC } \\
1847\end{array}$ & Cajanus cajan & unknown & $\begin{array}{c}\mathrm{JN} 3908 \\
36\end{array}$ & 562 & $\begin{array}{l}\text { HM131513 (C. } \\
\text { jasminigenum) }\end{array}$ & 1114 & 0 & $\begin{array}{l}562 / 562 \\
(100 \%)\end{array}$ \\
\hline C. capsici & $\begin{array}{l}\text { ITCC } \\
2041\end{array}$ & $\begin{array}{l}\text { Capsicum } \\
\text { annum }\end{array}$ & $\begin{array}{c}\text { Nagpur, } \\
\text { Maharashtra }\end{array}$ & $\begin{array}{c}\text { JN3908 } \\
88\end{array}$ & 562 & $\begin{array}{l}\mathrm{HM} 131513(C . \\
\text { jasminigenum })\end{array}$ & 1106 & 0 & $\begin{array}{c}561 / 562 \\
(99 \%)\end{array}$ \\
\hline C. capsici & $\begin{array}{l}\text { ITCC } \\
2701\end{array}$ & $\begin{array}{l}\text { Solanum } \\
\text { melongena }\end{array}$ & $\begin{array}{l}\text { Ujjain, } \\
\text { Madhya } \\
\text { Pradesh }\end{array}$ & $\begin{array}{c}\text { JN3908 } \\
89\end{array}$ & 562 & $\begin{array}{l}\text { HM131513 (C. } \\
\text { jasminigenum) }\end{array}$ & 1106 & 0 & $\begin{array}{c}561 / 562 \\
(99 \%)\end{array}$ \\
\hline $\begin{array}{c}\text { C. } \\
\text { gloeosporioides }\end{array}$ & $\begin{array}{l}\text { ITCC } \\
3005\end{array}$ & Cocoa sp. & $\begin{array}{l}\text { Ratnagiri, } \\
\text { Maharashtra }\end{array}$ & $\begin{array}{c}\mathrm{JN} 3908 \\
90\end{array}$ & 532 & $\begin{array}{c}\mathrm{JX} 010146(C . \\
\text { musae })\end{array}$ & 1055 & 0 & $\begin{array}{l}532 / 532 \\
(100 \%)\end{array}$ \\
\hline $\begin{array}{c}C . \\
\text { gloeosporioides }\end{array}$ & $\begin{array}{l}\text { ITCC } \\
3508\end{array}$ & Dalbergia & Delhi & $\begin{array}{c}\text { JN3908 } \\
92\end{array}$ & 557 & $\begin{array}{l}\text { JX010165 (C. } \\
\text { fructicola) }\end{array}$ & 1088 & 0 & $\begin{array}{c}555 / 557 \\
(99 \%)\end{array}$ \\
\hline C. dematium & $\begin{array}{l}\text { ITCC } \\
3535\end{array}$ & Gossypium sp. & $\begin{array}{c}\text { Dapoli, } \\
\text { Maharashtra }\end{array}$ & $\begin{array}{c}\text { JN3908 } \\
37\end{array}$ & 557 & $\begin{array}{l}\text { HM131513 }(C . \\
\text { jasminigenum) }\end{array}$ & 1104 & 0 & $\begin{array}{l}557 / 557 \\
(100 \%)\end{array}$ \\
\hline $\begin{array}{c}C . \\
\text { gloeosporioides }\end{array}$ & $\begin{array}{l}\text { ITCC } \\
3086\end{array}$ & Cyclamen sp. & $\begin{array}{l}\text { Solan, } \\
\text { Himachal } \\
\text { Pradesh }\end{array}$ & $\begin{array}{c}\text { JN3908 } \\
91\end{array}$ & 557 & $\begin{array}{c}\text { JX010165 (C. } \\
\text { fructicola) }\end{array}$ & 1096 & 0 & $\begin{array}{c}556 / 557 \\
(99 \%)\end{array}$ \\
\hline $\begin{array}{c}C . \\
\text { gloeosporioides }\end{array}$ & $\begin{array}{l}\text { ITCC } \\
3851\end{array}$ & Pouteria sapota & $\begin{array}{c}\text { Navsari, } \\
\text { Gujarat }\end{array}$ & $\begin{array}{c}\mathrm{JN} 3908 \\
93\end{array}$ & 530 & $\begin{array}{c}\mathrm{JX} 010146(C . \\
\text { musae })\end{array}$ & 1051 & 0 & $\begin{array}{l}530 / 530 \\
(100 \%)\end{array}$ \\
\hline $\begin{array}{c}\text { C. } \\
\text { gloeosporioides }\end{array}$ & $\begin{array}{l}\text { ITCC } \\
4145\end{array}$ & Gossypium sp. & $\begin{array}{l}\text { Nagpur, } \\
\text { Maharashtra }\end{array}$ & $\begin{array}{c}\text { JN3908 } \\
94\end{array}$ & 556 & $\begin{array}{l}\text { JX010171 (C. } \\
\text { siamense })\end{array}$ & 1102 & 0 & $\begin{array}{l}556 / 556 \\
(100 \%)\end{array}$ \\
\hline $\begin{array}{c}\text { C. } \\
\text { gloeosporioides }\end{array}$ & $\begin{array}{l}\text { ITCC } \\
4202\end{array}$ & $\begin{array}{c}\text { Arachis } \\
\text { hypogaea }\end{array}$ & $\begin{array}{l}\text { Udaipur, } \\
\text { Rajasthan }\end{array}$ & $\begin{array}{c}\mathrm{JN} 3908 \\
95\end{array}$ & 546 & $\begin{array}{c}\mathrm{JX} 010264(C . \\
\text { tropicale })\end{array}$ & 1078 & 0 & $\begin{array}{l}544 / 544 \\
(100 \%)\end{array}$ \\
\hline $\begin{array}{c}\text { C. } \\
\text { gloeosporioides }\end{array}$ & $\begin{array}{l}\text { ITCC } \\
4207\end{array}$ & Allium cepa & $\begin{array}{l}\text { Karnal, } \\
\text { Haryana }\end{array}$ & $\begin{array}{c}\text { JN3908 } \\
96\end{array}$ & 556 & $\begin{array}{c}\text { JX010171 }(C . \\
\text { siamense })\end{array}$ & 1102 & 0 & $\begin{array}{c}556 / 556 \\
(100 \%)\end{array}$ \\
\hline $\begin{array}{c}\text { C. } \\
\text { gloeosporioides }\end{array}$ & $\begin{array}{l}\text { ITCC } \\
4215\end{array}$ & Fern & $\begin{array}{l}\text { Warangal, } \\
\text { Andhra } \\
\text { Pradesh }\end{array}$ & $\begin{array}{c}\text { JN3908 } \\
97\end{array}$ & 556 & $\begin{array}{c}\text { JX010171 (C. } \\
\text { siamense) }\end{array}$ & 1102 & 0 & $\begin{array}{l}556 / 556 \\
(100 \%)\end{array}$ \\
\hline $\begin{array}{c}C . \\
\text { gloeosporioides }\end{array}$ & $\begin{array}{r}\text { ITCC } \\
4216\end{array}$ & Ixora & $\begin{array}{c}\text { Warangal, } \\
\text { Andhra } \\
\text { Pradesh }\end{array}$ & $\begin{array}{c}\text { JN3908 } \\
98\end{array}$ & 556 & $\begin{array}{l}\text { JX010171 (C. } \\
\text { siamense })\end{array}$ & 1102 & 0 & $\begin{array}{c}556 / 556 \\
(100 \%)\end{array}$ \\
\hline $\begin{array}{l}\text { Colletotrichum } \\
\text { sp. }\end{array}$ & $\begin{array}{l}\text { ITCC } \\
4220\end{array}$ & $\begin{array}{c}\text { Abelmoschus } \\
\text { esculentus }\end{array}$ & New Delhi & $\begin{array}{c}\mathrm{JN} 3908 \\
38\end{array}$ & 550 & $\begin{array}{l}\mathrm{HM} 131513(C . \\
\text { jasminigenum) }\end{array}$ & 1090 & 0 & $\begin{array}{l}550 / 550 \\
(100 \%)\end{array}$ \\
\hline $\begin{array}{c}\text { C. } \\
\text { gloeosporioides }\end{array}$ & $\begin{array}{l}\text { ITCC } \\
4315\end{array}$ & - & $\begin{array}{c}\text { Nasik, } \\
\text { Maharashtra }\end{array}$ & $\begin{array}{c}\mathrm{JN} 3908 \\
99\end{array}$ & 536 & $\begin{array}{c}\text { JX010171 ( } C \text {. } \\
\text { siamense) }\end{array}$ & 1041 & 0 & $\begin{array}{c}535 / 537 \\
(99 \%)\end{array}$ \\
\hline $\begin{array}{c}\text { C. } \\
\text { gloeosporioides }\end{array}$ & $\begin{array}{l}\text { ITCC } \\
4468\end{array}$ & Cassia sp. & $\begin{array}{l}\text { Junagarh, } \\
\text { Gujrat }\end{array}$ & $\begin{array}{c}\mathrm{JN} 3909 \\
01\end{array}$ & 540 & $\begin{array}{c}\mathrm{JX} 010264(C . \\
\text { tropicale })\end{array}$ & 1013 & 0 & $\begin{array}{c}517 / 519 \\
(99 \%)\end{array}$ \\
\hline $\begin{array}{c}\text { C. } \\
\text { gloeosporioides }\end{array}$ & $\begin{array}{l}\text { ITCC } \\
4573\end{array}$ & $\begin{array}{l}\text { Solanum } \\
\text { melongena }\end{array}$ & $\begin{array}{l}\text { Siliguri, West } \\
\text { Bengal }\end{array}$ & $\begin{array}{c}\mathrm{JN} 3909 \\
02\end{array}$ & 556 & $\begin{array}{c}\mathrm{JX} 010264(C . \\
\text { tropicale })\end{array}$ & 1102 & 0 & $\begin{array}{l}556 / 556 \\
(100 \%)\end{array}$ \\
\hline $\begin{array}{c}\text { C. } \\
\text { lindemuthianum }\end{array}$ & $\begin{array}{l}\text { ITCC } \\
4765\end{array}$ & Phaseolus sp. & unknown & $\begin{array}{c}\text { JN3908 } \\
83\end{array}$ & 533 & $\begin{array}{c}\text { GQ485607 }(C . \\
\text { cliviae) }\end{array}$ & 983 & 0 & $\begin{array}{c}506 / 508 \\
(99 \%)\end{array}$ \\
\hline $\begin{array}{c}\text { C. } \\
\text { gloeosporioides }\end{array}$ & $\begin{array}{c}\text { ITCC } \\
4770\end{array}$ & $\begin{array}{l}\text { Agalonema } \\
\text { commutatum }\end{array}$ & $\begin{array}{l}\text { Kottayam, } \\
\text { Kerala }\end{array}$ & $\begin{array}{c}\text { JN3909 } \\
03\end{array}$ & 508 & $\begin{array}{l}\text { JX010171 ( } C . \\
\text { siamense })\end{array}$ & 1007 & 0 & $\begin{array}{l}508 / 508 \\
(100 \%)\end{array}$ \\
\hline $\begin{array}{c}\text { C. } \\
\text { gloeosporioides }\end{array}$ & $\begin{array}{l}\text { ITCC } \\
4772\end{array}$ & $\begin{array}{l}\text { Begonia } \\
\text { saachsen }\end{array}$ & $\begin{array}{c}\text { Kottayam, } \\
\text { Kerala }\end{array}$ & $\begin{array}{c}\text { JN3909 } \\
17\end{array}$ & 531 & $\begin{array}{c}\text { JX010171 (C. } \\
\text { siamense })\end{array}$ & 1053 & 0 & $\begin{array}{l}531 / 531 \\
(100 \%)\end{array}$ \\
\hline $\begin{array}{c}\text { C. } \\
\text { gloeosporioides }\end{array}$ & $\begin{array}{r}\text { ITCC } \\
4776 \\
\end{array}$ & Lantana camara & $\begin{array}{c}\text { Kottayam, } \\
\text { Kerala }\end{array}$ & $\begin{array}{c}\mathrm{JN} 3909 \\
04\end{array}$ & 556 & $\begin{array}{c}\text { JX010171 (C. } \\
\text { siamense })\end{array}$ & 1102 & 0 & $\begin{array}{l}556 / 556 \\
(100 \%)\end{array}$ \\
\hline
\end{tabular}




\begin{tabular}{|c|c|c|c|c|c|c|c|c|c|}
\hline 芯 & 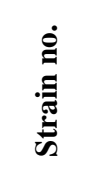 & $\stackrel{\vec{t}}{0}$ & 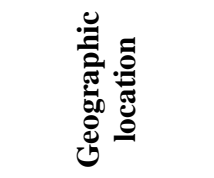 & 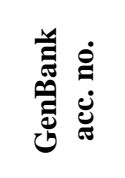 & 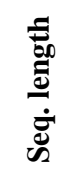 & 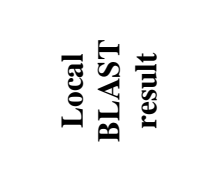 & : & 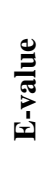 & : \\
\hline $\begin{array}{c}C . \\
\text { gloeosporioides }\end{array}$ & $\begin{array}{l}\text { ITCC } \\
4777\end{array}$ & $\begin{array}{l}\text { Mussaenda } \\
\text { frondasa }\end{array}$ & $\begin{array}{l}\text { Kottayam, } \\
\text { Kerala }\end{array}$ & $\begin{array}{c}\text { JN3909 } \\
05\end{array}$ & 509 & $\begin{array}{c}\mathrm{KC} 790940(C . \\
\text { hymenocallidis } \\
)\end{array}$ & 977 & 0 & $\begin{array}{c}506 / 509 \\
(99 \%)\end{array}$ \\
\hline C. falcatum & $\begin{array}{l}\text { ITCC } \\
4800\end{array}$ & Saccharum sp. & $\begin{array}{l}\text { Daurala, Uttar } \\
\text { Pradesh }\end{array}$ & $\begin{array}{c}\mathrm{JN} 3909 \\
06\end{array}$ & 533 & $\begin{array}{l}\text { JQ005772 ( } C \text {. } \\
\text { falcatum })\end{array}$ & 1025 & 0 & $\begin{array}{c}529 / 533 \\
(99 \%)\end{array}$ \\
\hline C. falcatum & $\begin{array}{l}\text { ITCC } \\
4803\end{array}$ & Saccharum sp. & $\begin{array}{l}\text { Daurala, Uttar } \\
\text { Pradesh }\end{array}$ & $\begin{array}{c}\mathrm{JN} 3908 \\
39\end{array}$ & 543 & $\begin{array}{l}\text { JQ005772 ( } C \text {. } \\
\text { falcatum) }\end{array}$ & 1037 & 0 & $\begin{array}{c}535 / 539 \\
(99 \%)\end{array}$ \\
\hline $\begin{array}{c}C . \\
\text { gloeosporioides }\end{array}$ & $\begin{array}{l}\text { ITCC } \\
4849\end{array}$ & Nerium sp. & New Delhi & $\begin{array}{c}\text { JN3909 } \\
07\end{array}$ & 557 & $\begin{array}{c}\text { KC790945 (C. } \\
\text { jasminisambac } \\
\text { ) }\end{array}$ & 1080 & 0 & $\begin{array}{c}555 / 557 \\
(99 \%)\end{array}$ \\
\hline C. capsici & $\begin{array}{l}\text { ITCC } \\
4871\end{array}$ & Gomphrena sp. & Sikkim & $\begin{array}{c}\mathrm{JN} 3908 \\
40\end{array}$ & 562 & $\begin{array}{l}\mathrm{HM} 131513(C . \\
\text { jasminigenum })\end{array}$ & 1106 & 0 & $\begin{array}{c}561 / 562 \\
(99 \%)\end{array}$ \\
\hline $\begin{array}{c}C . \\
\text { gloeosporioides }\end{array}$ & $\begin{array}{l}\text { ITCC } \\
4894\end{array}$ & Morus alba & $\begin{array}{l}\text { Kalimpong, } \\
\text { West Bengal }\end{array}$ & $\begin{array}{c}\mathrm{JN} 3909 \\
00\end{array}$ & 557 & $\begin{array}{l}\mathrm{JX} 010165(C . \\
\text { fructicola) }\end{array}$ & 1104 & 0 & $\begin{array}{l}557 / 557 \\
(100 \%)\end{array}$ \\
\hline $\begin{array}{c}\text { C. } \\
\text { gloeosporioides }\end{array}$ & $\begin{array}{l}\text { ITCC } \\
4915\end{array}$ & $\begin{array}{l}\text { Dracena } \\
\text { fragrans }\end{array}$ & $\begin{array}{l}\text { Lucknow, } \\
\text { Uttar Pradesh }\end{array}$ & $\begin{array}{c}\text { JN3909 } \\
08\end{array}$ & 556 & $\begin{array}{c}\text { JX010171 }(C . \\
\text { siamense })\end{array}$ & 1102 & 0 & $\begin{array}{l}556 / 556 \\
(100 \%)\end{array}$ \\
\hline C. dematium & $\begin{array}{c}\text { ITCC } \\
4970\end{array}$ & $\begin{array}{l}\text { Passiflora } \\
\text { foetida }\end{array}$ & $\begin{array}{c}\text { Kolkata, West } \\
\text { Bengal }\end{array}$ & $\begin{array}{c}\text { JN3908 } \\
41\end{array}$ & 562 & $\begin{array}{l}\text { HM131513 (C. } \\
\text { jasminigenum) }\end{array}$ & 1114 & 0 & $\begin{array}{r}562 / 562 \\
(100 \%)\end{array}$ \\
\hline C. dematium & $\begin{array}{c}\text { ITCC } \\
4971\end{array}$ & Gerbera sp. & $\begin{array}{c}\text { Chlutta, West } \\
\text { Bengal }\end{array}$ & $\begin{array}{c}\mathrm{JN} 3908 \\
42\end{array}$ & 562 & $\begin{array}{l}\text { HM131513 (C. } \\
\text { jasminigenum) }\end{array}$ & 1106 & 0 & $\begin{array}{c}561 / 562 \\
(99 \%)\end{array}$ \\
\hline $\begin{array}{c}\text { C. } \\
\text { gloeosporioides }\end{array}$ & $\begin{array}{l}\text { ITCC } \\
4981\end{array}$ & Cocos nucifera & $\begin{array}{l}\text { CPCRI, } \\
\text { Kerala }\end{array}$ & $\begin{array}{c}\mathrm{JN} 3909 \\
09\end{array}$ & 556 & $\begin{array}{l}\text { JX010171 (C. } \\
\text { siamense })\end{array}$ & 1102 & 0 & $\begin{array}{l}556 / 556 \\
(100 \%)\end{array}$ \\
\hline $\begin{array}{c}\text { C. } \\
\text { gloeosporioides }\end{array}$ & $\begin{array}{l}\text { ITCC } \\
5105\end{array}$ & Soil & $\begin{array}{l}\text { Hyderabad, } \\
\text { Andhra } \\
\text { Pradesh }\end{array}$ & $\begin{array}{c}\text { JN3909 } \\
10\end{array}$ & 557 & $\begin{array}{c}\mathrm{JX} 010146(C . \\
\text { musae })\end{array}$ & 1096 & 0 & $\begin{array}{c}556 / 557 \\
(99 \%)\end{array}$ \\
\hline $\begin{array}{c}C . \\
\text { gloeosporioides }\end{array}$ & $\begin{array}{c}\text { ITCC } \\
5123\end{array}$ & Psidium guajava & $\begin{array}{l}\text { Allahabad, } \\
\text { Uttar Pradesh }\end{array}$ & $\begin{array}{c}\text { JN3908 } \\
43\end{array}$ & 529 & $\begin{array}{c}\mathrm{JX} 010264(C . \\
\text { tropicale })\end{array}$ & 1021 & 0 & $\begin{array}{c}529 / 531 \\
(99 \%)\end{array}$ \\
\hline $\begin{array}{c}\text { C. } \\
\text { gloeosporioides }\end{array}$ & $\begin{array}{c}\text { ITCC } \\
5213\end{array}$ & Cattleya sp. & Sikkim & $\begin{array}{c}\text { JN3908 } \\
44\end{array}$ & 543 & $\begin{array}{c}\text { KC790943 }(C . \\
\text { brevisporum })\end{array}$ & 989 & 0 & $\begin{array}{c}533 / 543 \\
(98 \%)\end{array}$ \\
\hline C. capsici & $\begin{array}{l}\text { ITCC } \\
5227\end{array}$ & Citrus sp. & $\begin{array}{l}\text { IARI, New } \\
\text { Delhi }\end{array}$ & $\begin{array}{c}\mathrm{JN} 3908 \\
45\end{array}$ & 558 & $\begin{array}{l}\mathrm{HM} 131513(C . \\
\text { jasminigenum) }\end{array}$ & 1098 & 0 & $\begin{array}{c}557 / 558 \\
(99 \%)\end{array}$ \\
\hline $\begin{array}{c}C . \\
\text { gloeosporioides }\end{array}$ & $\begin{array}{l}\text { ITCC } \\
5255\end{array}$ & $\begin{array}{l}\text { Anacardium } \\
\text { occidentale }\end{array}$ & $\begin{array}{c}\text { Dapoli, } \\
\text { Maharashtra }\end{array}$ & $\begin{array}{c}\text { JN3908 } \\
46\end{array}$ & 556 & $\begin{array}{l}\mathrm{KC} 790945(C . \\
\text { jasminisambac }\end{array}$ & 1102 & 0 & $\begin{array}{l}556 / 556 \\
(100 \%)\end{array}$ \\
\hline C. dematium & $\begin{array}{l}\text { ITCC } \\
5306\end{array}$ & $\begin{array}{l}\text { Withania } \\
\text { somnifera }\end{array}$ & $\begin{array}{l}\text { Lucknow, } \\
\text { Uttar Pradesh }\end{array}$ & $\begin{array}{c}\mathrm{JN} 3909 \\
11\end{array}$ & 562 & $\begin{array}{l}\mathrm{HM} 131513(C . \\
\text { jasminigenum) }\end{array}$ & 1106 & 0 & $\begin{array}{c}561 / 562 \\
(99 \%)\end{array}$ \\
\hline C. dematium & $\begin{array}{c}\text { ITCC } \\
5363\end{array}$ & Fragaria sp. & $\begin{array}{l}\text { NBPGR, New } \\
\text { Delhi }\end{array}$ & $\begin{array}{c}\text { JN3908 } \\
47\end{array}$ & 562 & $\begin{array}{l}\text { HM131513 (C. } \\
\text { jasminigenum) }\end{array}$ & 1106 & 0 & $\begin{array}{c}561 / 562 \\
(99 \%)\end{array}$ \\
\hline $\begin{array}{c}C . \\
\text { gloeosporioides }\end{array}$ & $\begin{array}{c}\text { ITCC } \\
5402\end{array}$ & M. indica & $\begin{array}{l}\text { IARI, New } \\
\text { Delhi }\end{array}$ & $\begin{array}{c}\text { JN3908 } \\
48\end{array}$ & 539 & $\begin{array}{c}\text { JX010171 (C. } \\
\text { siamense })\end{array}$ & 1068 & 0 & $\begin{array}{r}539 / 539 \\
(100 \%)\end{array}$ \\
\hline $\begin{array}{c}\text { C. } \\
\text { gloeosporioides }\end{array}$ & $\begin{array}{c}\text { ITCC } \\
5514\end{array}$ & Amoтum sp. & $\begin{array}{l}\text { Kalimpong, } \\
\text { West Bengal }\end{array}$ & $\begin{array}{c}\mathrm{JN} 3908 \\
49\end{array}$ & 549 & $\begin{array}{c}\text { KC790943 }(C . \\
\text { brevisporum })\end{array}$ & 993 & 0 & $\begin{array}{c}538 / 549 \\
(97 \%)\end{array}$ \\
\hline $\begin{array}{c}\text { C. } \\
\text { gloeosporioides }\end{array}$ & $\begin{array}{l}\text { ITCC } \\
5554\end{array}$ & Rosa indica & $\begin{array}{c}\text { Kalyani, West } \\
\text { Bengal }\end{array}$ & $\begin{array}{c}\mathrm{JN} 3908 \\
50\end{array}$ & 556 & $\begin{array}{l}\text { JX010171 (C. } \\
\text { siamense) }\end{array}$ & 1102 & 0 & $\begin{array}{l}556 / 556 \\
(100 \%)\end{array}$ \\
\hline $\begin{array}{c}\text { C. } \\
\text { gloeosporioides }\end{array}$ & $\begin{array}{l}\text { ITCC } \\
5557\end{array}$ & Vanilla sp. & unknown & $\begin{array}{c}\mathrm{JN} 3908 \\
51\end{array}$ & 556 & $\begin{array}{l}\text { JX010171 (C. } \\
\text { siamense) }\end{array}$ & 1102 & 0 & $\begin{array}{l}556 / 556 \\
(100 \%)\end{array}$ \\
\hline $\begin{array}{c}C . \\
\text { gloeosporioides }\end{array}$ & $\begin{array}{l}\text { ITCC } \\
5571\end{array}$ & Elaeis sp. & $\begin{array}{c}\text { Padavegi, } \\
\text { Andra } \\
\text { Pradesh }\end{array}$ & $\begin{array}{c}\text { JN3908 } \\
52\end{array}$ & 515 & $\begin{array}{c}\text { JX010264 }(C . \\
\text { tropicale })\end{array}$ & 1005 & 0 & $\begin{array}{c}513 / 515 \\
(99 \%)\end{array}$ \\
\hline $\begin{array}{c}C . \\
\text { gloeosporioides }\end{array}$ & $\begin{array}{l}\text { ITCC } \\
6015\end{array}$ & $\begin{array}{c}\text { Zamia } \\
\text { neurophyllidia }\end{array}$ & $\begin{array}{l}\text { Chennai, } \\
\text { Tamil Nadu }\end{array}$ & $\begin{array}{c}\mathrm{JN} 3908 \\
53\end{array}$ & 551 & $\begin{array}{c}\mathrm{JX} 010171(C . \\
\text { siamense })\end{array}$ & 1076 & 0 & $\begin{array}{c}550 / 551 \\
(99 \%)\end{array}$ \\
\hline C. capsici & $\begin{array}{c}\text { ITCC } \\
6023\end{array}$ & $\begin{array}{c}\text { Polianthes } \\
\text { tuberose }\end{array}$ & $\begin{array}{l}\text { IARI, New } \\
\text { Delhi }\end{array}$ & $\begin{array}{c}\text { JN3908 } \\
54\end{array}$ & 562 & $\begin{array}{l}\mathrm{HM} 131513(C . \\
\text { jasminigenum) }\end{array}$ & 1114 & 0 & $\begin{array}{c}562 / 562 \\
(100 \%)\end{array}$ \\
\hline G. tucumanensis & $\begin{array}{l}\text { ITCC } \\
6032\end{array}$ & Saccharum sp. & $\begin{array}{l}\text { Navasari, } \\
\text { Gujarat }\end{array}$ & $\begin{array}{c}\text { JN3909 } \\
13\end{array}$ & 535 & $\begin{array}{c}\text { GQ485607 ( } C . \\
\text { cliviae })\end{array}$ & 983 & 0 & $\begin{array}{c}506 / 508 \\
(99 \%)\end{array}$ \\
\hline $\begin{array}{c}C . \\
\text { gloeosporioides }\end{array}$ & $\begin{array}{c}\text { ITCC } \\
6038\end{array}$ & Rosa sp. & $\begin{array}{l}\text { Navsari, } \\
\text { Gujarat }\end{array}$ & $\begin{array}{c}\text { JN3908 } \\
84\end{array}$ & 550 & $\begin{array}{c}\mathrm{KC} 790945(C . \\
\text { jasminisambac } \\
)\end{array}$ & 1082 & 0 & $\begin{array}{c}549 / 550 \\
(99 \%)\end{array}$ \\
\hline $\begin{array}{c}C . \\
\text { gloeosporioides }\end{array}$ & $\begin{array}{c}\text { ITCC } \\
6053\end{array}$ & Elaeis sp. & $\begin{array}{c}\text { Padavegi, } \\
\text { Andra } \\
\text { Pradesh }\end{array}$ & $\begin{array}{c}\text { JN3908 } \\
55\end{array}$ & 556 & $\begin{array}{c}\text { JX010171 (C. } \\
\text { siamense) }\end{array}$ & 1102 & 0 & $\begin{array}{c}556 / 556 \\
(100 \%)\end{array}$ \\
\hline $\begin{array}{c}C . \\
\text { gloeosporioides }\end{array}$ & $\begin{array}{l}\text { ITCC } \\
6066\end{array}$ & Cocos nucifera & $\begin{array}{c}\text { Bhuvaneshwa } \\
\text { r, Orissa }\end{array}$ & $\begin{array}{c}\mathrm{JN} 3909 \\
14\end{array}$ & 556 & $\begin{array}{c}\text { JX010171 (C. } \\
\text { siamense) }\end{array}$ & 1102 & 0 & $\begin{array}{l}556 / 556 \\
(100 \%)\end{array}$ \\
\hline
\end{tabular}




\begin{tabular}{|c|c|c|c|c|c|c|c|c|c|}
\hline 気 & 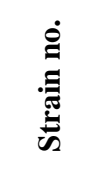 & $\stackrel{\ddot{\mathscr{O}}}{\underline{0}}$ & 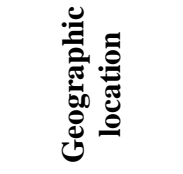 & 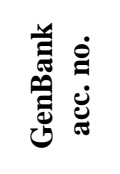 & 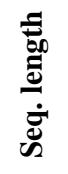 & 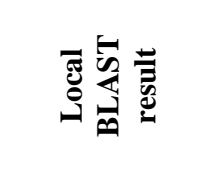 & 巳ֶّ & 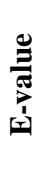 & : \\
\hline C. capsici & $\begin{array}{c}\text { ITCC } \\
6071\end{array}$ & Capsicum sp. & $\begin{array}{c}\text { Jammu, } \\
\text { Jammu \& } \\
\text { Kashmir }\end{array}$ & $\begin{array}{c}\text { JN3908 } \\
56\end{array}$ & 562 & $\begin{array}{l}\mathrm{HM} 131513(C . \\
\text { jasminigenum) }\end{array}$ & 1106 & 0 & $\begin{array}{c}561 / 562 \\
(99 \%)\end{array}$ \\
\hline C. capsici & $\begin{array}{c}\text { ITCC } \\
6078\end{array}$ & Capsicum sp. & $\begin{array}{l}\text { Jammu, } \\
\text { Jammu \& } \\
\text { Kashmir }\end{array}$ & $\begin{array}{c}\text { JN3908 } \\
85\end{array}$ & 535 & $\begin{array}{l}\mathrm{HM} 131513(C . \\
\text { jasminigenum) }\end{array}$ & 1053 & 0 & $\begin{array}{c}534 / 535 \\
(99 \%)\end{array}$ \\
\hline $\begin{array}{c}\text { C. } \\
\text { gloeosporioides }\end{array}$ & $\begin{array}{c}\text { ITCC } \\
6079\end{array}$ & Capsicum sp. & $\begin{array}{l}\text { Solan, } \\
\text { Himachal } \\
\text { Pradesh }\end{array}$ & $\begin{array}{c}\text { JN3908 } \\
57\end{array}$ & 558 & $\begin{array}{c}\text { HM171679 }(C . \\
\text { coccodes })\end{array}$ & 1106 & 0 & $\begin{array}{c}558 / 558 \\
(100 \%)\end{array}$ \\
\hline C. capsici & $\begin{array}{c}\text { ITCC } \\
6083\end{array}$ & Capsicum sp. & $\begin{array}{l}\text { Jammu, } \\
\text { Jammu \& } \\
\text { Kashmir }\end{array}$ & $\begin{array}{c}\text { JN3908 } \\
58\end{array}$ & 562 & $\begin{array}{l}\mathrm{HM} 131513(C . \\
\text { jasminigenum })\end{array}$ & 1106 & 0 & $\begin{array}{c}561 / 562 \\
(99 \%)\end{array}$ \\
\hline C. capsici & $\begin{array}{c}\text { ITCC } \\
6143\end{array}$ & $\begin{array}{l}\text { Raphanus } \\
\text { sativus }\end{array}$ & $\begin{array}{c}\text { IARI, New } \\
\text { Delhi }\end{array}$ & $\begin{array}{c}\text { JN3908 } \\
59\end{array}$ & 546 & $\begin{array}{l}\text { HM131513 (C. } \\
\text { jasminigenum) }\end{array}$ & 1074 & 0 & $\begin{array}{c}545 / 546 \\
(99 \%)\end{array}$ \\
\hline $\begin{array}{c}C . \\
\text { gloeosporioides }\end{array}$ & $\begin{array}{c}\text { ITCC } \\
6150\end{array}$ & Areca catechu & $\begin{array}{c}\text { Rahuri, } \\
\text { Maharashtra }\end{array}$ & $\begin{array}{c}\text { JN3908 } \\
60\end{array}$ & 543 & $\begin{array}{c}\mathrm{JX} 010264(C . \\
\text { tropicale })\end{array}$ & 1068 & 0 & $\begin{array}{c}542 / 543 \\
(99 \%)\end{array}$ \\
\hline $\begin{array}{c}C . \\
\text { gloeosporioides }\end{array}$ & $\begin{array}{c}\text { ITCC } \\
6152\end{array}$ & Citrus sp. & $\begin{array}{c}\text { Rahuri, } \\
\text { Maharashtra }\end{array}$ & $\begin{array}{c}\text { JN3908 } \\
61\end{array}$ & 556 & $\begin{array}{c}\text { JX010171 ( } C . \\
\text { siamense })\end{array}$ & 1094 & 0 & $\begin{array}{c}555 / 556 \\
(99 \%)\end{array}$ \\
\hline $\begin{array}{c}C . \\
\text { gloeosporioides }\end{array}$ & $\begin{array}{c}\text { ITCC } \\
6153\end{array}$ & Citrus sp. & $\begin{array}{c}\text { Rahuri, } \\
\text { Maharashtra }\end{array}$ & $\begin{array}{c}\text { JN3908 } \\
62\end{array}$ & 555 & $\begin{array}{c}\text { JX010171 ( } C . \\
\text { siamense })\end{array}$ & 1086 & 0 & $\begin{array}{c}555 / 556 \\
(99 \%)\end{array}$ \\
\hline $\begin{array}{c}\text { C. } \\
\text { gloeosporioides }\end{array}$ & $\begin{array}{l}\text { ITCC } \\
6155\end{array}$ & Citrus sp. & $\begin{array}{c}\text { Rahuri, } \\
\text { Maharashtra }\end{array}$ & $\begin{array}{c}\text { JN3908 } \\
63\end{array}$ & 556 & $\begin{array}{c}\text { JX010171 ( } C . \\
\text { siamense) }\end{array}$ & 1102 & 0 & $\begin{array}{l}556 / 556 \\
(100 \%)\end{array}$ \\
\hline $\begin{array}{c}\text { C. } \\
\text { gloeosporioides }\end{array}$ & $\begin{array}{l}\text { ITCC } \\
6156\end{array}$ & $\begin{array}{c}\text { Mangifera } \\
\text { indica }\end{array}$ & $\begin{array}{c}\text { Rahuri, } \\
\text { Maharashtra }\end{array}$ & $\begin{array}{c}\text { JN3908 } \\
64\end{array}$ & 557 & $\begin{array}{c}\text { JX010171 ( } C . \\
\text { siamense })\end{array}$ & 1088 & 0 & $\begin{array}{c}556 / 557 \\
(99 \%)\end{array}$ \\
\hline $\begin{array}{c}\text { C. } \\
\text { gloeosporioides }\end{array}$ & $\begin{array}{c}\text { ITCC } \\
6158\end{array}$ & $\begin{array}{c}\text { Mangifera } \\
\text { indica }\end{array}$ & $\begin{array}{c}\text { Rahuri, } \\
\text { Maharashtra }\end{array}$ & $\begin{array}{c}\text { JN3909 } \\
15\end{array}$ & 548 & $\begin{array}{c}\text { JX010171 ( } C . \\
\text { siamense })\end{array}$ & 1086 & 0 & $\begin{array}{l}548 / 548 \\
(100 \%)\end{array}$ \\
\hline $\begin{array}{c}\text { C. } \\
\text { gloeosporioides }\end{array}$ & $\begin{array}{c}\text { ITCC } \\
6159\end{array}$ & Psidium guajava & $\begin{array}{c}\text { Rahuri, } \\
\text { Maharashtra }\end{array}$ & $\begin{array}{c}\text { JN3908 } \\
65\end{array}$ & 556 & $\begin{array}{c}\text { JX010171 (C. } \\
\text { siamense) }\end{array}$ & 1102 & 0 & $\begin{array}{l}556 / 556 \\
(100 \%)\end{array}$ \\
\hline $\begin{array}{c}\text { C. } \\
\text { gloeosporioides }\end{array}$ & $\begin{array}{c}\text { ITCC } \\
6160\end{array}$ & $\begin{array}{l}\text { Punica } \\
\text { granatum }\end{array}$ & $\begin{array}{c}\text { Rahuri, } \\
\text { Maharashtra }\end{array}$ & $\begin{array}{c}\text { JN3908 } \\
66\end{array}$ & 558 & $\begin{array}{c}\text { KC790945 (C. } \\
\text { jasminisambac } \\
\text { ) }\end{array}$ & 1066 & 0 & $\begin{array}{c}555 / 558 \\
(99 \%)\end{array}$ \\
\hline $\begin{array}{c}\text { C. } \\
\text { gloeosporioides }\end{array}$ & $\begin{array}{c}\text { ITCC } \\
6161\end{array}$ & P. granatum & $\begin{array}{c}\text { Rahuri, } \\
\text { Maharashtra }\end{array}$ & $\begin{array}{c}\text { JN3908 } \\
67\end{array}$ & 559 & $\begin{array}{c}\text { KC790937 (C. } \\
\text { fragariae) }\end{array}$ & 1104 & 0 & $\begin{array}{l}557 / 557 \\
(100 \%)\end{array}$ \\
\hline $\begin{array}{c}\text { C. } \\
\text { gloeosporioides }\end{array}$ & $\begin{array}{c}\text { ITCC } \\
6163\end{array}$ & $\begin{array}{c}\text { Punica } \\
\text { granatum }\end{array}$ & $\begin{array}{c}\text { Rahuri, } \\
\text { Maharashtra }\end{array}$ & $\begin{array}{c}\text { JN3908 } \\
68\end{array}$ & 558 & $\begin{array}{c}\text { KC790945 (C. } \\
\text { jasminisambac } \\
\text { ) }\end{array}$ & 1066 & 0 & $\begin{array}{c}555 / 558 \\
(99 \%)\end{array}$ \\
\hline $\begin{array}{c}C . \\
\text { gloeosporioides }\end{array}$ & $\begin{array}{r}\text { ITCC } \\
6164\end{array}$ & $\begin{array}{c}\text { Punica } \\
\text { granatum }\end{array}$ & $\begin{array}{c}\text { Rahuri, } \\
\text { Maharashtra }\end{array}$ & $\begin{array}{c}\text { JN3908 } \\
69\end{array}$ & 558 & $\begin{array}{c}\mathrm{KC} 790937(C . \\
\text { fragariae })\end{array}$ & 1088 & 0 & $\begin{array}{c}556 / 557 \\
(99 \%)\end{array}$ \\
\hline $\begin{array}{c}\text { C. } \\
\text { gloeosporioides }\end{array}$ & $\begin{array}{c}\text { ITCC } \\
6165\end{array}$ & $P$. granatum & $\begin{array}{c}\text { Rahuri, } \\
\text { Maharashtra }\end{array}$ & $\begin{array}{c}\text { JN3908 } \\
70\end{array}$ & 529 & $\begin{array}{c}\text { KC790945 (C. } \\
\text { jasminisambac } \\
\text { ) }\end{array}$ & 1025 & 0 & $\begin{array}{c}527 / 529 \\
(99 \%)\end{array}$ \\
\hline $\begin{array}{c}\text { C. } \\
\text { gloeosporioides }\end{array}$ & $\begin{array}{c}\text { ITCC } \\
6166\end{array}$ & $\begin{array}{l}\text { Punica } \\
\text { granatum }\end{array}$ & $\begin{array}{c}\text { Rahuri, } \\
\text { Maharashtra }\end{array}$ & $\begin{array}{c}\text { JN3908 } \\
71\end{array}$ & 557 & $\begin{array}{c}\text { KC790945 (C. } \\
\text { jasminisambac } \\
\text { ) }\end{array}$ & 1080 & 0 & $\begin{array}{c}555 / 557 \\
(99 \%)\end{array}$ \\
\hline $\begin{array}{c}\text { C. } \\
\text { gloeosporioides }\end{array}$ & $\begin{array}{c}\text { ITCC } \\
6178\end{array}$ & Passiflora edulis & Mizoram & $\begin{array}{c}\text { JN3908 } \\
72\end{array}$ & 576 & $\begin{array}{c}\text { JQ005221 ( } C . \\
\text { phyllanthi) }\end{array}$ & 1100 & 0 & $\begin{array}{l}555 / 555 \\
(100 \%)\end{array}$ \\
\hline $\begin{array}{c}C . \\
\text { gloeosporioides }\end{array}$ & $\begin{array}{c}\text { ITCC } \\
6187\end{array}$ & $\begin{array}{l}\text { Ricinus } \\
\text { communis }\end{array}$ & $\begin{array}{c}\text { Navsari, } \\
\text { Gujarat }\end{array}$ & $\begin{array}{c}\text { JN3908 } \\
73\end{array}$ & 556 & $\begin{array}{l}\text { KC790945 (C. } \\
\text { jasminisambac }\end{array}$ & 1094 & 0 & $\begin{array}{c}555 / 556 \\
(99 \%)\end{array}$ \\
\hline G. cingulata & $\begin{array}{c}\text { ITCC } \\
6028\end{array}$ & Castor & $\begin{array}{l}\text { Berhampur, } \\
\text { Orissa }\end{array}$ & $\begin{array}{c}\text { JN3909 } \\
12\end{array}$ & 535 & $\begin{array}{c}\text { GQ485607 ( } C . \\
\text { cliviae) }\end{array}$ & 975 & 0 & $\begin{array}{c}505 / 508 \\
(99 \%)\end{array}$ \\
\hline C. dematium & $\begin{array}{l}\text { ITCC } \\
6226\end{array}$ & unknown & unknown & $\begin{array}{c}\text { JN3908 } \\
86\end{array}$ & 562 & $\begin{array}{l}\text { HM131513 (C. } \\
\text { jasminigenum) }\end{array}$ & 1098 & 0 & $\begin{array}{c}560 / 562 \\
(99 \%)\end{array}$ \\
\hline C. capsici & $\begin{array}{c}\text { ITCC } \\
6250\end{array}$ & Capsicum sp. & $\begin{array}{c}\text { Jaipur, } \\
\text { Rajasthan }\end{array}$ & $\begin{array}{c}\text { JN3908 } \\
74\end{array}$ & 562 & $\begin{array}{l}\mathrm{HM} 131513 \text { (C. } \\
\text { jasminigenum) }\end{array}$ & 1106 & 0 & $\begin{array}{c}561 / 562 \\
(99 \%)\end{array}$ \\
\hline C. capsici & $\begin{array}{c}\text { ITCC } \\
6268\end{array}$ & Curcuma longa & $\begin{array}{l}\text { Anand, } \\
\text { Gujarat }\end{array}$ & $\begin{array}{c}\text { JN3908 } \\
75\end{array}$ & 562 & $\begin{array}{l}\mathrm{HM} 131513(C . \\
\text { jasminigenum })\end{array}$ & 1106 & 0 & $\begin{array}{c}561 / 562 \\
(99 \%)\end{array}$ \\
\hline $\begin{array}{c}\text { C. } \\
\text { gloeosporioides }\end{array}$ & $\begin{array}{c}\text { ITCC } \\
6270\end{array}$ & Capsicum sp. & $\begin{array}{l}\text { Port Blair, } \\
\text { Andaman } \\
\text { Island }\end{array}$ & $\begin{array}{c}\text { JN3908 } \\
76\end{array}$ & 534 & $\begin{array}{l}\text { JX010165 (C. } \\
\text { fructicola) }\end{array}$ & 1059 & 0 & $\begin{array}{c}534 / 534 \\
(100 \%)\end{array}$ \\
\hline
\end{tabular}




\begin{tabular}{|c|c|c|c|c|c|c|c|c|c|}
\hline 気 & 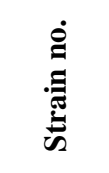 & $\underline{\underline{0}}$ & 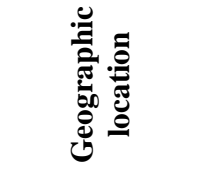 & 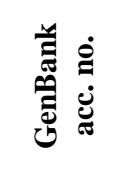 & 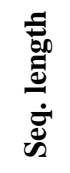 & 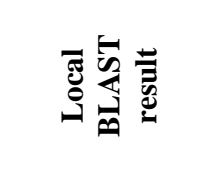 & 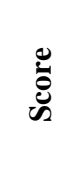 & 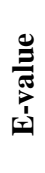 & : \\
\hline $\begin{array}{c}\text { C. } \\
\text { gloeosporioides }\end{array}$ & $\begin{array}{c}\text { ITCC } \\
6271\end{array}$ & Bean & $\begin{array}{l}\text { Port Blair, } \\
\text { Andaman } \\
\text { Island }\end{array}$ & $\begin{array}{c}\text { JN3909 } \\
16\end{array}$ & 559 & $\begin{array}{c}\mathrm{KC} 790943(C . \\
\text { brevisporum })\end{array}$ & 1076 & 0 & $\begin{array}{c}555 / 559 \\
(99 \%)\end{array}$ \\
\hline $\begin{array}{c}\text { C. } \\
\text { gloeosporioides }\end{array}$ & $\begin{array}{l}\text { ITCC } \\
6272\end{array}$ & Lagenaria sp. & $\begin{array}{c}\text { Port Blair, } \\
\text { Andaman Isla } \\
\text { nd }\end{array}$ & $\begin{array}{c}\text { JN3908 } \\
77\end{array}$ & 545 & $\begin{array}{c}\text { KC790943 (C. } \\
\text { brevisporum) }\end{array}$ & 1037 & 0 & $\begin{array}{c}532 / 535 \\
(99 \%)\end{array}$ \\
\hline C. capsici & $\begin{array}{r}\text { ITCC } \\
6307\end{array}$ & Dioscorea alata & $\begin{array}{c}\text { Navsari, } \\
\text { Gujarat }\end{array}$ & $\begin{array}{c}\text { JN3908 } \\
78\end{array}$ & 543 & $\begin{array}{l}\mathrm{HM} 131513(C . \\
\text { jasminigenum })\end{array}$ & 1068 & 0 & $\begin{array}{c}542 / 543 \\
(99 \%)\end{array}$ \\
\hline $\begin{array}{c}\text { C. } \\
\text { gloeosporioides }\end{array}$ & $\begin{array}{r}\text { ITCC } \\
6328\end{array}$ & Cymbidium sp. & Sikkim & $\begin{array}{c}\text { JN3908 } \\
79\end{array}$ & 561 & $\begin{array}{l}\text { JQ005166 ( } C \text {. } \\
\text { cymbidiicola) }\end{array}$ & 1098 & 0 & $\begin{array}{c}554 / 554 \\
(100 \%)\end{array}$ \\
\hline $\begin{array}{c}\text { C. } \\
\text { gloeosporioides }\end{array}$ & $\begin{array}{r}\text { ITCC } \\
6330\end{array}$ & $\begin{array}{l}\text { Mangifera } \\
\text { indica }\end{array}$ & unknown & $\begin{array}{c}\text { JN3908 } \\
80\end{array}$ & 558 & $\begin{array}{l}\text { KC790945 (C. } \\
\text { jasminisambac } \\
\text { ) }\end{array}$ & 1066 & 0 & $\begin{array}{c}555 / 558 \\
(99 \%)\end{array}$ \\
\hline $\begin{array}{c}\text { C. } \\
\text { gloeosporioides }\end{array}$ & $\begin{array}{r}\text { ITCC } \\
6336\end{array}$ & Citrus sp. & $\begin{array}{c}\text { Jobner, } \\
\text { Rajasthan }\end{array}$ & $\begin{array}{c}\text { JN3908 } \\
81\end{array}$ & 550 & $\begin{array}{c}\text { JX010171 (C. } \\
\text { siamense) }\end{array}$ & 1061 & 0 & $\begin{array}{c}549 / 551 \\
(99 \%)\end{array}$ \\
\hline C. capsici & $\begin{array}{r}\text { ITCC } \\
6450\end{array}$ & Vigna mungo & $\begin{array}{l}\text { Navsari, } \\
\text { Gujarat }\end{array}$ & $\begin{array}{c}\text { JN3908 } \\
82\end{array}$ & 562 & $\begin{array}{l}\mathrm{HM} 131513(C . \\
\text { jasminigenum })\end{array}$ & 1106 & 0 & $\begin{array}{c}561 / 562 \\
(99 \%)\end{array}$ \\
\hline $\begin{array}{c}\text { C. } \\
\text { gloeosporioides }\end{array}$ & $\begin{array}{r}\text { ITCC } \\
6480\end{array}$ & unknown & unknown & $\begin{array}{c}\text { JN3908 } \\
87\end{array}$ & 556 & $\begin{array}{c}\mathrm{JX} 010264(C . \\
\text { tropicale })\end{array}$ & 1102 & 0 & $\begin{array}{c}556 / 556 \\
(100 \%)\end{array}$ \\
\hline C. crassipes & $\begin{array}{c}\text { MTCC } \\
2175\end{array}$ & Citrus jambher & Haryana & $\begin{array}{c}\text { JN3909 } \\
18\end{array}$ & 500 & $\begin{array}{l}\text { JN050242 (C. } \\
\text { thailandicum) }\end{array}$ & 765 & 0 & $\begin{array}{c}403 / 406 \\
(99 \%)\end{array}$ \\
\hline C. capsici & $\begin{array}{c}\text { MTCC } \\
3414\end{array}$ & $\begin{array}{c}\text { Capsicum } \\
\text { annum }\end{array}$ & Pondicherry & $\begin{array}{c}\text { JN3909 } \\
19\end{array}$ & 562 & $\begin{array}{l}\text { HM131513 (C. } \\
\text { jasminigenum) }\end{array}$ & 1106 & 0 & $\begin{array}{c}561 / 562 \\
(99 \%)\end{array}$ \\
\hline $\begin{array}{c}\text { C. } \\
\text { gloeosporioides }\end{array}$ & $\begin{array}{c}\text { MTCC } \\
3439\end{array}$ & $\begin{array}{l}\text { Capsicum } \\
\text { annum }\end{array}$ & Pondicherry & $\begin{array}{c}\text { JN3909 } \\
20\end{array}$ & 550 & $\begin{array}{c}\mathrm{JX} 010264(C . \\
\text { tropicale })\end{array}$ & 1082 & 0 & $\begin{array}{c}549 / 550 \\
(99 \%)\end{array}$ \\
\hline $\begin{array}{c}\text { C. } \\
\text { gloeosporioides }\end{array}$ & $\begin{array}{c}\text { MTCC } \\
4088\end{array}$ & Dioscorea alata & $\begin{array}{l}\text { Udaipur, } \\
\text { Rajasthan }\end{array}$ & $\begin{array}{c}\text { JN3909 } \\
21\end{array}$ & 513 & $\begin{array}{c}\mathrm{JX} 010190(C . \\
\text { alatae })\end{array}$ & 1003 & 0 & $\begin{array}{c}513 / 514 \\
(99 \%)\end{array}$ \\
\hline C. musae & $\begin{array}{c}\text { MTCC } \\
4352\end{array}$ & $\begin{array}{c}\text { Avicennia } \\
\text { marina }\end{array}$ & $\begin{array}{l}\text { Pichavaram, } \\
\text { Tamil Nadu }\end{array}$ & $\begin{array}{c}\text { JN3909 } \\
22\end{array}$ & 548 & $\begin{array}{c}\text { KC790945 (C. } \\
\text { jasminisambac } \\
)\end{array}$ & 1086 & 0 & $\begin{array}{l}548 / 548 \\
(100 \%)\end{array}$ \\
\hline $\begin{array}{c}\text { C. } \\
\text { gloeosporioides }\end{array}$ & $\begin{array}{c}\text { MTCC } \\
4618\end{array}$ & $\begin{array}{c}\text { Mangifera } \\
\text { indica }\end{array}$ & $\begin{array}{l}\text { IMTECH , } \\
\text { Chandigarh }\end{array}$ & $\begin{array}{c}\text { JN3909 } \\
23\end{array}$ & 539 & $\begin{array}{c}\text { JX010171 (C. } \\
\text { siamense) }\end{array}$ & 1068 & 0 & $\begin{array}{l}539 / 539 \\
(100 \%)\end{array}$ \\
\hline $\begin{array}{c}\text { C. } \\
\text { gloeosporioides }\end{array}$ & $\begin{array}{c}\text { MTCC } \\
4626\end{array}$ & Psidium guajava & $\begin{array}{l}\text { IMTECH, } \\
\text { Chandigarh }\end{array}$ & $\begin{array}{c}\text { JN3909 } \\
24\end{array}$ & 539 & $\begin{array}{c}\text { KC790945 (C. } \\
\text { jasminisambac } \\
\text { ) }\end{array}$ & 1068 & 0 & $\begin{array}{l}539 / 539 \\
(100 \%)\end{array}$ \\
\hline $\begin{array}{c}\text { C. } \\
\text { gloeosporioides }\end{array}$ & $\begin{array}{c}\text { MTCC } \\
4646\end{array}$ & Soil & $\begin{array}{l}\text { IMTECH , } \\
\text { Chandigarh }\end{array}$ & $\begin{array}{c}\text { JN3909 } \\
25\end{array}$ & 541 & $\begin{array}{c}\text { JX010171 ( } C . \\
\text { siamense) }\end{array}$ & 1072 & 0 & $\begin{array}{l}541 / 541 \\
(100 \%)\end{array}$ \\
\hline $\begin{array}{c}\text { C. } \\
\text { gloeosporioides }\end{array}$ & $\begin{array}{c}\text { MTCC } \\
6948\end{array}$ & Carica papaya & $\begin{array}{l}\text { Rehman } \\
\text { Khera, Uttar } \\
\text { Pradesh }\end{array}$ & $\begin{array}{c}\text { JN3909 } \\
26\end{array}$ & 555 & $\begin{array}{c}\text { JQ005221 ( } C . \\
\text { phyllanthi) }\end{array}$ & 1078 & 0 & $\begin{array}{l}544 / 544 \\
(100 \%)\end{array}$ \\
\hline $\begin{array}{c}\text { C. } \\
\text { gloeosporioides }\end{array}$ & $\begin{array}{c}\text { MTCC } \\
9660\end{array}$ & $\begin{array}{c}\text { Mangifera } \\
\text { indica }\end{array}$ & $\begin{array}{c}\text { Vasco } \\
\text { Market, Goa }\end{array}$ & $\begin{array}{c}\text { JN3909 } \\
28\end{array}$ & 556 & $\begin{array}{c}\text { JX010171 ( } C . \\
\text { alienum })\end{array}$ & 1088 & 0 & $\begin{array}{c}556 / 557 \\
(99 \%)\end{array}$ \\
\hline $\begin{array}{c}\text { C. } \\
\text { gloeosporioides }\end{array}$ & $\begin{array}{c}\text { MTCC } \\
9661\end{array}$ & M. indica & $\begin{array}{c}\text { Merces- } \\
\text { Bardez, Goa }\end{array}$ & $\begin{array}{c}\text { JN3909 } \\
29\end{array}$ & 556 & $\begin{array}{c}\text { JX010171 (C. } \\
\text { siamense) }\end{array}$ & 1102 & 0 & $\begin{array}{l}556 / 556 \\
(100 \%)\end{array}$ \\
\hline $\begin{array}{c}\text { C. } \\
\text { gloeosporioides }\end{array}$ & $\begin{array}{c}\text { MTCC } \\
9662\end{array}$ & M. indica & $\begin{array}{c}\text { Vasco } \\
\text { Market, Goa }\end{array}$ & $\begin{array}{c}\text { JN3909 } \\
30\end{array}$ & 556 & $\begin{array}{c}\text { JX010171 ( } C . \\
\text { siamense) }\end{array}$ & 1102 & 0 & $\begin{array}{l}556 / 556 \\
(100 \%)\end{array}$ \\
\hline $\begin{array}{c}\text { C. } \\
\text { gloeosporioides }\end{array}$ & $\begin{array}{c}\text { MTCC } \\
9663\end{array}$ & Psidium guajava & $\begin{array}{l}\text { Kurti-Pondo, } \\
\text { Goa }\end{array}$ & $\begin{array}{c}\text { JN3909 } \\
31\end{array}$ & 557 & $\begin{array}{c}\text { JX010171 ( } C . \\
\text { alienum })\end{array}$ & 1104 & 0 & $\begin{array}{l}557 / 557 \\
(100 \%)\end{array}$ \\
\hline $\begin{array}{c}\text { C. } \\
\text { gloeosporioides }\end{array}$ & $\begin{array}{c}\text { MTCC } \\
9664\end{array}$ & Carica papaya & $\begin{array}{c}\text { Panjim } \\
\text { Market, Goa }\end{array}$ & $\begin{array}{c}\text { JN3909 } \\
32\end{array}$ & 556 & $\begin{array}{c}\text { JX010171 (C. } \\
\text { siamense) }\end{array}$ & 1102 & 0 & $\begin{array}{l}556 / 556 \\
(100 \%)\end{array}$ \\
\hline $\begin{array}{c}\text { C. } \\
\text { gloeosporioides }\end{array}$ & $\begin{array}{c}\text { MTCC } \\
9665\end{array}$ & Murraya sp. & $\begin{array}{c}\text { Mysore, } \\
\text { Karnataka }\end{array}$ & $\begin{array}{c}\text { JN3909 } \\
33\end{array}$ & 556 & $\begin{array}{c}\mathrm{JX} 010264(C . \\
\text { tropicale })\end{array}$ & 1094 & 0 & $\begin{array}{c}555 / 556 \\
(99 \%)\end{array}$ \\
\hline C. capsici & $\begin{array}{c}\text { MTCC } \\
9691\end{array}$ & $\begin{array}{c}\text { Capsicum } \\
\text { annum }\end{array}$ & $\begin{array}{l}\text { Kharar, } \\
\text { Punjab }\end{array}$ & $\begin{array}{c}\text { JN3909 } \\
27\end{array}$ & 562 & $\begin{array}{l}\text { HM131513 (C. } \\
\text { jasminigenum) }\end{array}$ & 1106 & 0 & $\begin{array}{c}561 / 562 \\
(99 \%)\end{array}$ \\
\hline $\begin{array}{c}\text { C. } \\
\text { gloeosporioides }\end{array}$ & $\begin{array}{c}\text { NFCCI } \\
1611\end{array}$ & unknown & unknown & $\begin{array}{c}\text { JN3909 } \\
40\end{array}$ & 576 & $\begin{array}{c}\text { JQ005221 }(C . \\
\text { phyllanthi) }\end{array}$ & 1100 & 0 & $\begin{array}{l}555 / 555 \\
(100 \%)\end{array}$ \\
\hline $\begin{array}{l}\text { Colletotrichum } \\
\text { sp. }\end{array}$ & $\begin{array}{c}\text { NFCCI } \\
1737\end{array}$ & unknown & unknown & $\begin{array}{c}\text { JN3909 } \\
41\end{array}$ & 556 & $\begin{array}{c}\text { JX010264 (C. } \\
\text { tropicale })\end{array}$ & 1102 & 0 & $\begin{array}{l}556 / 556 \\
(100 \%)\end{array}$ \\
\hline $\begin{array}{l}\text { Colletotrichum } \\
\text { sp. }\end{array}$ & $\begin{array}{c}\text { NFCCI } \\
1925\end{array}$ & unknown & unknown & $\begin{array}{c}\text { JN3909 } \\
42\end{array}$ & 556 & $\begin{array}{c}\text { JX010171 ( } C . \\
\text { siamense) }\end{array}$ & 1102 & 0 & $\begin{array}{l}556 / 556 \\
(100 \%)\end{array}$ \\
\hline $\begin{array}{c}C . \\
\text { gloeosporioides }\end{array}$ & $\begin{array}{l}\text { UASB- } \\
\text { Cg-01 }\end{array}$ & Capsicum sp. & $\begin{array}{c}\text { Kolar, } \\
\text { Karnataka }\end{array}$ & $\begin{array}{c}\mathrm{JN} 2486 \\
18\end{array}$ & 496 & $\begin{array}{c}\text { JX010165 (C. } \\
\text { fructicola) }\end{array}$ & 983 & 0 & $\begin{array}{l}496 / 496 \\
(100 \%)\end{array}$ \\
\hline
\end{tabular}




\begin{tabular}{|c|c|c|c|c|c|c|c|c|c|}
\hline 芯 & 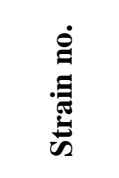 & $\stackrel{\vec{t}}{0}$ & 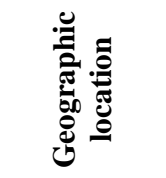 & 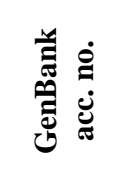 & 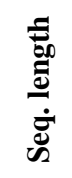 & 氙 & : & 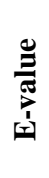 & : \\
\hline $\begin{array}{c}C . \\
\text { gloeosporioides }\end{array}$ & $\begin{array}{l}\text { UASB- } \\
\text { Cg-02 }\end{array}$ & Capsicum sp. & $\begin{array}{c}\text { Tumkur, } \\
\text { Karnataka }\end{array}$ & $\begin{array}{c}\text { JN2486 } \\
19\end{array}$ & 492 & $\begin{array}{c}\mathrm{JX} 010165(C . \\
\text { fructicola })\end{array}$ & 975 & 0 & $\begin{array}{r}492 / 492 \\
(100 \%)\end{array}$ \\
\hline $\begin{array}{c}\text { C. } \\
\text { gloeosporioides }\end{array}$ & $\begin{array}{l}\text { UASB- } \\
\text { Cg-03 }\end{array}$ & Capsicum sp. & $\begin{array}{l}\text { Raichur, } \\
\text { Karnataka }\end{array}$ & $\begin{array}{c}\mathrm{JN} 2486 \\
20\end{array}$ & 525 & $\begin{array}{l}\mathrm{JX} 010165(C . \\
\text { fructicola) }\end{array}$ & 1035 & 0 & $\begin{array}{c}524 / 525 \\
(99 \%)\end{array}$ \\
\hline $\begin{array}{c}\text { C. } \\
\text { gloeosporioides }\end{array}$ & $\begin{array}{l}\text { UASB- } \\
\mathrm{Cg}-04\end{array}$ & Capsicum sp. & $\begin{array}{l}\text { Raichur, } \\
\text { Karnataka }\end{array}$ & $\begin{array}{c}\mathrm{JN} 2486 \\
21\end{array}$ & 557 & $\begin{array}{c}\text { JX010165 }(C . \\
\text { fructicola) }\end{array}$ & 1096 & 0 & $\begin{array}{c}556 / 557 \\
(99 \%)\end{array}$ \\
\hline $\begin{array}{c}\text { C. } \\
\text { gloeosporioides }\end{array}$ & $\begin{array}{l}\text { UASB- } \\
\text { Cg-05 }\end{array}$ & Capsicum sp. & $\begin{array}{l}\text { Raichur, } \\
\text { Karnataka }\end{array}$ & $\begin{array}{c}\mathrm{JN} 2486 \\
22\end{array}$ & 531 & $\begin{array}{l}\mathrm{JX} 010165(C . \\
\text { fructicola) }\end{array}$ & 1037 & 0 & $\begin{array}{c}530 / 531 \\
(99 \%)\end{array}$ \\
\hline $\begin{array}{c}\text { C. } \\
\text { gloeosporioides }\end{array}$ & $\begin{array}{l}\text { UASB- } \\
\text { Cg-06 }\end{array}$ & Capsicum sp. & $\begin{array}{l}\text { Gulbarga, } \\
\text { Karnataka }\end{array}$ & $\begin{array}{c}\mathrm{JN} 2486 \\
23\end{array}$ & 557 & $\begin{array}{l}\mathrm{JX} 010165(C . \\
\text { fructicola) }\end{array}$ & 1104 & 0 & $\begin{array}{l}557 / 557 \\
(100 \%)\end{array}$ \\
\hline $\begin{array}{c}\text { C. } \\
\text { gloeosporioides }\end{array}$ & $\begin{array}{l}\text { UASB- } \\
\text { Cg-07 }\end{array}$ & Capsicum sp. & $\begin{array}{l}\text { Gulbarga, } \\
\text { Karnataka }\end{array}$ & $\begin{array}{c}\mathrm{JN} 2486 \\
24\end{array}$ & 530 & $\begin{array}{l}\text { JX010165 }(C . \\
\text { fructicola) }\end{array}$ & 1051 & 0 & $\begin{array}{l}530 / 530 \\
(100 \%)\end{array}$ \\
\hline $\begin{array}{c}\text { C. } \\
\text { gloeosporioides }\end{array}$ & $\begin{array}{l}\text { UASB- } \\
\text { Cg-08 }\end{array}$ & Capsicum sp. & $\begin{array}{l}\text { Gulbarga, } \\
\text { Karnataka }\end{array}$ & $\begin{array}{c}\mathrm{JN} 2486 \\
25\end{array}$ & 530 & $\begin{array}{l}\mathrm{JX} 010165(C . \\
\text { fructicola) }\end{array}$ & 1051 & 0 & $\begin{array}{l}530 / 530 \\
(100 \%)\end{array}$ \\
\hline $\begin{array}{c}C . \\
\text { gloeosporioides }\end{array}$ & $\begin{array}{l}\text { UASB- } \\
\text { Cg-09 }\end{array}$ & Capsicum sp. & $\begin{array}{l}\text { Bellary, } \\
\text { Karnataka }\end{array}$ & $\begin{array}{c}\text { JN2486 } \\
26\end{array}$ & 526 & $\begin{array}{l}\mathrm{JX} 010165(C . \\
\text { fructicola })\end{array}$ & 1029 & 0 & $\begin{array}{c}526 / 527 \\
(99 \%)\end{array}$ \\
\hline $\begin{array}{c}C . \\
\text { gloeosporioides }\end{array}$ & $\begin{array}{l}\text { UASB- } \\
\text { Cg-10 }\end{array}$ & Capsicum sp. & $\begin{array}{l}\text { Nellore, } \\
\text { Andhra } \\
\text { Pradesh }\end{array}$ & $\begin{array}{c}\text { JN2486 } \\
27\end{array}$ & 529 & $\begin{array}{c}\text { JX010165 }(C . \\
\text { fructicola })\end{array}$ & 1049 & 0 & $\begin{array}{r}529 / 529 \\
(100 \%)\end{array}$ \\
\hline $\begin{array}{c}C . \\
\text { gloeosporioides }\end{array}$ & $\begin{array}{l}\text { UASB- } \\
\text { Cg-11 }\end{array}$ & Capsicum sp. & $\begin{array}{l}\text { Nellore, } \\
\text { Andhra } \\
\text { Pradesh }\end{array}$ & $\begin{array}{c}\text { JN2486 } \\
28\end{array}$ & 549 & $\begin{array}{c}\mathrm{JX} 010165(C . \\
\text { fructicola })\end{array}$ & 1088 & 0 & $\begin{array}{r}549 / 549 \\
(100 \%)\end{array}$ \\
\hline $\begin{array}{c}C . \\
\text { gloeosporioides }\end{array}$ & $\begin{array}{l}\text { UASB- } \\
\text { Cg-12 }\end{array}$ & Capsicum sp. & $\begin{array}{l}\text { Nellore, } \\
\text { Andhra } \\
\text { Pradesh }\end{array}$ & $\begin{array}{c}\text { JN2486 } \\
29\end{array}$ & 527 & $\begin{array}{c}\text { JX010165 (C. } \\
\text { fructicola) }\end{array}$ & 1031 & 0 & $\begin{array}{c}527 / 528 \\
(99 \%)\end{array}$ \\
\hline $\begin{array}{c}C . \\
\text { gloeosporioides }\end{array}$ & $\begin{array}{l}\text { UASB- } \\
\text { Cg-13 }\end{array}$ & Capsicum sp. & $\begin{array}{l}\text { Nellore, } \\
\text { Andhra } \\
\text { Pradesh }\end{array}$ & $\begin{array}{c}\text { JN2486 } \\
30\end{array}$ & 528 & $\begin{array}{c}\mathrm{JX} 010165(C . \\
\text { fructicola })\end{array}$ & 1047 & 0 & $\begin{array}{l}528 / 528 \\
(100 \%)\end{array}$ \\
\hline $\begin{array}{c}C . \\
\text { gloeosporioides }\end{array}$ & $\begin{array}{l}\text { UASB- } \\
\text { Cg-14 }\end{array}$ & Capsicum sp. & $\begin{array}{l}\text { Guntur, } \\
\text { Andhra } \\
\text { Pradesh }\end{array}$ & $\begin{array}{c}\text { JN2486 } \\
31\end{array}$ & 540 & $\begin{array}{c}\mathrm{JX} 010165(C . \\
\text { fructicola })\end{array}$ & 1070 & 0 & $\begin{array}{r}540 / 540 \\
(100 \%)\end{array}$ \\
\hline $\begin{array}{c}C . \\
\text { gloeosporioides }\end{array}$ & $\begin{array}{l}\text { UASB- } \\
\text { Cg-15 }\end{array}$ & Capsicum sp. & $\begin{array}{l}\text { Guntur, } \\
\text { Andhra } \\
\text { Pradesh }\end{array}$ & $\begin{array}{c}\mathrm{JN} 2486 \\
32\end{array}$ & 532 & $\begin{array}{c}\mathrm{JX} 010165(C . \\
\text { fructicola })\end{array}$ & 1023 & 0 & $\begin{array}{c}530 / 532 \\
(99 \%)\end{array}$ \\
\hline $\begin{array}{c}C . \\
\text { gloeosporioides }\end{array}$ & $\begin{array}{l}\text { UASB- } \\
\text { Cg-16 }\end{array}$ & Capsicum sp. & $\begin{array}{l}\text { Guntur, } \\
\text { Andhra } \\
\text { Pradesh }\end{array}$ & $\begin{array}{c}\mathrm{JN} 2486 \\
33\end{array}$ & 532 & $\begin{array}{c}\mathrm{JX} 010165(C . \\
\text { fructicola })\end{array}$ & 1055 & 0 & $\begin{array}{r}532 / 532 \\
(100 \%)\end{array}$ \\
\hline $\begin{array}{c}C . \\
\text { gloeosporioides }\end{array}$ & $\begin{array}{l}\text { UASB- } \\
\text { Cg-17 }\end{array}$ & Capsicum sp. & $\begin{array}{l}\text { Guntur, } \\
\text { Andhra } \\
\text { Pradesh }\end{array}$ & $\begin{array}{c}\text { JN2486 } \\
34\end{array}$ & 524 & $\begin{array}{c}\mathrm{JX} 010165(C . \\
\text { fructicola })\end{array}$ & 1015 & 0 & $\begin{array}{c}519 / 520 \\
(99 \%)\end{array}$ \\
\hline $\begin{array}{c}C . \\
\text { gloeosporioides }\end{array}$ & $\begin{array}{l}\text { UASB- } \\
\text { Cg-18 }\end{array}$ & Capsicum sp. & $\begin{array}{l}\text { Guntur, } \\
\text { Andhra } \\
\text { Pradesh }\end{array}$ & $\begin{array}{c}\text { JN2486 } \\
35\end{array}$ & 557 & $\begin{array}{c}\text { JX010165 }(C . \\
\text { fructicola })\end{array}$ & 1096 & 0 & $\begin{array}{c}556 / 557 \\
(99 \%)\end{array}$ \\
\hline $\begin{array}{c}C . \\
\text { gloeosporioides }\end{array}$ & $\begin{array}{l}\text { UASB- } \\
\text { Cg-19 }\end{array}$ & Capsicum sp. & $\begin{array}{l}\text { Guntur, } \\
\text { Andhra } \\
\text { Pradesh }\end{array}$ & $\begin{array}{c}\text { JN2486 } \\
36\end{array}$ & 521 & $\begin{array}{c}\mathrm{JX} 010165(C . \\
\text { fructicola })\end{array}$ & 1011 & 0 & $\begin{array}{c}520 / 522 \\
(99 \%)\end{array}$ \\
\hline $\begin{array}{c}C . \\
\text { gloeosporioides }\end{array}$ & $\begin{array}{l}\text { UASB- } \\
\text { Cg-20 }\end{array}$ & Capsicum sp. & $\begin{array}{l}\text { Guntur, } \\
\text { Andhra } \\
\text { Pradesh }\end{array}$ & $\begin{array}{c}\text { JN2486 } \\
37\end{array}$ & 557 & $\begin{array}{c}\text { JX010165 }(C . \\
\text { fructicola) }\end{array}$ & 1096 & 0 & $\begin{array}{c}556 / 557 \\
(99 \%)\end{array}$ \\
\hline $\begin{array}{c}C . \\
\text { gloeosporioides }\end{array}$ & $\begin{array}{l}\text { UASB- } \\
\text { Cg-21 }\end{array}$ & Capsicum sp. & $\begin{array}{l}\text { Guntur, } \\
\text { Andhra } \\
\text { Pradesh }\end{array}$ & $\begin{array}{c}\mathrm{JN} 2486 \\
38\end{array}$ & 530 & $\begin{array}{c}\text { JX010165 (C. } \\
\text { fructicola) }\end{array}$ & 1051 & 0 & $\begin{array}{l}530 / 530 \\
(100 \%)\end{array}$ \\
\hline $\begin{array}{c}C . \\
\text { gloeosporioides }\end{array}$ & $\begin{array}{l}\text { UASB- } \\
\text { Cg-22 }\end{array}$ & Capsicum sp. & $\begin{array}{l}\text { Guntur, } \\
\text { Andhra } \\
\text { Pradesh }\end{array}$ & $\begin{array}{c}\mathrm{JN} 2486 \\
39\end{array}$ & 557 & $\begin{array}{c}\mathrm{JX} 010165(C . \\
\text { fructicola })\end{array}$ & 1104 & 0 & $\begin{array}{r}557 / 557 \\
(100 \%)\end{array}$ \\
\hline $\begin{array}{c}C . \\
\text { gloeosporioides }\end{array}$ & $\begin{array}{l}\text { UASB- } \\
\text { Cg- } 23\end{array}$ & Capsicum sp. & $\begin{array}{l}\text { Guntur, } \\
\text { Andhra } \\
\text { Pradesh }\end{array}$ & $\begin{array}{c}\mathrm{JN} 2486 \\
40\end{array}$ & 546 & $\begin{array}{c}\mathrm{JX} 010165(C . \\
\text { fructicola })\end{array}$ & 1082 & 0 & $\begin{array}{c}546 / 546 \\
(100 \%)\end{array}$ \\
\hline $\begin{array}{c}C . \\
\text { gloeosporioides }\end{array}$ & $\begin{array}{l}\text { UASB- } \\
\text { Cg-24 }\end{array}$ & Capsicum sp. & $\begin{array}{l}\text { Guntur, } \\
\text { Andhra } \\
\text { Pradesh }\end{array}$ & $\begin{array}{c}\mathrm{JN} 2486 \\
41\end{array}$ & 507 & $\begin{array}{c}\mathrm{JX} 010165(C . \\
\text { fructicola })\end{array}$ & 1005 & 0 & $\begin{array}{r}507 / 507 \\
(100 \%)\end{array}$ \\
\hline $\begin{array}{c}C . \\
\text { gloeosporioides }\end{array}$ & $\begin{array}{l}\text { UASB- } \\
\text { Cg-25 }\end{array}$ & Capsicum sp. & $\begin{array}{c}\text { Prakasham, } \\
\text { Andhra } \\
\text { Pradesh }\end{array}$ & $\begin{array}{c}\mathrm{JN} 2486 \\
42\end{array}$ & 554 & $\begin{array}{c}\mathrm{JX} 010165(C . \\
\text { fructicola })\end{array}$ & 1098 & 0 & $\begin{array}{l}554 / 554 \\
(100 \%)\end{array}$ \\
\hline
\end{tabular}




\begin{tabular}{|c|c|c|c|c|c|c|c|c|c|}
\hline 芯 & $\stackrel{\dot{\Xi}}{\stackrel{\Xi}{\pi}}$ & 方 & 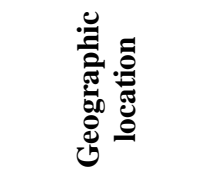 & 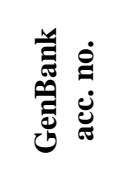 & 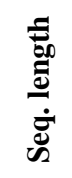 & 氙 & 岂 & 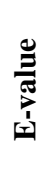 & 駦 \\
\hline $\begin{array}{c}\text { C. } \\
\text { gloeosporioides }\end{array}$ & $\begin{array}{l}\text { UASB- } \\
\text { Cg-26 }\end{array}$ & Capsicum sp. & $\begin{array}{c}\text { Prakasham, } \\
\text { Andhra } \\
\text { Pradesh }\end{array}$ & $\begin{array}{c}\text { JN2486 } \\
43\end{array}$ & 555 & $\begin{array}{c}\mathrm{JX} 010165(C . \\
\text { fructicola })\end{array}$ & 1100 & 0 & $\begin{array}{l}555 / 555 \\
(100 \%)\end{array}$ \\
\hline $\begin{array}{c}C . \\
\text { gloeosporioides }\end{array}$ & $\begin{array}{l}\text { UASB- } \\
\text { Cg-27 }\end{array}$ & Capsicum sp. & $\begin{array}{l}\text { Kammam, } \\
\text { Andhra } \\
\text { Pradesh }\end{array}$ & $\begin{array}{c}\text { JN2486 } \\
44\end{array}$ & 557 & $\begin{array}{c}\mathrm{JX} 010165(C . \\
\text { fructicola })\end{array}$ & 1104 & 0 & $\begin{array}{r}557 / 557 \\
(100 \%)\end{array}$ \\
\hline $\begin{array}{c}C . \\
\text { gloeosporioides }\end{array}$ & $\begin{array}{l}\text { UASB- } \\
\text { Cg-28 }\end{array}$ & Capsicum sp. & $\begin{array}{l}\text { Kammam, } \\
\text { Andhra } \\
\text { Pradesh }\end{array}$ & $\begin{array}{c}\mathrm{JN} 2486 \\
45\end{array}$ & 555 & $\begin{array}{c}\text { JX010165 (C. } \\
\text { fructicola) }\end{array}$ & 1100 & 0 & $\begin{array}{l}555 / 555 \\
(100 \%)\end{array}$ \\
\hline $\begin{array}{c}C . \\
\text { gloeosporioides }\end{array}$ & $\begin{array}{l}\text { UASB- } \\
\text { Cg-29 }\end{array}$ & Capsicum sp. & $\begin{array}{c}\text { Kammam, } \\
\text { Andhra } \\
\text { Pradesh }\end{array}$ & $\begin{array}{c}\mathrm{JN} 2486 \\
46\end{array}$ & 555 & $\begin{array}{c}\text { JX010165 (C. } \\
\text { fructicola) }\end{array}$ & 1100 & 0 & $\begin{array}{l}555 / 555 \\
(100 \%)\end{array}$ \\
\hline $\begin{array}{c}C . \\
\text { gloeosporioides }\end{array}$ & $\begin{array}{l}\text { UASB- } \\
\text { Cg-30 }\end{array}$ & Capsicum sp. & $\begin{array}{c}\text { Kammam, } \\
\text { Andhra } \\
\text { Pradesh }\end{array}$ & $\begin{array}{c}\text { JN2486 } \\
47\end{array}$ & 555 & $\begin{array}{c}\mathrm{JX} 010165(C . \\
\text { fructicola })\end{array}$ & 1100 & 0 & $\begin{array}{l}555 / 555 \\
(100 \%)\end{array}$ \\
\hline $\begin{array}{c}C . \\
\text { gloeosporioides }\end{array}$ & $\begin{array}{l}\text { UASB- } \\
\text { Cg-31 }\end{array}$ & Capsicum sp. & $\begin{array}{c}\text { Kammam, } \\
\text { Andhra } \\
\text { Pradesh }\end{array}$ & $\begin{array}{c}\text { JN2486 } \\
48\end{array}$ & 555 & $\begin{array}{c}\text { JX010165 (C. } \\
\text { fructicola) }\end{array}$ & 1100 & 0 & $\begin{array}{l}555 / 555 \\
(100 \%)\end{array}$ \\
\hline $\begin{array}{c}\text { C. } \\
\text { gloeosporioides }\end{array}$ & $\begin{array}{l}\text { UASB- } \\
\text { Cg-32 }\end{array}$ & Capsicum sp. & $\begin{array}{c}\text { Kammam, } \\
\text { Andhra } \\
\text { Pradesh }\end{array}$ & $\begin{array}{c}\text { JN2486 } \\
49\end{array}$ & 552 & $\begin{array}{l}\text { JX010165 (C. } \\
\text { fructicola) }\end{array}$ & 1074 & 0 & $\begin{array}{r}542 / 542 \\
(100 \%)\end{array}$ \\
\hline $\begin{array}{c}C . \\
\text { gloeosporioides }\end{array}$ & $\begin{array}{l}\text { UASB- } \\
\text { Cg-33 }\end{array}$ & Capsicum sp. & $\begin{array}{c}\text { Kammam, } \\
\text { Andhra } \\
\text { Pradesh }\end{array}$ & $\begin{array}{c}\text { JN2486 } \\
50\end{array}$ & 527 & $\begin{array}{c}\mathrm{JX} 010165(C . \\
\text { fructicola })\end{array}$ & 1025 & 0 & $\begin{array}{c}526 / 528 \\
(99 \%)\end{array}$ \\
\hline $\begin{array}{c}C . \\
\text { gloeosporioides }\end{array}$ & $\begin{array}{l}\text { UASB- } \\
\text { Cg-34 }\end{array}$ & Capsicum sp. & $\begin{array}{l}\text { Gadag, } \\
\text { Karnataka }\end{array}$ & $\begin{array}{c}\mathrm{JN} 2486 \\
51\end{array}$ & 555 & $\begin{array}{c}\mathrm{JX} 010165(C . \\
\text { fructicola) }\end{array}$ & 1100 & 0 & $\begin{array}{l}555 / 555 \\
(100 \%)\end{array}$ \\
\hline $\begin{array}{c}\text { C. } \\
\text { gloeosporioides }\end{array}$ & $\begin{array}{l}\text { UASB- } \\
\text { Cg-35 }\end{array}$ & Capsicum sp. & $\begin{array}{l}\text { Dharwad, } \\
\text { Karnataka }\end{array}$ & $\begin{array}{c}\text { JN2486 } \\
52\end{array}$ & 557 & $\begin{array}{c}\text { JX010165 (C. } \\
\text { fructicola) }\end{array}$ & 1096 & 0 & $\begin{array}{c}556 / 557 \\
(99 \%)\end{array}$ \\
\hline $\begin{array}{c}\text { C. } \\
\text { gloeosporioides }\end{array}$ & $\begin{array}{l}\text { UASB- } \\
\text { Cg-36 }\end{array}$ & Capsicum sp. & $\begin{array}{l}\text { Dharwad, } \\
\text { Karnataka }\end{array}$ & $\begin{array}{c}\text { JN2486 } \\
53\end{array}$ & 549 & $\begin{array}{c}\text { JX010165 (C. } \\
\text { fructicola) }\end{array}$ & 1068 & 0 & $\begin{array}{c}546 / 547 \\
(99 \%)\end{array}$ \\
\hline $\begin{array}{c}\text { C. } \\
\text { gloeosporioides }\end{array}$ & $\begin{array}{l}\text { UASB- } \\
\text { Cg-37 }\end{array}$ & Capsicum sp. & $\begin{array}{l}\text { Dharwad, } \\
\text { Karnataka }\end{array}$ & $\begin{array}{c}\text { JN2486 } \\
54\end{array}$ & 555 & $\begin{array}{c}\text { JX010165 }(C . \\
\text { fructicola) }\end{array}$ & 1100 & 0 & $\begin{array}{l}555 / 555 \\
(100 \%)\end{array}$ \\
\hline $\begin{array}{c}\text { C. } \\
\text { gloeosporioides }\end{array}$ & $\begin{array}{l}\text { UASB- } \\
\text { Cg-38 }\end{array}$ & Capsicum sp. & $\begin{array}{l}\text { Dharwad, } \\
\text { Karnataka }\end{array}$ & $\begin{array}{c}\mathrm{JN} 2486 \\
55\end{array}$ & 549 & $\begin{array}{c}\text { JX010165 }(C . \\
\text { fructicola) }\end{array}$ & 1088 & 0 & $\begin{array}{l}549 / 549 \\
(100 \%)\end{array}$ \\
\hline $\begin{array}{c}\text { C. } \\
\text { gloeosporioides }\end{array}$ & $\begin{array}{l}\text { UASB- } \\
\text { Cg-39 }\end{array}$ & Capsicum sp. & $\begin{array}{l}\text { Dharwad, } \\
\text { Karnataka }\end{array}$ & $\begin{array}{c}\mathrm{JN} 2486 \\
56\end{array}$ & 551 & $\begin{array}{c}\text { JX010165 }(C . \\
\text { fructicola })\end{array}$ & 1092 & 0 & $\begin{array}{r}551 / 551 \\
(100 \%)\end{array}$ \\
\hline $\begin{array}{c}\text { C. } \\
\text { gloeosporioides }\end{array}$ & $\begin{array}{l}\text { UASB- } \\
\text { Cg-40 }\end{array}$ & Capsicum sp. & $\begin{array}{l}\text { Dharwad, } \\
\text { Karnataka }\end{array}$ & $\begin{array}{c}\mathrm{JN} 2486 \\
57\end{array}$ & 530 & $\begin{array}{l}\mathrm{JX} 010165(C . \\
\text { fructicola) }\end{array}$ & 1051 & 0 & $\begin{array}{l}530 / 530 \\
(100 \%)\end{array}$ \\
\hline $\begin{array}{c}\text { C. } \\
\text { gloeosporioides }\end{array}$ & $\begin{array}{l}\text { UASB- } \\
\text { Cg-41 }\end{array}$ & Capsicum sp. & $\begin{array}{l}\text { Dharwad, } \\
\text { Karnataka }\end{array}$ & $\begin{array}{c}\mathrm{JN} 2486 \\
58\end{array}$ & 540 & $\begin{array}{l}\mathrm{JX} 010165(C . \\
\text { fructicola) }\end{array}$ & 1043 & 0 & $\begin{array}{c}537 / 540 \\
(99 \%)\end{array}$ \\
\hline $\begin{array}{c}\text { C. } \\
\text { gloeosporioides }\end{array}$ & $\begin{array}{l}\text { UASB- } \\
\text { Cg-42 }\end{array}$ & Capsicum sp. & $\begin{array}{l}\text { Kolar, } \\
\text { Karnataka }\end{array}$ & $\begin{array}{c}\mathrm{JN} 2486 \\
59\end{array}$ & 540 & $\begin{array}{c}\text { JX010165 }(C . \\
\text { fructicola) }\end{array}$ & 1070 & 0 & $\begin{array}{l}540 / 540 \\
(100 \%)\end{array}$ \\
\hline $\begin{array}{c}\text { C. } \\
\text { gloeosporioides }\end{array}$ & $\begin{array}{l}\text { UASB- } \\
\text { Cg-43 }\end{array}$ & Capsicum sp. & $\begin{array}{l}\text { Belgaum, } \\
\text { Karnataka }\end{array}$ & $\begin{array}{c}\mathrm{JN} 2486 \\
60\end{array}$ & 539 & $\begin{array}{l}\text { JX010165 (C. } \\
\text { fructicola) }\end{array}$ & 1068 & 0 & $\begin{array}{l}539 / 539 \\
(100 \%)\end{array}$ \\
\hline $\begin{array}{c}\text { C. } \\
\text { gloeosporioides }\end{array}$ & $\begin{array}{l}\text { UASB- } \\
\text { Cg-44 }\end{array}$ & Capsicum sp. & $\begin{array}{l}\text { Belgaum, } \\
\text { Karnataka }\end{array}$ & $\begin{array}{c}\mathrm{JN} 2486 \\
61\end{array}$ & 539 & $\begin{array}{l}\text { JX010165 (C. } \\
\text { fructicola) }\end{array}$ & 1068 & 0 & $\begin{array}{l}539 / 539 \\
(100 \%)\end{array}$ \\
\hline $\begin{array}{c}\text { C. } \\
\text { gloeosporioides }\end{array}$ & $\begin{array}{l}\text { UASB- } \\
\text { Cg-45 }\end{array}$ & Capsicum sp. & $\begin{array}{l}\text { Belgaum, } \\
\text { Karnataka }\end{array}$ & $\begin{array}{c}\mathrm{JN} 2486 \\
62\end{array}$ & 545 & $\begin{array}{c}\mathrm{JX} 010165(C . \\
\text { fructicola })\end{array}$ & 1080 & 0 & $\begin{array}{r}545 / 545 \\
(100 \%)\end{array}$ \\
\hline $\begin{array}{c}\text { C. } \\
\text { gloeosporioides }\end{array}$ & $\begin{array}{l}\text { UASB- } \\
\text { Cg-46 }\end{array}$ & Capsicum sp. & $\begin{array}{c}\text { Chikkamaglur } \\
\text {, Karnataka }\end{array}$ & $\begin{array}{c}\mathrm{JN} 2486 \\
63\end{array}$ & 539 & $\begin{array}{l}\mathrm{JX} 010165(C . \\
\text { fructicola })\end{array}$ & 1068 & 0 & $\begin{array}{r}539 / 539 \\
(100 \%)\end{array}$ \\
\hline $\begin{array}{c}\text { C. } \\
\text { gloeosporioides }\end{array}$ & $\begin{array}{l}\text { UASB- } \\
\text { Cg-47 }\end{array}$ & Capsicum sp. & $\begin{array}{c}\text { Chikkamaglur } \\
\text {, Karnataka }\end{array}$ & $\begin{array}{c}\text { JN2486 } \\
64\end{array}$ & 537 & $\begin{array}{c}\text { JX010165 (C. } \\
\text { fructicola) }\end{array}$ & 1065 & 0 & $\begin{array}{l}537 / 537 \\
(100 \%)\end{array}$ \\
\hline $\begin{array}{c}\text { C. } \\
\text { gloeosporioides }\end{array}$ & $\begin{array}{l}\text { UASB- } \\
\text { Cg-48 }\end{array}$ & Capsicum sp. & $\begin{array}{c}\text { Chikkamaglur } \\
\text {, Karnataka }\end{array}$ & $\begin{array}{c}\text { JN2486 } \\
65\end{array}$ & 538 & $\begin{array}{c}\text { JX010165 (C. } \\
\text { fructicola) }\end{array}$ & 1066 & 0 & $\begin{array}{l}538 / 538 \\
(100 \%)\end{array}$ \\
\hline $\begin{array}{c}\text { C. } \\
\text { gloeosporioides }\end{array}$ & $\begin{array}{l}\text { UASB- } \\
\text { Cg-49 }\end{array}$ & Capsicum sp. & $\begin{array}{l}\text { Bengaluru, } \\
\text { Karnataka }\end{array}$ & $\begin{array}{c}\text { JN2486 } \\
66\end{array}$ & 552 & $\begin{array}{c}\text { JX010165 }(C . \\
\text { fructicola) }\end{array}$ & 1094 & 0 & $\begin{array}{l}552 / 552 \\
(100 \%)\end{array}$ \\
\hline $\begin{array}{c}\text { C. } \\
\text { gloeosporioides }\end{array}$ & $\begin{array}{l}\text { UASB- } \\
\text { Cg-50 }\end{array}$ & Capsicum sp. & $\begin{array}{l}\text { Hassan, } \\
\text { Karnataka }\end{array}$ & $\begin{array}{c}\mathrm{JN} 2486 \\
67\end{array}$ & 553 & $\begin{array}{l}\mathrm{JX} 010165(C . \\
\text { fructicola) }\end{array}$ & 1082 & 0 & $\begin{array}{c}548 / 549 \\
(99 \%)\end{array}$ \\
\hline $\begin{array}{c}\text { C. } \\
\text { gloeosporioides }\end{array}$ & BDS 157 & & & $\begin{array}{c}\text { JN3909 } \\
38\end{array}$ & 556 & $\begin{array}{l}\text { JX010165 (C. } \\
\text { fructicola) }\end{array}$ & 1066 & 0 & $\begin{array}{c}553 / 557 \\
(99 \%)\end{array}$ \\
\hline C. kahawae & BDS 162 & & & $\begin{array}{c}\text { JN3909 } \\
39\end{array}$ & 553 & $\begin{array}{c}\mathrm{JX} 010264(C . \\
\text { tropicale })\end{array}$ & 1096 & 0 & $\begin{array}{r}553 / 553 \\
(100 \%)\end{array}$ \\
\hline
\end{tabular}

Note: GUFCC = Goa University, Fungal Culture Collection, Goa; ITCC = Indian Type Culture Collection, IARI, New Delhi; MTCC = Microbial

Type Culture Collection and Gene Bank, CSIR-IMTECH, Chandigarh; UASB = University of Agricultural Sciences, Bengaluru. 
Table 3 List of the Colletotrichum type strains included in this study with information on taxon, strain designation, and GenBank accession number for the ITS/ 5.8S rRNA sequences

\begin{tabular}{|c|c|c|}
\hline Taxon & GenBank acc. no. & Strain no. \\
\hline C. acerbum & JQ948459 & CBS 128530 \\
\hline C. acutatum & JQ005776, AF411700, KC790936 & CBS 112996, IMI 117617, MTCC 10324 \\
\hline C. aenigma & JX010244 & ICMP 18608 \\
\hline C. aeschynomenes & JX010176 & ICMP 17673 \\
\hline C. agaves & DQ286221 & CBS 118190 \\
\hline C. alatae & JX010190 & ICMP 17919 \\
\hline C. alienum & JX010251 & ICMP 12071 \\
\hline C. annellatum & JQ005222 & CBS 129826 \\
\hline C. anthrisci & GU227845, KC790954 & CBS 125334, MTCC 10328 \\
\hline C. aotearoa & JX010205 & ICMP 18537 \\
\hline C. asianum & FJ972612, KC790939 & CBS 130418, LC0037 \\
\hline C. australe & JQ948455 & CBS 116478 \\
\hline C. axonopodi & EU554086 & IMI 279189 \\
\hline C. beeveri & JQ005171 & CBS 128527 \\
\hline C. bletillum & JX625178* & CGMCC 3.15117 \\
\hline C. boninense & AB051400, KC790934 & MAFF 305972, MTCC 10287 \\
\hline C. brasiliense & JQ005235 & CBS 128501 \\
\hline C. brassicicola & JQ005172 & CBS 101059 \\
\hline C. brevisporum & KC790943, JN050238, JQ247623 & LC0600, BCC 38876, GZAAS 5.09545 \\
\hline C. brisbanense & JQ948291 & CBS 292.67 \\
\hline C. carthami & AB696998 & SAPA100011 \\
\hline C. caudasporum & JX625162* & CGMCC 3.15106 \\
\hline C. cereale & DQ126177 & KS-20BIG \\
\hline C. chlorophyti & GU227894 & IMI 103806 \\
\hline C. chrysanthemi & JQ948273, AB696999 & IMI 364540, SAPA100010 \\
\hline C. circinans & GU227855, KC790955 & CBS 221.81, MTCC 10329 \\
\hline C. citri & KC293581* & CGMCC3.15228 \\
\hline C. citricola & KC293576* & CBS 134228 \\
\hline C. clavatum $=C$. godetiae & JN121126 & IMI 398854 \\
\hline C. clidemiae & JX010265 & ICMP 18658 \\
\hline C. cliviae & GQ485607,KC790958 & CBS 125375, MTCC 10289 \\
\hline C. coccodes & HM171679 & CBS 369.75 \\
\hline C. colombiense & JQ005174 & CBS 129818 \\
\hline C. constrictum & JQ005238 & CBS 128504 \\
\hline C. cordylinicola & JX010226, HM470246 & ICMP 18579,MFLUCC090551 \\
\hline C. cosmi & JQ948274 & CBS 853.73 \\
\hline C. costaricense & JQ948180 & CBS 330.75 \\
\hline C. curcumae & GU227893, KC790931 & IMI 288937 \\
\hline C. cuscutae & JQ948195 & IMI 304802 \\
\hline C. cymbidiicola & JQ005166 & IMI 347923 \\
\hline C. dacrycarpi & JQ005236 & CBS 130241 \\
\hline C. dematium & GU227819, KC790957 & CBS 125.25, MTCC 10283 \\
\hline C. destructivum & AJ301942 & CBS 149.34 \\
\hline C. dianesei $(=C$. siamense $)$ & KC $329805^{*}$ & MFLU 1300062 \\
\hline C. dracaenophilum & DQ286209 & CBS 118199 \\
\hline C. duyunensis & JX625160* & CGMCC 3.15105 \\
\hline C. echinochloae & AB439811, KC790953 & MAFF 511473 \\
\hline C. eleusines & EU554131, KC790952 & MAFF 511155 \\
\hline C. endophytica & KC633854* & LC0324 \\
\hline C. endophytum & JX625177* & CGMCC 3.15108 \\
\hline C. eremochloae & JQ478447 & CBS 129661 \\
\hline C. excelsum-altitudum & HM751815 & CGMCC 3.15130 \\
\hline C. falcatum & JQ005772, HM171677 & CBS 147945, CGMCC 3.14187 \\
\hline C. fioriniae & JQ948292, EF464594 & CBS 128517, EHS58 \\
\hline C. fragariae s. $s .(=C$. theobromicola $)$ & KC790937 & MTCC 10325 \\
\hline C. fructi & GU227844 & CBS 346.37 \\
\hline C. fructicola & FJ972603, JX010165 & BPDI16, CBS 130416 \\
\hline C. fructivorum & JX145145 & CBS 133125 \\
\hline C. fuscum & JQ005762 & CBS 130.57 \\
\hline C. gigasporum & AM982797 & MUCL 44947 \\
\hline C. gloeosporioides & $\begin{array}{l}\text { JQ005152, JX010152, EU371022, } \\
\text { KC790935 }\end{array}$ & CBS 112999, IMI 356878, MTCC 10323 \\
\hline C. godetiae & JQ948402 & CBS 133.44 \\
\hline C. graminicola & JQ005767, DQ003110 & CBS 130836, M1.001 \\
\hline
\end{tabular}


Current Research in Environmental \& Applied Mycology Doi 10.5943/cream/3/2/3

\begin{tabular}{|c|c|c|}
\hline Taxon & GenBank acc. no. & Strain no. \\
\hline C. grevilleae & KC297078* & CBS 132879 \\
\hline C. guajavae & JQ948270 & IMI 350839 \\
\hline C. guizhouensis & JX625158* & CGMCC 3.15112 \\
\hline C. hanaui & EU554101, KC790949 & MAFF350404 \\
\hline C. hemerocallidis & JQ400005 & CDLG5 \\
\hline C. higginsianum & JQ005760 & IMI 349063 \\
\hline C. hippeastri & JQ005231, GQ485599, KC790959 & CBS 125376, CSSG1, MTCC 10290 \\
\hline C. horii & GQ329690, KC790929 & ICMP 10492 \\
\hline C. hymenocallidis s. s. $(=$ C. siamense) & KC790940, КС790933 & LC0043, MTCC 10286 \\
\hline C. indonesiense & JQ948288 & CBS 127551 \\
\hline C. jacksonii & EU554108, KC790950 & MAFF 305460 \\
\hline C. jasminigenum & HM131513 & CGMCC LLTX-01 \\
\hline $\begin{array}{l}\text { C. jasmini-sambac s. s. }(=C \text {. } \\
\text { siamense })\end{array}$ & KC790945 & LC0921 \\
\hline C. johnstonii & JQ948444 & CBS 128532 \\
\hline C. kahawae subsp. kahawae & GU174550, JX010231, KC790932 & ICMP 17816, IMI 319418 \\
\hline C. karstii & HM585409 & CBS 132134 \\
\hline C. kinghornii & JQ948454 & CBS 198.35 \\
\hline C. laticiphilum & JQ948289 & CBS 112989 \\
\hline C. lilii & GU227810 & CBS 109214 \\
\hline C. limetticola & JQ948193 & CBS 114.14 \\
\hline C. lindemuthianum & JQ005779 & CBS 144.31 \\
\hline C. lineola & GU227829 & CBS 125337 \\
\hline C. linicola & JQ005765 & CBS 172.51 \\
\hline C. liriopes & GU227804 & CBS 119444 \\
\hline C. lupini & DQ286119, JQ948155 & BBA 70884, CBS 109225 \\
\hline C. malvarum & not available* & LW1 \\
\hline C. melanocaulon & JX145144 & CBS 133251 \\
\hline C. melonis & JQ948194 & CBS 159.84 \\
\hline C. miscanthi & EU554121 & MAFF 510857 \\
\hline C. murrayae (=C. siamense) & JQ247633 & GZAAS5.09506 \\
\hline C. musae & HQ596292, JX010146 & CBS 116870 \\
\hline C. navitas & GQ919067, JQ005769, KC790960 & CBS 125086, MTCC 10326 \\
\hline C. nicholsonii & EU554126, JQ005770, KC790951 & MAFF511115 \\
\hline C. nigrum & JX546838 & CBS 169.49 \\
\hline C. novae-zelandiae & JQ005228 & CBS 128505 \\
\hline C. nupharicola & JX010187 & ICMP 18187 \\
\hline C. nymphaeae & JQ948197 & CBS 515.78 \\
\hline C. ochracea & JX625168 & CGMCC 3.15104 \\
\hline C. oncidii & JQ005169 & CBS 129828 \\
\hline C. orbiculare & JQ005778 & CBS 514.97 \\
\hline C. orchidophilum & JQ948151 & CBS 632.80 \\
\hline C. parsonsiae & JQ005233 & CBS 128525 \\
\hline C. paspali & EU554100, KC790948 & MAFF 305403 \\
\hline C. paxtonii & JQ948285 & IMI 165753 \\
\hline C. petchii & JQ005223 & CBS 378.94 \\
\hline C. phaseolorum & GU227896 & CBS 157.36 \\
\hline C. phormii & DQ286136, JQ948446 & CBS 118194 \\
\hline C. phyllanthi & JQ005221 & CBS 175.67 \\
\hline C. proteae & KC297079* & CBS 132882 \\
\hline C. pseudoacutatum & JQ948480 & CBS 436.77 \\
\hline C. psidii & JX010219 & CBS 145.29 \\
\hline C. pyricola & JQ948445 & CBS 128531 \\
\hline C. queenslandicum & JX010276 & ICMP 1778 \\
\hline C. rhexiae & JX145128 & CBS 133134 \\
\hline C. rhombiforme & JQ948457 & CBS 129953 \\
\hline C. rusci & GU227818 & CBS 119206 \\
\hline C. salicis & JQ948460 & CBS 607.94 \\
\hline C. salsolae & JX010242 & ICMP 19051 \\
\hline C. sansevieriae & AB212991" & MAFF239721 \\
\hline C. scovillei & JQ948267 & CBS 126529 \\
\hline C. siamense & FJ972613, JX010171 & ICMP 18578 \\
\hline C. simmondsii & FJ972601, JQ948276, KC790946 & BRIP28519, CBS 122122, LC0937 \\
\hline C. sloanei & JQ948287 & IMI 364297 \\
\hline C. spaethianum & GU227807, KC790956 & CBS 167.49, MTCC 10330 \\
\hline C. spinaciae & GU227847 & CBS 128.57 \\
\hline C. sublineolum & DQ003114, JQ478437, JQ005771 & S3.001, BPI399463, CBS 131301 \\
\hline C. syzygicola & KF242094* & MFLUCC 10-0624 \\
\hline
\end{tabular}


Current Research in Environmental \& Applied Mycology Doi 10.5943/cream/3/2/3

\begin{tabular}{|c|c|c|}
\hline Taxon & GenBank acc. no. & Strain no. \\
\hline C. tabacum & JQ005763 & CBS 161.53 \\
\hline C. tamarilloi & JQ948184 & CBS 129814 \\
\hline C. tanaceti & JX218228* & CBS 132693/BRIP 57314 \\
\hline C. temperatum & JX145159 & CBS 133122 \\
\hline C. thailandicum & JN050242, KC790941 & BCC38879, LC0596 \\
\hline C. theobromicola & JX010294, GU994360 & CBS 124945, ICMP 18649 \\
\hline C. $t i$ & JX010269 & ICMP 4832 \\
\hline C. tofieldiae & GU227801 & CBS 495.85 \\
\hline C. torulosum & JQ005164 & CBS 128544 \\
\hline C. trichellum & GU227812 & CBS 217.64 \\
\hline C. tropicale & GU994331, JX010264 & CBS 124949, ICMP 18653 \\
\hline C. tropicicola & JN050240, KC790942 & BCC 38877, LC0598 \\
\hline C. truncatum & GU227862 & CBS 151.35 \\
\hline C. verruculosum & GU227806, KC790930 & IMI 45525 \\
\hline C. viniferum & JN412804 & GZAAS5.08601 \\
\hline C. walleri & JQ948275 & CBS 125472 \\
\hline C. xanthorrhoeae & GU048667, JX010261, GU174551 & BRIP 45094, CBS 127831, ICMP 17903 \\
\hline C. yunnanense & EF369490 & CGMCC AS3.9617 \\
\hline
\end{tabular}

[Abbreviations: BBA = Biologische Bundesanstalt für Land- und Forstwirtschaft, Germany; $\mathbf{B C C}=$ BIOTEC Culture Collection, Thailand; BRIP = Queensland Plant Pathology Herbarium, Australia; CBS = Culture Collection of the Centraalbureau voor Schimmelcultures, Fungal Biodiversity centre, Utrecht, The Netherlands; CGMCC $=$ China General Microbiological Culture Collection Center, China; GZAAS = Guizhou Academy of Agricultural Sciences herbarium, China; ICMP = International Collection of Microorganisms from Plants, Landcare Research, Auckland, New Zealand; IMI = Culture Collection of CABI Europe, UK centre, Egham, UK $; \mathbf{L C}=$ Cultures shared by Dr. Lei Cai, China; $\mathbf{M A F F}=$ Microorganisms Section of the NIAS (National Institute of Agrobiological Sciences) Genebank, Japan; MFLUCC = Mae Fah Luang University Culture Collection, Thailand; MTCC $=$ Microbial Type Culture Collection and Gene Bank, Chandigarh; MUCL $=$ Belgian Co-ordinated Collections of Microorganisms, (agro)industrial fungi \& yeasts, Belgium. Note: $*$ = sequence not used in the analyses due to unavailability; \# = sequence not used in the analyses due to short length; sequences in bold have been generated in this study]

identification does not suffice the objective of accurate identification of fungus. So, we need better methodology for identification of Colletotrichum species-complexes. We could employ polyphasic approach of identification as suggested by Cai et al. (2009), along with multi-gene phylogeny using different gene markers as suggested by Damm et al. (2009). As recently recommended by Pires and Marinoni (2010) Integrative Taxonomy, an integrated approach employing both traditional taxonomy and DNA barcoding, could also serve the purpose of accurate identification of fungal species. It is also apparent from the study that we need to search for new genemarkers that can help us to resolve the speciescomplex which can not be resolved effectively with the help of ITS/ 5.8S rRNA gene. One such marker is the intergenic region between the Apn2 and Mat 1-2-1 gene (Apmat) which has been recently shown as a candidate secondary barcode marker for resolving the members of $C$. gloeosporioides species complex members (Sharma et al. 2013a). Researchers should also follow a polyphasic approach for species identification, which would definitely not be rapid; nevertheless would be more reliable and accurate.

\section{Acknowledgments}

We thank Dr. D. Ananthapadmanaban for assistance in fungal culturing. Mr. Deepak Bhatt is thanked for help in sequencing. Drs. Kevin D. Hyde, Bevan Weir and Lei Cai are thanked for their inspiration and useful discussions on Colletotrichum taxonomy. This work was supported by CSIR-IMTECHOLP0071 and OLP0022/ GAP0010 projects and CSIR-SRF fellowship awarded to GS.

\section{References}

Agarwal D, Sharma H. 2012 - A new anthracnose disease of grape vine (Vilis vinifera) In India. Indian Phytopathology 50, 147-150.

Altschul SF, Gish W, Miller W, Myers EW, Lipman DJ. 1990 - Basic local alignment search tool. Journal of Molecular Biology. 215, 403-410.

Bailey JA, O'Connell RJ, Pring RJ, Nash C. 1992 - Infection strategies of Colletotrichum species. In: Colletotrichum: biology, pathology and control. (eds. JA Bailey, MJ Jeger) CAB International, Wallingford, United Kingdom 88-120. 
Barimani M, Pethybridge SJ, Vaghefi N, Hay, FS, Taylor PWJ. 2013 - A new anthracnose disease of pyrethrum caused by Colletotrichum tanaceti sp. nov. Plant Pathology. doi: 10.1111/ppa.12054

Begerow D, Nilsson H, Unterseher M, Maier W. 2010 - Current state and perspectives of fungal DNA barcoding and rapid identification procedures. Applied Microbiology and Biotechnology 87, 99-108.

Bellemain E, Carlsen T, Brochmann C, Coissac E, Taberlet P, Kauserud H. 2010 - ITS as an environmental DNA barcode for fungi: an in silico approach reveals potential PCR biases. BMC Microbiology 10, 189.

Benson DA, Boguski MS, Lipman DJ, Ostell J, Ouellette BFF. 1997 - GenBank. Nucleic Acids Research 26, 1-7.

Benson DA, Karsch-Mizrachi I, Lipman DJ, Ostell J, Wheeler DL. 2006 - GenBank. Nucleic Acids Research 34, D16-D20.

Bridge PD, Roberts PJ, Spooner BM, Panchal G. 2003 - On the unreliability of published DNA sequences. New Phytology 160, 43-48.

Cai L, Hyde KD, Taylor PWJ, Weir BS, Waller J, Abang MM, Zhang JZ, Yang YL, Phoulivong S, Liu ZY, Prihastuti $\mathrm{H}$, Shivas RG, McKenzie EHC, Johnston PR. 2009 - A polyphasic approach for studying Colletotrichum. Fungal Diversity 39, 183-204.

Cannon PF, Bridge PD, Monte E. 2000 Linking the past, present and future of Colletotrichum systematic. In: Colletotrichum host specificity, pathology and host-pathogen interaction (eds. D Prusky, S Freeman, MB Dickman). APS Press, St. Paul, Minnesota 1-20.

Cannon PF, Buddie AG, Bridge PD. 2008 The typification of Colletotrichum gloeosporioides. Mycotaxon 104, 189204.

Cannon PF, Damm U, Johnston PR, Weir BS. 2012 - Colletotrichum - current status and future directions. Studies in Mycology 73, 181-213.
CBOL Plant Working Group. 2009 - A DNA barcode for land plants. Proceedings of National Academy of Science, USA 106, 12794-12797.

Crouch JA, Clarke B, Hillman B. 2009 - What is the value of ITS sequence data in Colletotrichum systematic and species diagnosis? A case study using the falcate-spored graminicolous Colletotrichum group. Mycologia 101, 648-656.

Damm U, Woudenberg JHC, Cannon PF, Crous PW. 2009. Colletotrichum species with curved conidia from herbaceous hosts. Fungal Divers. 39:45-87.

Damm U, Cannon PF, Woudenberg JHC, Johnston PR, Weir BS, Tan YP, Shivas RG, Crous PW. 2012a - The Colletotrichum boninense species complex. Studies in Mycology 73, 1-36.

Damm U, Cannon PF, Woudenberg JHC, Crous PW. 2012b - The Colletotrichum acutatum species complex. Studies in Mycology 73, 37-113.

Doyle VP, Oudemans PV, Rehner SA, Litt A. 2013 - Habitat and host indicate lineage identity in Colletotrichum gloeosporioides $s$. $l$. from wild and agricultural landscapes in North America. PLOS One 8:e62394.

Edgar RC. 2004 - MUSCLE: multiple sequence alignment with high accuracy and high throughput. Nucleic Acids Research 32, 1792-1797.

Everett KR. 1997 - Progress in managing latent infections a review. Proceedings from Conference'97: Searching for Quality. Joint Meeting of the Australian Avocado Growers Federation, Inc. and NZ Avocado Growers Association, Inc., 23-26 September 1997. (ed. J G Cutting). 55-68.

Farr DF, Rossman AY. 2013 - Fungal databases, Systemic Botany and Mycology Laboratory, ARS, USDA. Retrieved January $17^{\text {th }}$ ，2013, from http://nt.ars-grin.gov/fungaldatabases/

Felsenstein J. 1985 - Confidence limits on phylogenies: an approach using the bootstrap. Evolution 39, 783-791. 
Fokulnang $\mathrm{CN}$, Ikotun $\mathrm{T}$, Akem $\mathrm{CN}$, Dixon AGO, Tembe EA, Koona P. 2000 Investigation of inoculum threshold and latent infection in Colletotrichum gloeosporioides f. sp. manihotis, in Cassava cultivars. Pakistan Journal of Biological Sciences 3, 713-716.

Folmer O, Black M, Hoeh W, Lutz R, Vrijenhoek R. 1994 - DNA primers for amplification of mitochondrial cytochrome c oxidase subunit I from diverse metazoan invertebrates. Molecular Marine Biology and Biotechnology 3, 294-299.

Freeman S, Katan T, Shabi E. 1998 Characterization of Colletotrichum species responsible for anthracnose diseases of various fruits. Plant Disease 82, 596-605.

Gautam AK, Avasthi S, Bhadauria R. 2012 First report of anthracnose caused by Colletotrichum gloeosporioides on Boehravia diffusa in India. Archives of Phytopathology and Plant Protection 45, 2502-2506.

Hajibabaei M, Singer GAC, Hebert PDN, Hickey DA. 2007 - DNA Barcoding: how it complements taxonomy, molecular phylogenetics and population genetics. Trends in Genetics 23, 167172.

Hall TA. 1999 - BioEdit: a user-friendly biological sequence alignment editor and analysis program for Windows 95/98/NT. Nucleic Acids Symposium Series 41, 95-98.

Hebert PDN, Cywinska A, Ball SL, deWaard JR. 2003a - Biological identifications through DNA barcodes. Proceedings of the Royal Society of London B 270, 313-321.

Hebert PDN, Ratnasingham S, deWaard JR. $2003 b$ - Barcoding animal life: cytochrome c oxidase subunit 1 diverge-nces among closely related species. Proceedings of Royal Society of London B: Biological Sciences 270, S96-S99.

Huang F, Chen GQ, Hou X, Fu YS, Cai L, Hyde KD, Li HY (2013) Colletotrichum species associated with cultivated citrus in China. Fungal Diversity 61, 61-74.

Hubballi M, Nakkeeran S, Raguchander T. 2012 - First report of anthracnose on noni caused by Colletotrichum gloeosporioides in India. Archives of Phytopathology and Plant Protection 45, 276-279.

Hyde KD, Cai L, McKenzie EHC, Yang YL, Zhang JZ, Prihastuti H. 2009a Colletotrichum: a catalogue of confusion. Fungal Diversity 39, 1-17.

Hyde KD, Cai L, Cannon PF, Crouch JA, Crous PW, Damm U, Goodwin PH, Chen H, Johnston PR, Jones EBG, Liu ZY, McKenzie EHC, Moriwaki J, Noireung P, Pennycook SR, Pfenning LH, Prihastuti H, Sato T, Shivas RG, Tan YP, Taylor PWJ, Weir BS, Yang YL, Zhang JZ. 2009b - Colletotrichum - names in current use. Fungal Diversity 39, 147-182.

Kimura M. 1980 - A simple method of estimating evolutionary rate of base substitutions through comparative studies of nucleotide sequences. Journal of Molecular Evolution 16, 111-120.

Kumar K, Singh DR, Amaresan N, Madhuri K. 2012 - Isolation and pathogenicity of Colletotrichum spp. causing anthracnose of Indian mulberry (Morinda citrifolia) in tropical islands of Andaman and Nicobar, India. Phytoparasitica 40, 485-491.

Liu F, Cai L, Crous PW, Damm U. 2013a Circumscription of the anthracnose pathogens Colletotrichum lindemuthianum and $C$. nigrum. Mycologia 105, 844-860.

Liu F, Damm U, Cai L, Crous PW. 2013b Species of the Colletotrichum gloeosporioides complex associated with anthracnose diseases of Proteaceae. Fungal Diversity 61, 89105.

Manamgoda DS, Udayanga D, Cai L, Chukeatirote E, Hyde KD. 2013 Endophytic Colletotrichum from tropical grasses with a new species $C$. endophytica. Fungal Diversity 61, 107105. 
Muirhead IF, Deverall BJ. 1981 - Role of appressoria in latent infection of banana fruits by Colletotrichum musae. Physiological Plant Pathology 19, 7784.

Nilsson RH, Ryberg M, Kristiansson E, Abarenkov K, Larsson K-H, Kŏljalg U. 2006 - Taxonomic reliability of DNA sequences in public sequence databases: A fungal perspective. PloS One 1, e59.

Nilsson RH, Kristiansson E, Ryberg M, Hallenberg N, Larsson K-H. 2008 Intraspecific ITS variability in the kingdom fungi as expressed in the internal sequence databases and its implications for molecular species identification.

Evolutionary

Bioinformatics 4, 193-201.

Nilsson RH, Ryberg M, Abarenkov K, Sjoekvist E, Kristiansson E. 2009 - The ITS region as a target for characterization of fungal communities using emerging sequencing technologies. FEMS Microbiology Letters 296, 97-101.

Noireung P, Phoulivong S, Liu F, Cai L, Mckenzie EHC, Chukeatirote E, Jones EBG, Bahkali AH, Hyde KD. 2012 Novel species of Colletotrichum revealed by morphology and molecular analysis. Cryptogamie Mycologie 33, 347-362.

Pakdeevaraporn P, Wasee S, Taylor PWJ, Mongkolporn O. 2005 - Inheritance of resistance to anthracnose caused by Colletotrichum capsici in Capsicum. Plant Breeding 124, 206-208.

Peng LJ, Sun T, Yang YL, Cai L, Hyde KD, Bahkali AH, Liu ZY. 2013 Colletotrichum species on grape in Guizhou and Yunnan provinces, China. Mycoscience. 54, 29-41.

Pires AC, Marinoni L. 2010 - DNA Barcoding and traditional taxonomy unified through integrative taxonomy: a view that challenges the debate questioning both methodologies. Biota Neotropica 10, 339-346.

Rakotoniriana EF, Scauflaire J, Rabemanantsoa C, Urveg-Ratsimamanga S, Corbisier A-M, Quetin-Leclercq J, Declerck S, Munaut F. 2012 - Colletotrichum gigasporum sp. nov., a new species of Colletotrichum producing long straight conidia. Mycological Progress 12: $403-$ 412.

Rossman A. 2007 - Report of the planning workshop for all fungi DNA barcoding. Inoculum 58, 1-5.

Ryberg M, Kristiansson E, Sjökvist E, Nilsson RH. 2009 - An outlook on the fungal internal transcribed spacer sequences in GenBank and the introduction of a webbased tool for the exploration of fungal diversity. New Phytologist 181, 471477.

Saitou N, Nei M. 1987 - The neighbor joining method: A new method for reconstructing phylogenetic trees. Molecular Biology Evolution 4, 406425.

Sawant IS, Narkar SP, Shetty DS, Upadhyay A, Sawant SD. 2012 - First report of Colletotrichum capsici causing anthracnose on grapes in Maharashtra, India. New Disease Reports 25, 2.

Schoch CL, Seifert KA, Huhndorf S, Robert V, Spouge JL, André Levesque C, Chen W et al. 2012 - Nuclear ribosomal internal transcribed spacer (ITS) region as a universal DNA barcode marker for Fungi. Proceedings of the National Academy of Sciences (USA) 109, 6241-6246.

Seifert KA. 2009 - Progress towards DNA barcoding of fungi. Molecular Ecology Resources 9: (Suppl.1) 83-89.

Seifert KA, Samson RA, deWaard JR, Houbraken J, Lévesque CA, Moncalvo J-M, Louis-Seize G, Hebert PDN. 2007

- Prospects for fungus identification using CO1 DNA barcodes, with Penicillium as a test case. Proceedings of National Academy of Science, U.S.A. 104, 3901-3906.

Sharma PN, Kaur M, Sharma OP, Sharma P, Pathania A. 2005 - Morphological and molecular variability in Colletotrichum capsici, the cause of Fruit rot of chillies in the subtropical region of Northwestern. Indian Journal of Phytopathology 153, 232-237.

Sharma P, Singh N, Verma OP. 2012 - First report of Colletotrichum 
gloeosporioides on Jasminum grandiflorum in india. Journal of Plant Protection Research 52, 91-92.

Sharma G, Kumar N, Weir BS, Hyde KD, Shenoy BD 2013a - Apmat gene marker can resolve Colletotrichum species: a case study with Mangifera indica. Fungal Diversity 61:117-138

Sharma G, Shenoy BD 2013b - Colletotrichum fructicola and $C$. siamense are involved in chilli anthracnose in India. Archives of Phytopathology and Plant Protection (http://dx.doi.org/10.1080/03235408.20 13.833749)

Shenoy BD, Jeewon R, Hyde KD. 2007a Impact of DNA sequence-data on the taxonomy of anamorphic fungi. Fungal Diversity 26, 1-54.

Shenoy BD, Jeewon R, Lam WH, Bhat DJ, Than PP, Taylor PWJ, Hyde KD. 2007b - Morpho - molecular characterization and epitypification of Colletotrichum capsici (Glomerellaceae, Sordariomycetes), the causative agent of anthracnose in chilli. Fungal Diversity 27, 197-211.

Soltis PS, Soltis DE, Wolf PG, Nickrent DL, Chaw S, Chapman RL. 1999 - The phylogeny of land plants inferred from $18 \mathrm{~S}$ rDNA sequences: pushing the limits of rDNA signal? Molecular Biology Evolution 16, 1774-1784.

Summerbell RC, Lévesque CA, Seifert KA, Bovers M, Fell JW, Diaz MR, Boekhout T, deHoog GS, Stalpers J, Crous PW. 2005 - Microcoding: the second step in DNA Barcoding. Philosophical Transactions of the Royal Society B. 360, 1897-1903.
Tamura K, Peterson D, Peterson N, Stecher G, Nei M, Kumar S. 2011 - MEGA5: Molecular Evolutionary Genetics Analysis using Maximum Likelihood, Evolutionary Distance, and Maximum Parsimony Methods. Molecular Biology and Evolution 28, 2731-2739.

Tao G, Liu ZY, Liu F, Gao YH, Cai L. 2013 Endophytic Colletotrichum species from Bletilla ochracea (Orchidaceae), with descriptions of seven new speices. 61, 139-164.

Udayanga D, Manamgoda DS, Liu X, Chukeatirote E, Hyde KD. 2013 - What are the common anthracnose pathogens of tropical fruits?. Fungal Diversity 61, 165-179.

Waller JM. 1992 - Colletotrichum diseases of perennial and other cash crops. In Colletotrichum: biology, pathology and control (JA Bailey, MJ Jeger eds.) CAB International, Wallingford, United Kingdom 167-185.

Weir BS, Johnston PR, Damm U. 2012 - The Colletotrichum gloeosporioides species complex. Studies in Mycology 73, 115180.

White TJ, Bruns TD, Lee S, Taylor JW. 1990 Amplification and direct sequencing of fungal ribosomal RNA genes for phylogenetics. In PCR protocols: a guide to methods and applications (MA Innis, DH Gelfand, JJ Sninsky, TJ White eds.) Academic Press, Inc., New York, NY. 315-322.

Wilson K, Naseema A. 2012 - New records of fungi on some medicinal plants from India. Indian Phytopathology 43, 595. 